Provided for non-commercial research and education use. Not for reproduction, distribution or commercial use.

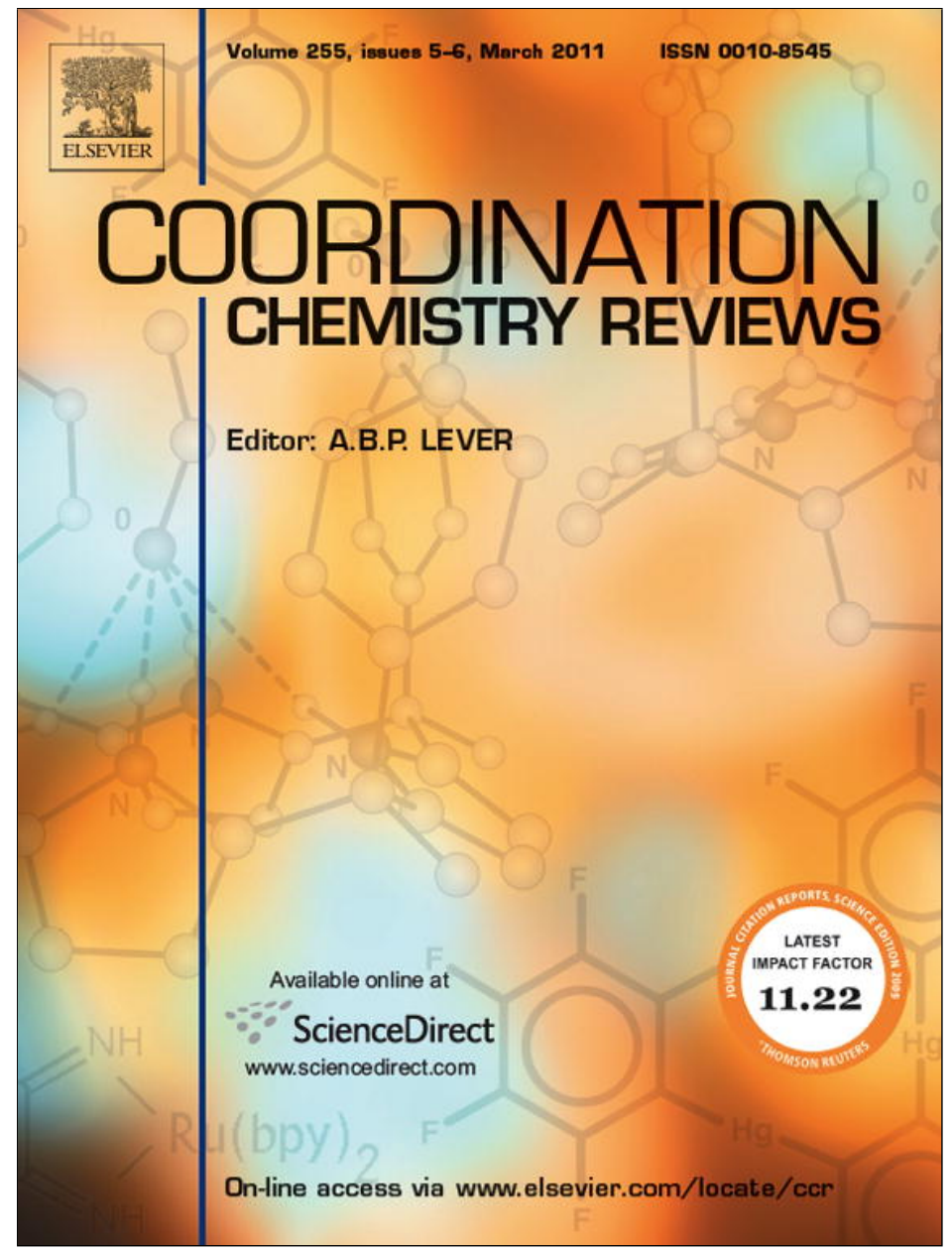

This article appeared in a journal published by Elsevier. The attached copy is furnished to the author for internal non-commercial research and education use, including for instruction at the authors institution and sharing with colleagues.

Other uses, including reproduction and distribution, or selling or licensing copies, or posting to personal, institutional or third party websites are prohibited.

In most cases authors are permitted to post their version of the article (e.g. in Word or Tex form) to their personal website or institutional repository. Authors requiring further information regarding Elsevier's archiving and manuscript policies are encouraged to visit:

http://www.elsevier.com/copyright 
Review

\title{
Metal centered ligand field excited states: Their roles in the design and performance of transition metal based photochemical molecular devices
}

\author{
Paul S. Wagenknecht ${ }^{\mathrm{a}, *}$, Peter C. Ford ${ }^{\mathrm{b}, *}$ \\ a Department of Chemistry, Furman University, Greenville, SC 29613 USA \\ b Department of Chemistry, University of California, Santa Barbara, Santa Barbara, CA, 93106 USA
}

\section{Contents}

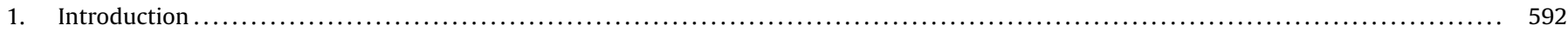

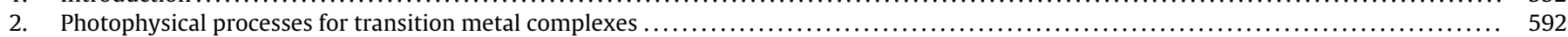

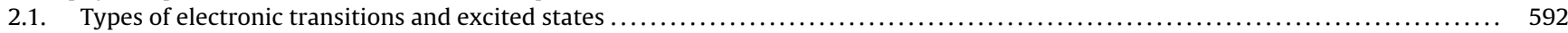

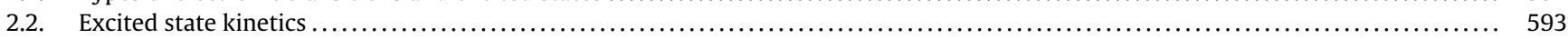

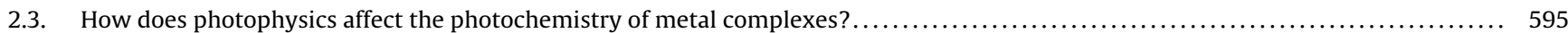

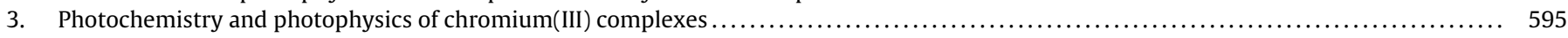

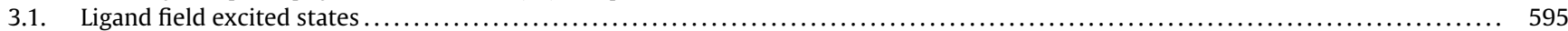

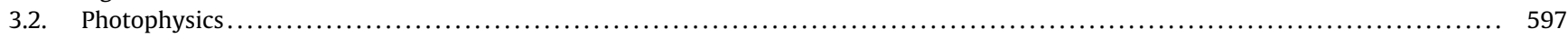

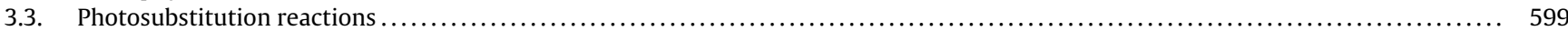

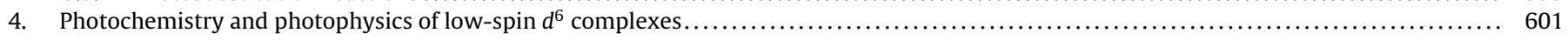

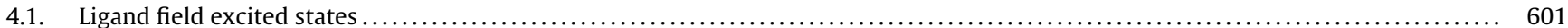

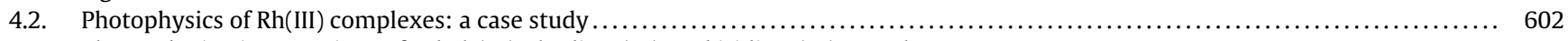

4.3. Photosubstitution reactions of cobalt(III), rhodium(III), and iridium(III) complexes................................... 602

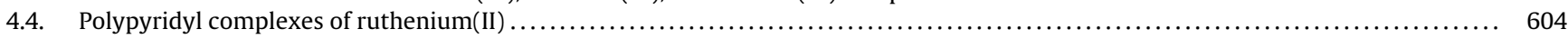

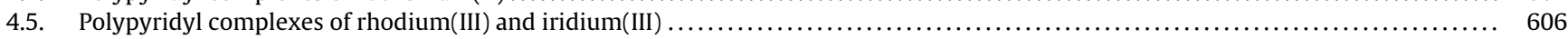

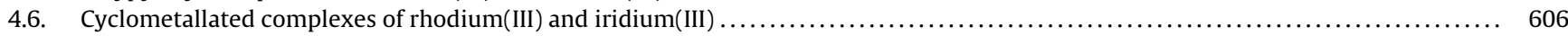

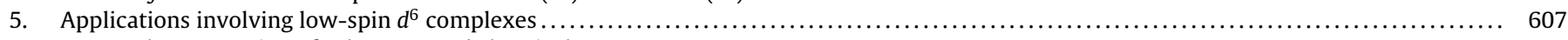

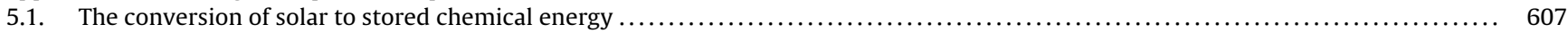

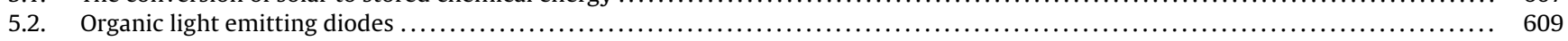

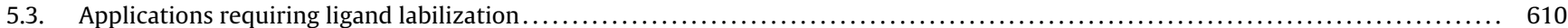

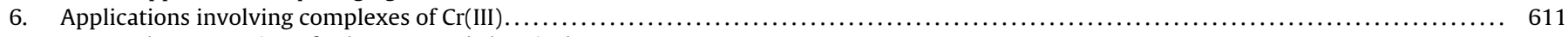

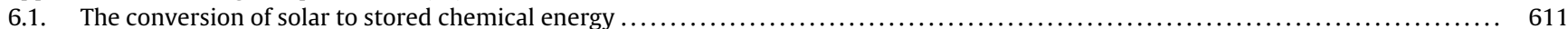

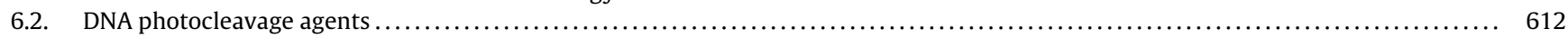

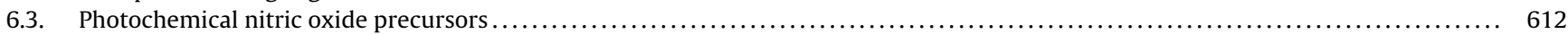

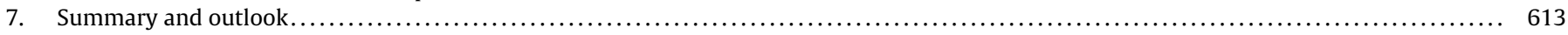

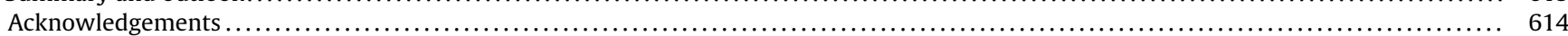

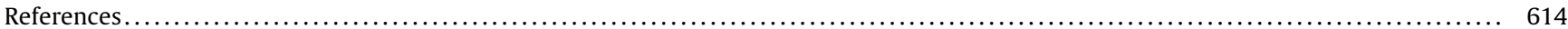

\footnotetext{
Abbreviations: acac, acetylacetonate; BISC, back intersystem crossing; bpy, 2,2'-bipyridine; bqp, 2,6-bis(8'-quinolinyl)pyridine; bzq, benzo[ $h]$ quinoline; CT, charge transfer; cyclam, 1,4,8,11-tetraazacyclotetradecane; dfbpzb, 1,5-difluoro-2,4-bis(3-methylpyrazolyl)benzene; diaz, 4,5-diazafluorene; DFT, density functional theory; DSSC, dye sensitized solar cell; dppz, dipyridophenazine; $\varepsilon$, molar extinction coefficient in units of $\mathrm{M}^{-1} \mathrm{~s}^{-1}$; EDTA, ethylenediaminetetraacetate; en, ethylenediamine (or 1,2diaminoethane); ES, excited state; $\Phi_{\mathrm{A}}$, quantum yield for process A; F, fluorescence; Glu, glutamate; GS, ground state; GSI, ground state intermediate; IC, internal conversion; IL, intra-ligand; ISC, intersystem crossing; LC, ligand centered; LEES, lowest energy excited state; $\lambda_{\text {ex }}$, excitation (irradiation) wavelength; LF, ligand field; LLCT, ligand to ligand charge transfer; LMCT, ligand to metal charge transfer; MC, metal centered; Mebib, bis( $N$-methylbenzimidazoly)-benzene; Me 2 phen, 5,6-dimethyl-1,10-phenanthroline; MLCT, metal to ligand charge transfer; MO, molecular orbital; MV, methylviologen; NHE, normal hydrogen electrode; NR, non-radiative; OLED, organic light emitting diode; P, phosphorescence; phbpy, 6-phenyl-2,2'-bipyridine; phen, 1,10-phenanthroline; PMD, photochemical molecular device; ppy, 2-phenylpyridine; SCE, saturated calomel electrode; SSCE, saturated sodium chloride calomel electrode; TBP, trigonal bipyramidal; VR, vibrational relaxation; tn, 1,3-propanediamine; tpy, 2,2' :6', $2^{\prime \prime}$-terpyridine; TPP, tetraphenylporphyrin; ttpy, 4'-tolyl, 2,2':6',2'-terpyridine; XLCT, ligand (halide) to ligand charge transfer.

* Corresponding authors.

E-mail addresses: paul.wagenknecht@furman.edu (P.S. Wagenknecht), ford@chem.ucsb.edu (P.C. Ford).
} 


\section{A R T I C L E I N F O}

\section{Article history:}

Received 14 July 2010

Accepted 9 November 2010

Available online 19 November 2010

Dedicated to Professor Noel Kane-Maguire on the occasion of his retirement, and for his many contributions to the field of transition metal photochemistry.

\section{Keywords:}

Photochemistry

Photophysics

Transition metal

Ligand field excited states

Solar energy

Organic light emitting diodes

Drug delivery

\begin{abstract}
A B S T R A C T
Transition metal complexes are vital components in a wide range of photooptical applications; these range from targeted drug delivery to devices for the conversion of solar energy to electrical and/or stored chemical energy. Metal centered (MC) ligand field excited states play important roles in the photophysics of those complexes having partially filled d-orbitals. This review offers a broad perspective on key investigations that have characterized the chemistry and physics of MC excited states in $d^{3}$ and $d^{6}$ transition metal complexes. It will also illustrate the impact of these excited states on various photooptical applications and highlight efforts to understand, control, and tune these MC excited states in the context of such applications.
\end{abstract}

(c) 2010 Elsevier B.V. All rights reserved.

\section{Introduction}

Transition metal (TM) complexes have played a leading role in the development of photochemical molecular devices (PMDs). Such devices include dye sensitized solar cells (DSSCs) [1-3], organic light emitting diodes (OLEDs) [4-6], drug delivery systems [7-10], and molecular machines [11]. All of these systems require a specific and controlled response to an external input of energy, and early investigations on the photochemistry of coordination compounds suggested that transition metal complexes were ideal candidates for the fulfillment of many of these functions.

A recent review article by Balzani [12] listed several functions that need to be managed in order to design PMDs: (i) generation and migration of electronic energy, (ii) photoinduced vectorial transport of electric charge, (iii) photoinduced conformational changes, and (iv) control and tuning of photochemical and photophysical properties. This fourth point is central to the previous three and has played a key role in developing transition metal systems for the aforementioned applications.

Charge transfer, especially metal-to-ligand charge transfer (MLCT) excited states (ES) generally garner the most attention. However, it is also necessary to consider the roles that metal centered (MC) ligand field excited states play, especially in undesired deactivation pathways that reduce device efficiency and lead to decomposition and diminished utility. In other instances, the MC excited states are integral to the desired device chemistry. The purpose of this review is to highlight the roles of these MC excited states and the efforts to "control and tune" these states in recent applications of TM based PMDs. We will first introduce key photochemical and photophysical concepts (Section 2), then further develop and apply these concepts first within the context of the MC states of $\mathrm{Cr}(\mathrm{III})$ complexes (Section 3) and of low-spin $d^{6}$ complexes (Section 4). Special attention is given to the interplay of the MC excited states with excited states of other orbital parentages. Finally, Sections 5 and 6 discuss photooptical applications where the MC states are central to the efficiency and/or utility of the device. Throughout, we will highlight examples demonstrating the manipulation of the relative excited state energies.

For more comprehensive discussions of the photochemistry and photophysics of transition metal complexes, mostly organized according to the identity of the specific metals, the reader is directed to several excellent reviews [13-20]. In addition, Balzani and Carassiti's monograph on the photochemistry of coordination compounds [21], as well as the multi-authored volume edited by
Adamson and Fleischauer [22] remain excellent introductions to the subject nearly 40 years after their publication.

\section{Photophysical processes for transition metal complexes}

\subsection{Types of electronic transitions and excited states}

Fig. 1 shows a simplified molecular orbital (MO) diagram for a transition metal complex in $O_{\mathrm{h}}$ symmetry. In this diagram, possible $\sigma$-donor, $\pi$-donor, and $\pi$-acceptor orbitals are included. The subscripts indicate whether the MO is predominantly metal (M) or ligand (L) in character. The $\pi_{\mathrm{M}}$ and $\sigma_{\mathrm{M}}{ }^{*}$ orbitals in the center of the MO diagram are predominantly metal d-orbitals with $t_{2 g}$ and $e_{g}$ symmetry, respectively. In the case of a ligand that is exclusively a sigma donor (such as $\mathrm{NH}_{3}$ ), the $\pi_{M}$ MOs are non-bonding. For ligands that are both $\sigma$ - and $\pi$-donating (e.g. the halides), the $\pi_{M}$ MOs are antibonding with respect to the M-L bond; and for ligands with dominant $\pi$-acceptor character, the $\pi_{\mathrm{M}}$ MOs are bonding. Notably, the predominantly

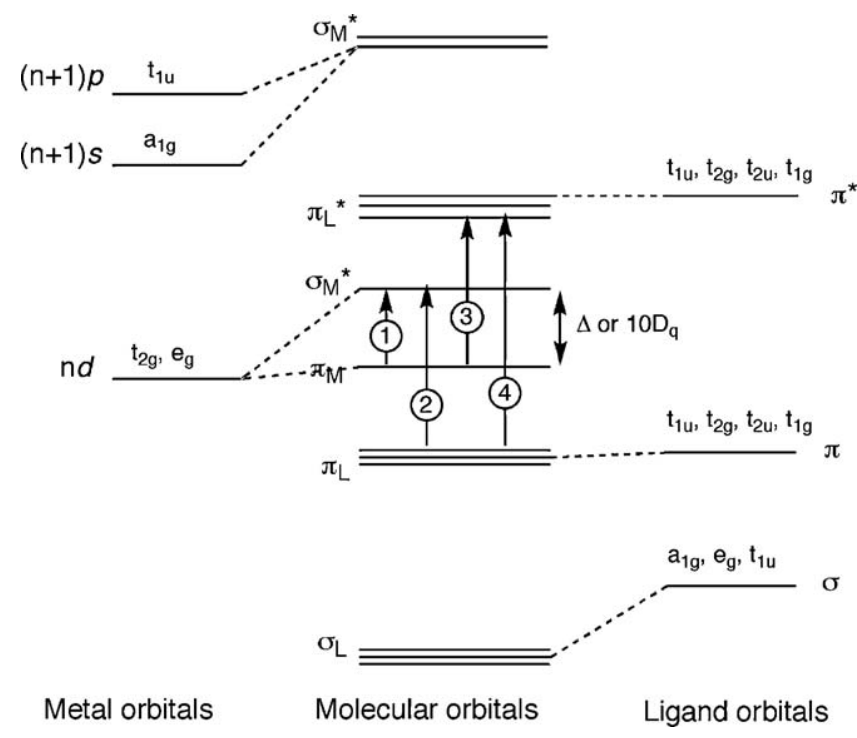

Fig. 1. Molecular orbital diagram for a transition metal complex in $O_{\mathrm{h}}$ symmetry. The arrows labeled 1-4 represent, respectively, a metal centered (MC) ligand field transition, a ligand to metal charge transfer (LMCT), a metal to ligand charge transfer (MLCT), and an intraligand or ligand centered (LC) band. 


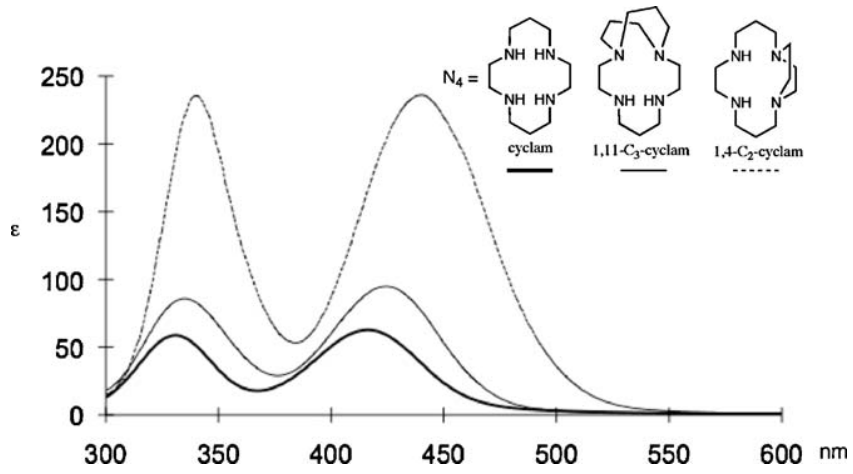

Fig. 2. UV-visible spectra of trans- $\mathrm{Cr}\left(\mathrm{N}_{4}\right)(\mathrm{CN})_{2}{ }^{+}$complexes. Note that the magnitude of the extinction coefficient $(\varepsilon)$ increases in the order cyclam $<1,11-\mathrm{C}_{3}$ cyclam $<1,4-\mathrm{C}_{2}$-cyclam.

metal $e_{g}$ MOs are always antibonding with respect to the $\mathrm{M}-\mathrm{L}$ bond.

Fig. 1 illustrates some electronic transitions characteristic of metal complexes. ${ }^{1}$ Transition 1 involves electronic promotion between orbitals that are predominantly metal d-orbital in character leading to metal centered ligand field (LF) excited states (ES) that are the focus of the present article. Others indicated involve promotion from an orbital largely ligand to one largely metal in character, or from one largely metal to one largely ligand in character. Both involve vectorial redistribution of charge and are charge transfer transitions, i.e., LMCT or MLCT, respectively. Another involves electronic promotion between ligand centered orbitals (e.g. $\pi$ to $\pi^{*}$ ) and these are termed ligand centered (LC) transitions. However, it is important to emphasize that many orbitals described as ligand or metal localized are indeed MOs of mixed character, so these convenient designations are occasionally misleading.

Intensities of electronic transitions are determined by spin and symmetry selection rules. For example, if the species is centrosymmetric, transitions between states of the same parity are forbidden (the Laporte selection rule). Thus, for metal complexes of $O_{\mathrm{h}}$ or other centrosymmetric symmetry, d-d transitions (gerade to gerade) are forbidden. However, such bands still appear with modest intensity $\left(\varepsilon \sim 5-100 \mathrm{M}^{-1} \mathrm{~cm}^{-1}\right)$ due to the coupling of the electronic wave functions with appropriate antisymmetric vibrational modes. CT and LC transitions, on the other hand, generally occur between states of different parity, thus involve larger dipole moment changes and display much higher intensities $\left(\varepsilon \gg 10^{3}\right)$.

Distortions of the equilibrium ground state geometry from centrosymmetry partially relax the Laporte selection rule $[23,24]$. This is exemplified for metal centered ligand field bands by the ligand field spectra of the trans- $\mathrm{Cr}\left(\mathrm{N}_{4}\right)(\mathrm{CN})_{2}{ }^{+}$complexes shown in Fig. 2 [25]. The cyclam complex is centrosymmetric, whereas crystallographic evidence shows increasing asymmetry in the 1,11$\mathrm{C}_{3}$-cyclam and 1,4- $\mathrm{C}_{2}$-cyclam complexes. The magnitudes of the extinction coefficient parallel the increased asymmetry.

Transitions between electronic states of different spin multiplicities are forbidden (spin selection rule). Thus, for molecules of light elements, spin forbidden transitions generally have very low intensity $(\varepsilon<0.1)$. However, compounds with heavy atoms, such as the second and third row transition elements, experience much larger spin-orbit coupling and nominally spin-forbidden transitions often have much larger extinction coefficients.

The orbital parentages discussed here for the electronic transitions may offer some predictive insight regarding the pho-

\footnotetext{
1 This list is not exhaustive. For example, there also have been proposed charge transfer transitions from one ligand to another (LLCT) or from a M-L bond to a ligand.
}

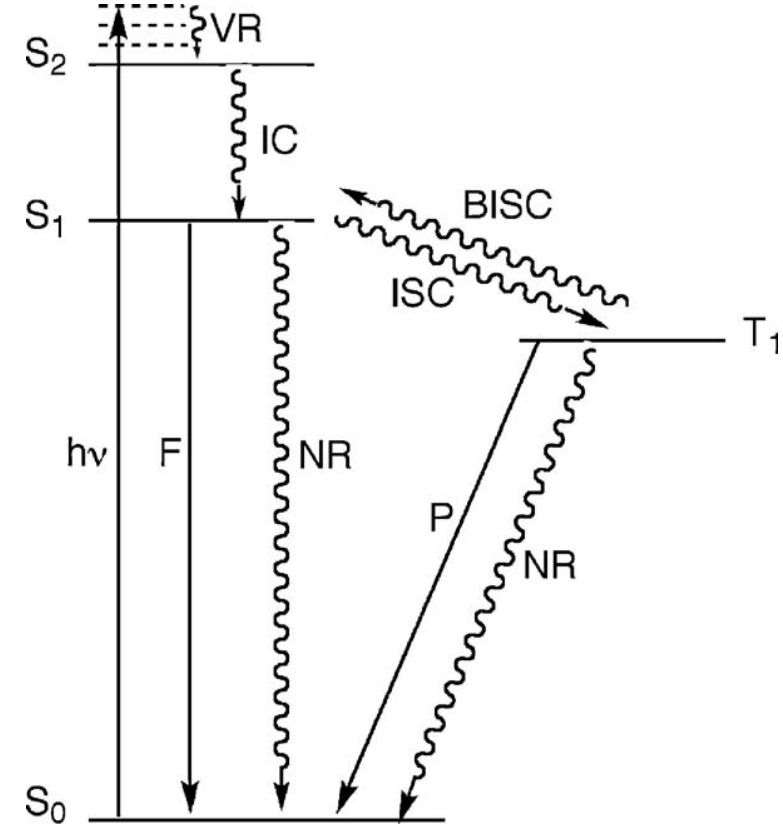

Fig. 3. Generic Jablonski diagram showing initial excitation to a vibrationally excited state of $\mathrm{S}_{2}$, vibrational relaxation (VR), internal conversion (IC), intersystem crossing (ISC), back intersystem crossing (BISC), fluorescence (F), phosphorescence (P), and nonradiative decay (NR). By convention, processes involving absorption or emission of a photon are designated by a straight arrow, while nonradiative processes are designated with a wavy arrow.

tochemistry. For example, because metal e $\mathrm{gOs}$ are antibonding in hexacoordinate complexes, electronic transitions such as 1 or 2 in Fig. 1 involve population of these $\sigma^{*}$ orbitals and should result in $\mathrm{M}-\mathrm{L}$ bond weakening. This may lead to chemistry not necessarily accessible to the GS complex. In contrast, the $t_{2 g}$-orbitals may be either $\pi^{\mathrm{b}}$ or $\pi^{*}$ character with respect to the metal-ligand bonds for $\pi$-acceptor or $\pi$-donor ligands, respectively. As a consequence, changes in the electronic population of such orbitals may result in weaker or stronger $\mathrm{M}-\mathrm{L}$ bonds, depending on the nature of these orbitals.

Excitation at a specific wavelength will often generate an electronic state that is vibrationally excited as well. Since the electronic transition occurs much more rapidly than nuclear motion, the ES is first formed with the GS nuclear configuration (Franck-Condon principle). This initial excitation is commonly followed by vibrational relaxation (generally on the ps timescale in condensed phase) as well as interconversions to other thermally accessible electronic states. Thus, understanding the dynamics of state-to-state transitions is crucial to understanding the photochemical and photophysical properties.

\subsection{Excited state kinetics}

Fig. 3 is a Jablonski diagram for a species with a singlet ground state $\left(S_{0}\right)$, and two excited state singlets $\left(S_{1}\right.$ and $\left.S_{2}\right)$ and one lower energy excited state triplet $\left(\mathrm{T}_{1}\right)$.

As shown, there are several photophysical pathways for excited state deactivation in addition to ES chemical reactions. Internal conversion and fluorescence are nonradiative and radiative, respectively, transitions between states of the same spin multiplicities while intersystem crossing and phosphorescence are nonradiative and radiative transitions between states of different spin multiplicities. Nonradiative decay leads from the electronic ES to the GS without concomitant emission of light.

The kinetics of ES processes can be quite complex owing to the numerous states potentially involved. The overall picture is sim- 
plified by the assumption that the internal conversion within any one spin manifold is significantly faster than direct deactivation to the ground state or intersystem crossing. ${ }^{2}$ In this context, early luminescence studies in condensed media have led to the general empirical rule that "The emitting level of a given multiplicity is the lowest excited level of that multiplicity", ${ }^{3}$ sometimes referred to as "Kasha's rule" [26]. This guideline implies that IC between excited states is more rapid than IC to the GS. Kasha's rule can be understood in the context of the energy gap law [28], which predicts that the rates for nonradiative transitions slow as $\Delta E$ between states increases. Typically, the energy gap between excited states is smaller than that between the lowest energy ES and the ground state.

It is useful to consider the quantum yields for the various photoprocesses depicted in Fig. 3. In general, the quantum yield for process $a$ is defined as

$$
\begin{aligned}
\Phi_{a} & =\frac{\text { number of molecules undergoing process } a}{\text { number of photons absorbed }} \\
& =\frac{\text { rate of process } a}{\text { rate of light absorption }}
\end{aligned}
$$

If the ES leading to process $a$ is directly excited (or is populated with unit efficiency from the initial ES) and gives rise to $n$ photoprocesses, the quantum yield can also be described by the ratio of rate constants (Eq. (2)) where $k_{a}$ is the first order rate constant for process $a$

$\Phi_{a}=\frac{k_{a}}{\sum_{i=1 \rightarrow n} k_{i}}$

from that state and $\sum_{i=1 \rightarrow n} k_{i}$ is the sum of all the rate constants, $k_{i}$, for the unimolecular decay processes of that ES. If Kasha's rule holds true, then, in the absence of BISC, one would describe the lifetime $\tau$ of the $S_{1}$ state in Fig. 3 in terms of the total rate constant for singlet deactivation,

$\tau\left(\mathrm{S}_{1}\right)=k_{d}\left(\mathrm{~S}_{1}\right)^{-1}$

where $k_{d}\left(\mathrm{~S}_{1}\right)=\Sigma k_{i}\left(\mathrm{~S}_{1}\right)=k_{\mathrm{nr}}\left(\mathrm{S}_{1}\right)+k_{\mathrm{F}}+k_{\mathrm{ISC}}$. The quantum yield $\Phi_{\mathrm{F}}$ for fluorescence would then be

$\Phi_{\mathrm{F}}=\frac{k_{\mathrm{F}}}{k_{d}\left(\mathrm{~S}_{1}\right)}=k_{\mathrm{F}} \cdot \tau\left(\mathrm{S}_{1}\right)$

Similarly, assuming $k_{\mathrm{ISC}} \gg k_{\mathrm{nr}}\left(\mathrm{T}_{1}\right)+k_{\mathrm{P}}$, then the lifetime of the triplet $\tau\left(\mathrm{T}_{1}\right)$ would be

$\tau\left(\mathrm{T}_{1}\right)=k_{d}\left(\mathrm{~T}_{1}\right)^{-1}$

and the phosphorescence quantum yield would be

$\Phi_{\mathrm{P}}=k_{\mathrm{P}} \cdot \tau\left(\mathrm{T}_{1}\right)$

where $k_{d}\left(\mathrm{~T}_{1}\right)=\Sigma k_{i}\left(\mathrm{~T}_{1}\right)=k_{\mathrm{nr}}\left(\mathrm{T}_{1}\right)+k_{\mathrm{P}}$. If either the $\mathrm{S}_{1}$ or the $\mathrm{T}_{1}$ state has a reactive deactivation channel leading to products, one would need to add the rate constants $k_{\mathrm{rxn}}\left(\mathrm{S}_{1}\right)$ and $k_{\mathrm{rxn}}\left(\mathrm{T}_{1}\right)$ to the terms $\Sigma k_{i}\left(\mathrm{~S}_{1}\right)$ and $\Sigma k_{i}\left(\mathrm{~T}_{1}\right)$, respectively. The quantum yields for reactions from these states would thus be defined as

$\Phi_{\mathrm{rxn}}\left(\mathrm{S}_{1}\right)=k_{\mathrm{rxn}}\left(\mathrm{S}_{1}\right) \cdot \tau\left(\mathrm{S}_{1}\right)$ and $\Phi_{\mathrm{rxn}}\left(\mathrm{T}_{1}\right)=k_{\mathrm{rxn}}\left(\mathrm{T}_{1}\right) \cdot \tau\left(\mathrm{T}_{1}\right)$

\footnotetext{
${ }^{2}$ However, as we will see in Section 3.2, there is growing evidence that the Franck-Condon state formed upon initial excitation sometimes do not follow this simple guideline.

3 Electronic states in thermal equilibrium with the lowest excited state should also be included [27].
}

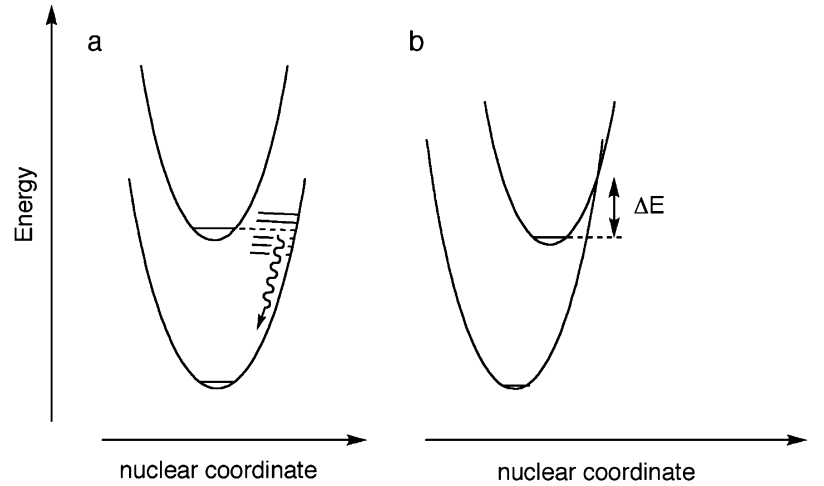

Fig. 4. Potential well diagrams for two limiting cases. (a) The potential wells are nested or weak-coupled. (b) The potential wells are displaced and strong-coupled.

The situation is more complex if back-intersystem crossing is significant. For example, if $k_{\mathrm{ISC}} \gg k_{\mathrm{BISC}}$, then fluorescence might be expected to display two components, one with a short $\tau$ defined in terms of the intrinsic lifetime of $S_{1}$ as described by Eq. (3) and a "delayed" fluorescence having the same lifetime as $\mathrm{T}_{1}$. Of course, in that case, the $k_{\mathrm{BISC}}$ would also contribute to $k_{d}\left(\mathrm{~T}_{1}\right)$, thereby shortening the triplet lifetime.

We can also picture electronic states as potential wells plotted with energy on the vertical axis and nuclear configuration on the horizontal axis (Fig. 4). ${ }^{4}$ The bottom of each well indicates the energy of that state at its equilibrium geometry. If the ground and excited states have very similar equilibrium geometries, their respective minima will occur at similar positions along the nuclear coordinate (Fig. 4a). States with different geometries will be displaced along the nuclear coordinate relative to each other (Fig. 4b).

The kinetic parameters for ES deactivation are dependent on whether or not there is a thermally accessible surface crossing to another state (e.g. the GS). In the case of nested electronic states (Fig. 4a) there is no surface crossing and the two states are "weakcoupled". Nonradiative decay from the upper to the lower state would then involve isoenergetic tunneling from the lowest vibrational state of the electronic excited state to a vibrationally excited state(s) of the ground electronic state (dashed line, Fig. 4a). The extent of coupling depends on the overlap between the wave functions of the two electronic/vibrational states.

Let us assume these states are the lowest energy ES and the GS, separated by about $14,000 \mathrm{~cm}^{-1}$ (not uncommon for transition metal complexes). In such a case, the best candidates for vibrational acceptor modes in the ground state are the highest energy electronically coupled modes (typically $\mathrm{N}-\mathrm{H}$ and $\mathrm{C}-\mathrm{H}$ stretching vibrations). Even so, four to five such vibrational quanta will be required to bridge the electronic energy gap. If the high frequency $\mathrm{N}-\mathrm{H}$ and/or $\mathrm{C}-\mathrm{H}$ oscillators are modified by deuteration, the decreased stretching frequencies correspondingly increase the number of vibrational quanta needed to bridge the gap. Thus, deuteration reduces the overlap between the relevant wave functions, thereby slowing the rate of nonradiative decay [28-30]. Consequently, in cases where emission and nonradiative decay from this ES are competitive, deuteration will increase the measured lifetime $\tau$ and the integrated intensity of emission by decreasing the rate of nonradiative

\footnotetext{
${ }^{4}$ It should be emphasized that such two-dimensional diagrams are strictly valid only for diatomic molecules. For any non-linear molecules or ion, the nuclear coordinates have $3 N-6$ degrees of freedom ( $N$ being the number of atoms), thus the nuclear coordinate surface may be extremely complicated. Although these potential wells are multi-dimensional surfaces, they are generally depicted as twodimensional surfaces where the nuclear coordinate is simplified to indicate the distortion most closely associated with the electronic transition of interest.
} 

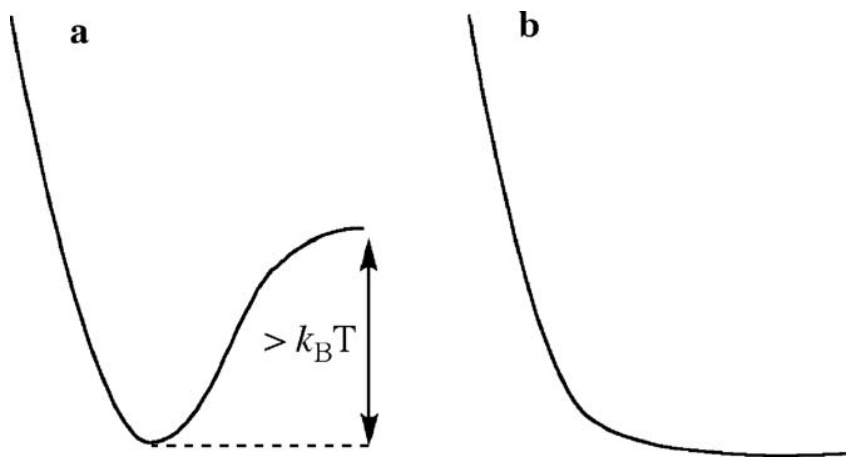

Fig. 5. Potential surfaces for (a) a bound state and (b) a dissociative state.

deactivation. Observation of such a deuterium isotope effect is often cited as evidence for NR decay occurring through a weak coupling mechanism.

When the relevant electronic excited state is significantly distorted from the ground state surface, the two states are "strongcoupled". In this case, the energy required for surface crossing from the ES to the GS ( $\Delta E$, Fig. $4 \mathrm{~b}$ ) is often thermally accessible and Arrhenius type behavior for the temperature dependence of the nonradiative decay rate may be found. Notably, it is common for both mechanisms to be functioning and for nonradiative decay rates to display both temperature-dependent and (relatively) temperature-independent components [31] (see also Section 4.2).

It should be noted that Fig. 4 depicts potential surfaces with clearly defined minima. Such states are referred to as "bound" states, for which there is an energy barrier (larger than $k_{\mathrm{B}} T$ ) to dissociation along the relevant reactive coordinate. It is also possible to have a "dissociative" state, where any such barrier is less than $k_{\mathrm{B}} T$ (see Fig. 5). In such a case the excited state lifetime is exceedingly short.

\subsection{How does photophysics affect the photochemistry of metal complexes?}

Developing systems to harness the energy stored in excited states requires a detailed understanding of both the physics and chemistry of these distinct chemical species. The previous discussion suggests several questions that should be considered in this pursuit:

(1) What are the relative rates of the photophysical processes of the types shown in Fig. 3? Are the excited state reactions competitive with these? Does one pathway to the GS dominate or are there multiple competitive paths?

(2) How does the electronic configuration affect the excited state geometry, and how does molecular structure affect the various photophysical and photochemical processes?

(3) What are the energy differences between various electronic states and how do these differences impact the various photophysical and photochemical processes?

(4) Which excited states are most likely to lead to photoreaction and/or to luminescence?

(5) What are the mechanisms of the excited state reactions?

(6) By what strategies can one tune the photophysical and photochemical properties?

Although the answers to these questions may vary from one system to another, we will primarily consider these questions within the context of the ligand field excited states of transition metal complexes, first those of $\mathrm{Cr}$ (III) and then those of low spin $d^{6}$ metal centers, certain features of which are paradigmatic of transition metal photochemistry in general.
For additional theoretical and spectroscopic treatment regarding some of these questions, the reader is directed to several reviews: ligand field theory (LFT) description of the relationship between electronic structure and M-L bond length [32,33]; the correlation of computational methods such as density functional theory (DFT) with experimental results [34,35]; the elucidation of details of electronic structure through the technique of spectral hole-burning [36]; spectroscopic methods to study coupled electronic states [32,37]; the effect of pressure on luminescence spectra [38,39]; low temperature luminescence spectra with resolved vibronic structure [40].

\section{Photochemistry and photophysics of chromium(III) complexes}

The purpose of this section is to illustrate some key concepts regarding metal centered ligand field excited states, drawing from the rich literature involving $\mathrm{Cr}(\mathrm{III})$ photophysics and phtochemistry. For more exhaustive reviews the reader is directed to several authoritative sources $[17,18,41-43]$.

\subsection{Ligand field excited states}

The ground state and lowest energy quartet and doublet electronic configurations for $\mathrm{Cr}(\mathrm{III})$ in an $O_{\mathrm{h}}$ ligand field are illustrated in Fig. 6 along with a potential well diagram and Jablonski type diagram. ${ }^{5}$ Since hexacoordinate $\mathrm{Cr}$ (III) complexes have quartet ground states, one can draw the following analogy between Figs. 3 and 6. Spin allowed excitation leads to quartet ES, while direct excitation into the doublet state(s) is forbidden. Note that the quartet excited states are distorted from the ground state, since a metal-ligand antibonding orbital has been populated, thus these ES should have elongated metal-ligand bonds relative to the GS. Indeed, for $\mathrm{Cr}\left(\mathrm{NH}_{3}\right)_{6}{ }^{3+}$ this distortion was estimated from spectroscopic data to involve a $12 \mathrm{pm}$ equatorial expansion along with a $2 \mathrm{pm}$ axial contraction [44]. The ${ }^{4} \mathrm{~T}_{2 \mathrm{~g}}$ potential minimum, therefore, is displaced relative to the ground state along a tetragonal distortion coordinate (Fig. 6b). The doublet states, on the other hand, have the same $\left(t_{2 g}\right)^{3}$ orbital population as the GS, and should be essentially undistorted. Thus, the potential well of the ${ }^{2} \mathrm{E}_{\mathrm{g}}$ state is "nested" with the ${ }^{4} \mathrm{~A}_{2 \mathrm{~g}}$ ground state.

Hexacoordinate complexes of lower symmetry (e.g. $C_{4 \mathrm{v}}$ and $D_{4 \mathrm{~h}}$ ) will demonstrate further splitting of the electronic states. The ${ }^{2} \mathrm{~T}_{1 \mathrm{~g}}$ $\left(O_{\mathrm{h}}\right)$ splitting depends only on the differences between axial and equatorial $\pi$-bonding parameters, which causes splitting in the $t_{2 g}$ orbitals. Splitting of the ${ }^{4} \mathrm{~T}_{2 \mathrm{~g}}$ and ${ }^{4} \mathrm{~T}_{1 \mathrm{~g}}$ states, on the other hand, depends on differences in both the $\sigma$ - and $\pi$-bonding parameters [45] (see also Section 4.3). As depicted in Fig. 7, the state(s) derived from that of ${ }^{2} \mathrm{E}_{\mathrm{g}}\left(\mathrm{O}_{\mathrm{h}}\right)$ parentage is/are typically the lowest energy doublet(s). However, the doublet state derived from ${ }^{2} \mathrm{~T}_{1 \mathrm{~g}}$ $\left(O_{\mathrm{h}}\right)$ parentage becomes the lowest in a few complexes with strong axial $\pi$-donors [46].

For $\mathrm{Cr}$ (III) complexes of $\mathrm{O}_{\mathrm{h}}$ symmetry, the lowest energy spinallowed excitation is into excited vibrational (Franck-Condon) states of the ${ }^{4} \mathrm{~T}_{2 \mathrm{~g}}$ electronic state. The displaced nature of this ES surface results in a manifold of vibronic transitions and a broad absorption band (Fig. 8). In contrast, direct (spin-forbidden) excitation into the undisplaced ${ }^{2} \mathrm{E}_{\mathrm{g}}$ state should give a narrow band. This same relationship between spectral width and distortion applies to the emission spectra (Fig. 8) [47]. $\mathrm{Cr}$ (III) complexes of $O_{\mathrm{h}}$ symmetry typically show two broad spin allowed "quartet" absorption

\footnotetext{
${ }^{5}$ For the sake of simplicity, only the lowest energy quartet and doublet ES are shown in Fig. $6 \mathrm{~b}$ and the ${ }^{2} \mathrm{~T}_{1 \mathrm{~g}}$ state, which is often energetically close to the ${ }^{2} \mathrm{E}_{\mathrm{g}}$, is omitted from Fig. 6c.
} 
a

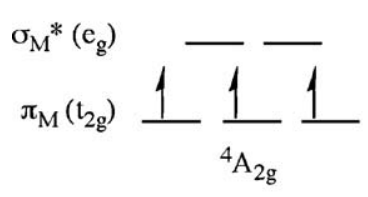

b

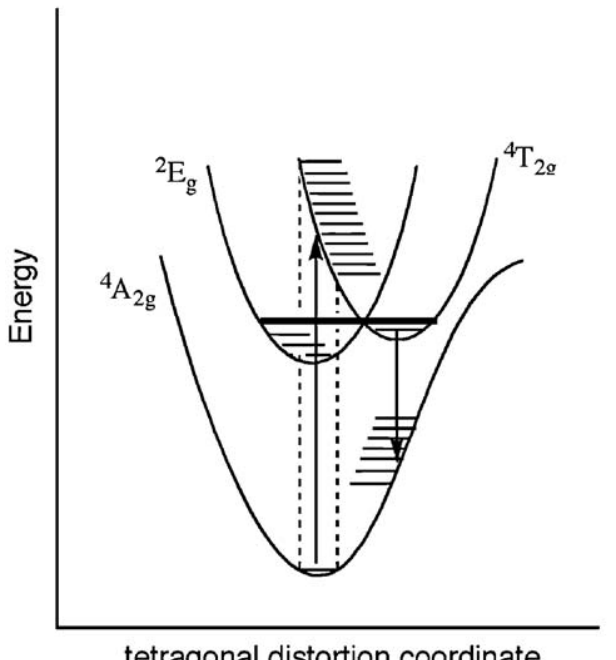

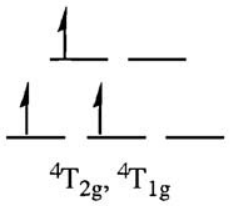
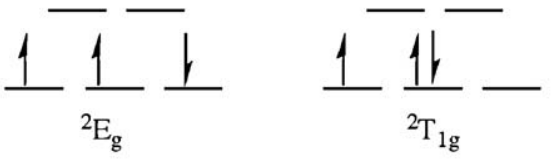

C

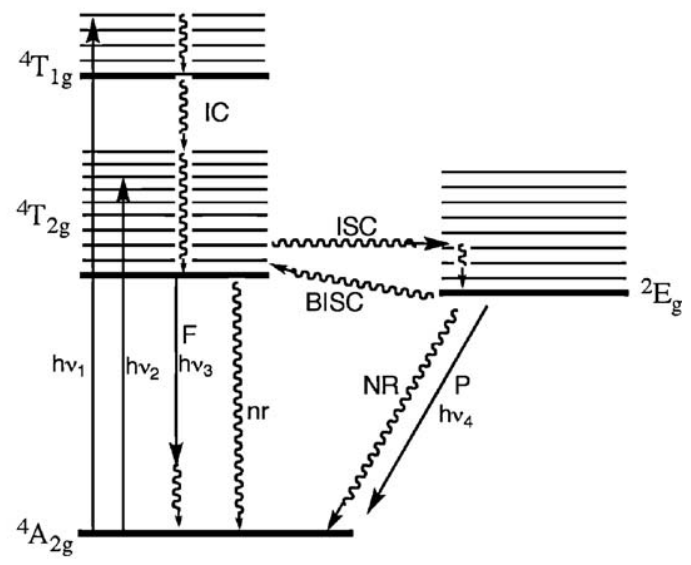

Fig. 6. (a) Electronic configurations for $\mathrm{Cr}(\mathrm{III})$ complexes in $\mathrm{O}_{\mathrm{h}}$ symmetry. (b) Potential well diagram showing the ground state and lowest energy quartet and doublet excited states along with absorption to and fluorescence from the ${ }^{4} \mathrm{~T}_{2 \mathrm{~g}}$. (c) Jablonski diagram depicting photophysical processes.

bands for ${ }^{4} \mathrm{~A}_{2 g} \rightarrow{ }^{4} \mathrm{~T}_{1 g}$ and ${ }^{4} \mathrm{~A}_{2 g} \rightarrow{ }^{4} \mathrm{~T}_{2 g}$ (e.g., see Fig. 2). Direct excitation into the spin forbidden doublet states is typically not observed, but occasionally shows up as weak, sharp features on the long wavelength side of the lowest energy quartet band. Classical examples of this absorption feature appear in the room temperature spectrum of $\mathrm{Cr}$ (urea) ${ }_{6}{ }^{3+}$ [48] and the $77 \mathrm{~K}$ spectrum of ruby [49]. Additionally, the ${ }^{4} \mathrm{~A}_{2 g} \rightarrow{ }^{2} \mathrm{E}_{\mathrm{g}}$ absorbance band is often split due to spin orbit coupling and a lowered crystal field symmetry [49-53].

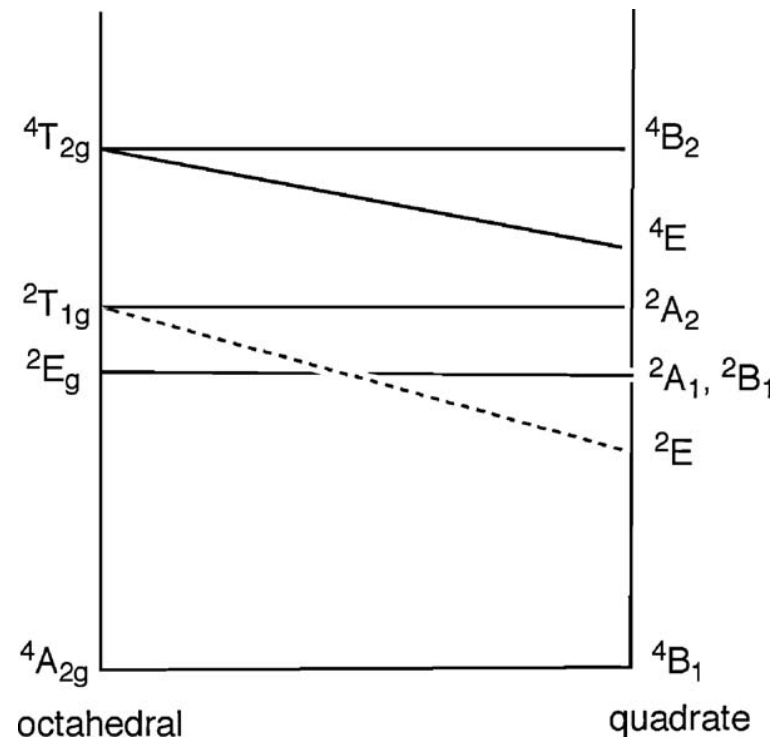

Fig. 7. Energy level diagram showing the splitting of $d^{3} O_{\mathrm{h}}$ electronic states in a quadrate field.

Adapted from Ref. [45].
After initial population of the ${ }^{4} \mathrm{~T}_{1 \mathrm{~g}}$ Franck-Condon states, rapid VR to an equilibrium geometry and IC to the ${ }^{4} \mathrm{~T}_{2 \mathrm{~g}}$ state occurs. Recent ultrafast spectroscopic studies [54] also suggest some prompt ISC to doublet ES manifolds from high energy excitation. From the lowest quartet ES there are possibilities of fluorescence, ISC to the doublet state(s) and direct nonradiative decay to the GS. Note that the energy of the F band will be shifted (Stokes shift) to lower energy relative to the absorption into the same lowest quartet state (Fig. 8). From the thermally equilibrated doublets, there is the possibility of (i) BISC, (ii) phosphorescence, or (iii) NR (another

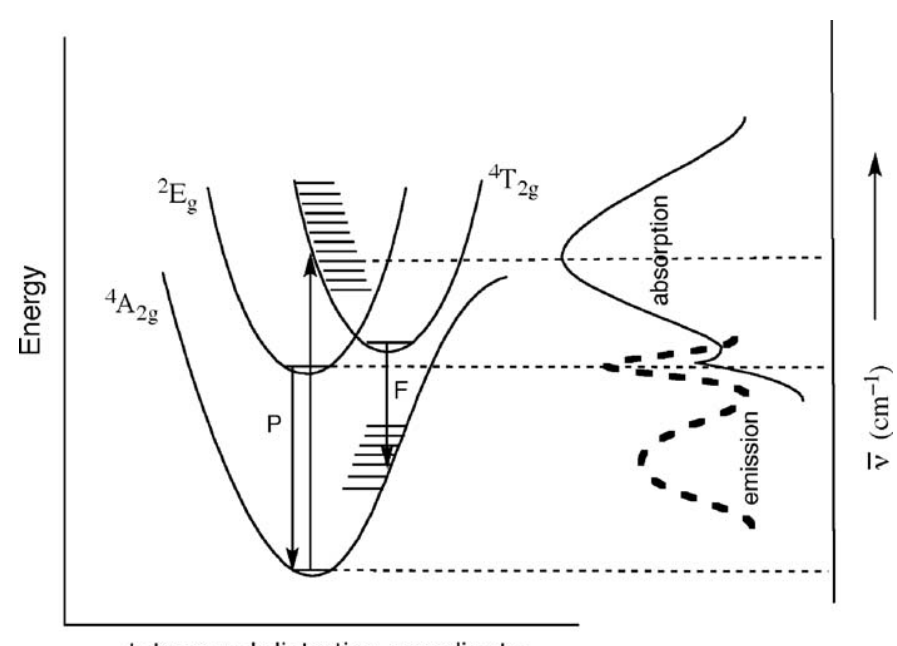

tetragonal distortion coordinate

Fig. 8. Schematic potential surface diagram for an octahedral $\mathrm{Cr}(\mathrm{III})$ complex depicting its relationship to the absorption and emission spectra. Adapted from Ref. [47]. 
ISC process) to the ground state. Reactions from the lowest energy quartet and doublet ES are also possible and will be discussed in Section 3.3.

\subsection{Photophysics}

Based on experience with organic systems, the rate constants for some of the photophysical processes described might be expected to follow the order $k_{\mathrm{VR}}>k_{\mathrm{IC}}>k_{\mathrm{ISC}}$ [29]. For certain $\mathrm{Cr}$ (III) complexes, however, it was found that ${ }^{2} E_{g}$ phosphorescence quantum yields are dependent on excitation wavelength $\left(\lambda_{\mathrm{ex}}\right)$ [55-58]. An example is the $\mathrm{Cr}\left(\mathrm{NH}_{3}\right)_{6}{ }^{3+}$ cation where the phosphorescence quantum yields $(298 \mathrm{~K})$ were determined for excitation at $514 \mathrm{~nm}$ and $436 \mathrm{~nm}$, both wavelengths corresponding to excitation into the first ligand field band. Under these conditions, $\Phi_{\mathrm{P}}(514 \mathrm{~nm}) / \Phi_{\mathrm{P}}(436 \mathrm{~nm})=0.60$ [56]. Likewise, the fraction of the photoreaction attenuated by selective doublet state quenchers was also dependent on $\lambda_{\text {ex }}$ [55-58]. These observations suggest that the higher energy irradiation populates quartet Franck-Condon states at energies above the quartet/doublet crossing point such that quartet to doublet ISC effectively competes with vibrational cooling. This interpretation was supported by ps laser studies on several $\mathrm{Cr}$ (III) complexes that demonstrated a rise time for ${ }^{2} \mathrm{E}_{\mathrm{g}}$ formation shorter than the time response of the instrument (1-2 ps) [59,60]. More recent studies on $\mathrm{Cr}(\mathrm{acac})_{3}$ indicate that $k_{\mathrm{ISC}}>1 \times 10^{13} \mathrm{~s}^{-1}$, thus ISC from such Franck-Condon states is at least competitive with VR to the lowest quartet [54]. These observations highlight the growing recognition that concepts regarding the relative rates of VR, IC, and ISC applicable to organic systems do not consistently apply to metal systems [61].

A recent time-resolved transient absorption investigation on $\mathrm{Cr}(\mathrm{acac})_{3}$ has revealed an oscillatory component $\left(164 \mathrm{~cm}^{-1}\right)$ superimposed on the ${ }^{4} \mathrm{~T}_{2}$ excited-state absorption [62]. The fact that this vibrational coherence is maintained on the timescale of ${ }^{4} \mathrm{~T}_{2} \rightarrow{ }^{2} \mathrm{E}$ ISC suggests that this frequency may be associated with the coordinate for the ISC. DFT calculations indicate that this frequency could correspond to a combination of excited state vibrations involving $\mathrm{Cr}-\mathrm{O}$ bond stretching and large amplitude motions of the acac ligand backbone. In support of this hypothesis, when the methyl groups on the acac ligand were replaced with sterically bulky $t$-butyl groups, the rate of ISC decreased by an order of magnitude. This result suggests that it may be possible to rationally control excited state dynamics [62].

According to Kasha's rule, the lowest energy quartet and doublet excited states (Fig. 6b) are the most worthy of attention when discussing the photophysics of the $\mathrm{Cr}(\mathrm{III})$ complexes. This suggests the possibility of observing fluorescence from the ${ }^{4} \mathrm{~T}_{2 g}\left(O_{\mathrm{h}}\right)$ ES as well as phosphorescence from the ${ }^{2} \mathrm{E}_{\mathrm{g}}\left(\mathrm{O}_{\mathrm{h}}\right) \mathrm{ES}$. Because the ${ }^{2} \mathrm{E}_{\mathrm{g}}$ energy is largely insensitive to ligand field strength (although dependent on ligand nephelauxetic parameters) $[43,63,64]$, while the ${ }^{4} T_{2 g}$ energy depends directly on LF strength (Fig. 9), the relative energies of the ES potential minima can be varied by choice of ligands. This results in "fluorescence only" from complexes of weak field ligands (e.g., $\left.\mathrm{Br}^{-}, \mathrm{Cl}^{-}, \mathrm{F}^{-}\right)$, and "phosphorescence only" from those with strong field ligands (e.g. $\mathrm{NH}_{3}, \mathrm{CN}^{-}$). Dual emission (i.e., $\mathrm{P}$ accompanied by $\mathrm{F}$ ) is sometimes observed for the intermediate case of oxygen donors [47]. A classic example is the dual emission observed for the complex $\mathrm{Cr}(\text { urea })_{6}{ }^{3+}$ in a $78 \mathrm{~K}$ glass [48].

The ability to tune emission properties by adjusting the ligand field strength was cleverly exploited by applying extreme pressures to solid $\left(\mathrm{NH}_{4}\right)_{3}\left[\mathrm{CrF}_{6}\right]$, a sample that shows only fluorescence under ambient pressures at $22 \mathrm{~K}$. As the pressure was increased in a diamond anvil cell, the compression of the solid increased the effective ligand field strength. The result was a blue-shift of the fluorescence between 0 and $7.8 \mathrm{GPa}$ applied pressure, and the onset

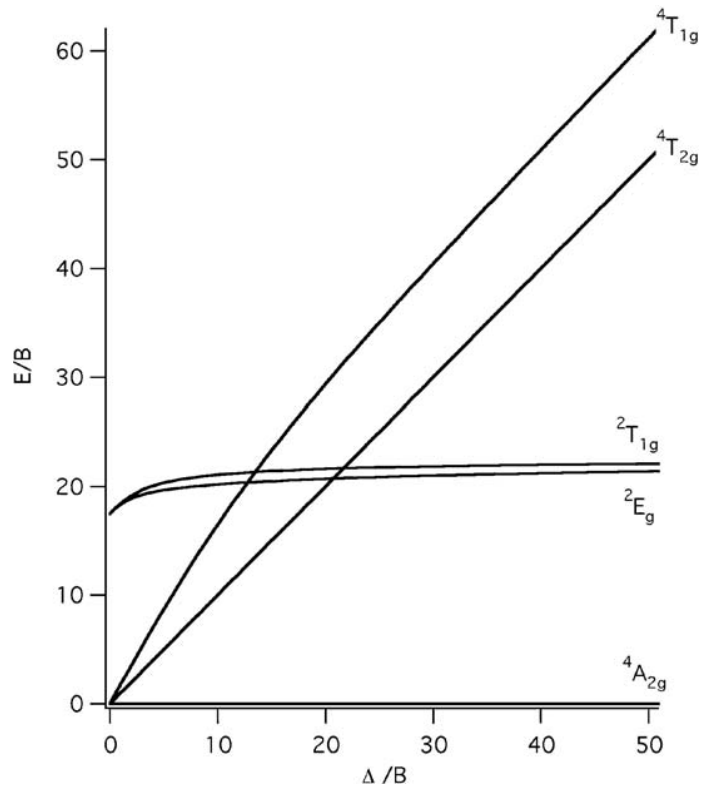

Fig. 9. Simplified Tanabe-Sugano type diagram for the $d^{3}$ electronic configuration in $O_{\mathrm{h}}$ symmetry. As the ligand field strength increases, the lowest energy excited state crosses from the ${ }^{4} \mathrm{~T}_{2 g}$ state to the ${ }^{2} \mathrm{E}_{\mathrm{g}}$ state.

of ${ }^{2} \mathrm{E}_{\mathrm{g}}$ phosphorescence $\left(14896 \mathrm{~cm}^{-1}\right.$ ) at $8.8 \mathrm{GPa}$ (Fig. 10) [65,66]. An earlier study of such pressure-induced tuning of fluorescence to phosphorescence involved $\left[\mathrm{Cr}(\mathrm{urea})_{6}\right]\left(\mathrm{ClO}_{4}\right)_{3}$ [67]. For a quantitative treatment of the increase of ligand field strength with pressure, the reader is directed to a review highlighting the effects of pressure on the luminescence of TM systems [38].

Polydentate ligands that invoke geometric constraints reducing orbital overlap can also significantly affect the quartet energy levels. For example, the trans- $\left[\mathrm{Cr}\left(\mathrm{N}_{4}\right)(\mathrm{CN})_{2}\right]^{+}$cations shown in Fig. 2 display red-shifts of the LF absorption bands (in addition to increased $\varepsilon$ ) as one proceeds from cyclam, to $1,11-C_{3}$-cyclam, to $1,4-C_{2}$-cyclam. This result is attributed to decreased orbital overlap through this series due to ligand imposed deviations from $O_{\mathrm{h}}$ microsymmetry [25]. Thus, it is possible to tune the relative LF

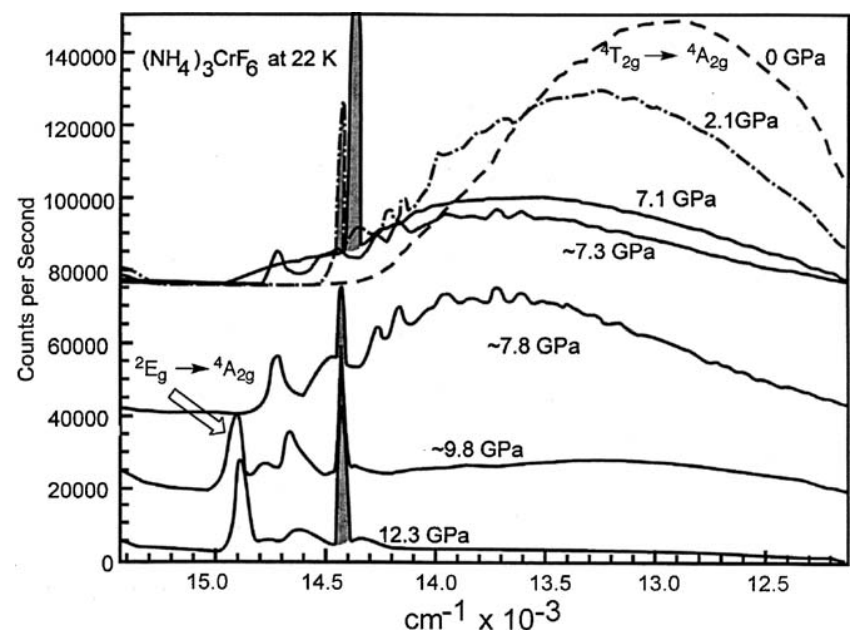

Fig. 10. Pressure-dependent luminescence spectra of $\left(\mathrm{NH}_{4}\right)_{3}\left[\mathrm{CrF}_{6}\right]$ measured at $22 \mathrm{~K}$ in a diamond anvil cell with $632.8 \mathrm{~nm}$ He/Ne laser excitation. Shaded peaks are due to either the $1332 \mathrm{~cm}^{-1}$ diamond Raman line or to the ruby phosphorescence used to measure pressure. Increasing the pressure leads to a gradual blue-shift of the ${ }^{4} \mathrm{~T}_{2 g} \rightarrow{ }^{4} \mathrm{~A}_{2 g}$ fluorescence and the onset of the ${ }^{2} \mathrm{E}_{\mathrm{g}} \rightarrow{ }^{4} \mathrm{~A}_{2 \mathrm{~g}}$ phosphorescence at applied pressures $>7.8 \mathrm{GPa}$.

Adapted from Ref. [66]. 
excited state energies by varying the ligands, modifying geometric constraints, or applying extreme conditions such as high pressure.

Detailed analysis of the kinetics and thermodynamics of ISC and BISC between the ${ }^{4} \mathrm{~T}_{2 \mathrm{~g}}$ and ${ }^{2} \mathrm{E}_{\mathrm{g}}\left(\mathrm{O}_{\mathrm{h}}\right)$ ES requires knowledge of the relative energies of the potential well minima and their crossing points. Assigning the energy of a specific ES relative to that of the ground state can in principle be accomplished spectroscopically by determining the energy of the electronic transition between the lowest vibrational level of each (that is, where $v=0$ ). Indeed, in a few cases, there is enough structure in the low temperature ${ }^{4} \mathrm{~A}_{2 \mathrm{~g}} \rightarrow{ }^{4} \mathrm{~T}_{2 \mathrm{~g}}$ absorption spectrum to locate the $0-0$ band [44,68-70]. For example, the spin-orbit split 0-0 lines for the ${ }^{4} \mathrm{~T}_{2 g}$ to ${ }^{4} \mathrm{~A}_{2 \mathrm{~g}}$ transition of single-crystal $\left[\mathrm{Cr}\left(\mathrm{NH}_{3}\right)_{6}\right]\left(\mathrm{ClO}_{4}\right)_{2} \mathrm{Cl} \cdot \mathrm{KCl}$ at $6 \mathrm{~K}$ place the vibrationally cooled quartet ES at $19,960 \mathrm{~cm}^{-1}$ above the ground state [44]. For complexes of $D_{4 \mathrm{~h}}$ symmetry, there is the additional question of whether the ${ }^{4} \mathrm{~B}_{2 \mathrm{~g}}$ or ${ }^{4} \mathrm{E}_{\mathrm{g}}$ state of ${ }^{4} \mathrm{~T}_{2 \mathrm{~g}}$ parentage (Fig. 7) lies lower in energy. For trans- $\mathrm{Cs}_{2}\left[\mathrm{CrCl}_{2}\left(\mathrm{H}_{2} \mathrm{O}\right)_{4}\right] \mathrm{Cl}_{3}$, single crystal polarized absorption and luminescence spectra at $5 \mathrm{~K}$ identified the lowest energy electronic origin $\left(13,630 \mathrm{~cm}^{-1}\right)$ as the ${ }^{4} \mathrm{~B}_{1 \mathrm{~g}} \rightarrow{ }^{4} \mathrm{E}_{\mathrm{g}}$ transition (see Fig. 7) [70]. In contrast with these cryogenic single crystal experiments, absorbance bands in room temperature solution tend to be broad and fluorescence under these conditions is rare [71], so it is necessary to estimate the energy differences.

An empirical rule for estimating the energy of the thermalized quartet from the absorption band is the $5 \%$ rule given by Eq. (8) [20],

$E\left({ }^{4} \mathrm{~T}_{2 \mathrm{~g}}^{\circ}\right)=1.11\left(\bar{v}_{0.05}\right)-880 \mathrm{~cm}^{-1}$

where $\bar{v}_{0.05}$ is the frequency (in $\mathrm{cm}^{-1}$ ) at which the absorption on the red side of the Gaussian shaped ${ }^{4} \mathrm{~A}_{2 \mathrm{~g}} \rightarrow{ }^{4} \mathrm{~T}_{2 \mathrm{~g}}$ band is $5 \%$ of its maximum intensity. However, some researchers argue that Eq. (8) overestimates the ${ }^{4} \mathrm{~T}_{2 g} /{ }^{4} \mathrm{~A}_{2 \mathrm{~g}}$ energy gap [42], while others argue that it underestimates this value [72].

Much more is known about the ${ }^{2} \mathrm{E}_{\mathrm{g}}$ state energies, since the ${ }^{2} \mathrm{E}_{\mathrm{g}} \rightarrow{ }^{4} \mathrm{~A}_{2 \mathrm{~g}}$ emission spectra in low temperature glasses often show considerable vibrational fine structure with a prominent $0-0$ band [43]. Such emission often persists at room temperature with relatively long $(0.1-1000 \mu \mathrm{s})$ lifetimes. However, given the ambiguity concerning the energy of the ${ }^{4} \mathrm{~T}_{2 g}$ state, it is clear that the ${ }^{4} \mathrm{~T}_{2 \mathrm{~g}} /{ }^{2} \mathrm{E}_{\mathrm{g}}$ energy gap cannot be accurately determined for most systems in room temperature solution, so it is necessary to make approximations such as the 5\% rule to estimate this energy gap.

In most cases when the doublet is the lowest energy excited state, intersystem crossing is efficient, with ISC quantum yields ( $\Phi_{\text {ISC }}$ ) typically in the range 0.7-1.0 [42]. Thus, it is essential to understand the modes of doublet deactivation. We will first focus on systems for which photochemistry is negligible. For these systems, P, NR, and BISC to the lowest quartet state must be considered. In addition, we will also consider a nonradiative crossing to a ground state intermediate (GSI) with a quartet electronic configuration as has been proposed for certain $\mathrm{Cr}$ (III) systems (Fig. 11) [72-75].

These processes for $\mathrm{Cr}(\mathrm{III})$ complexes are reflected in the response of the measured ${ }^{2} \mathrm{E}_{\mathrm{g}} \rightarrow{ }^{4} \mathrm{~A}_{2 \mathrm{~g}}$ emission lifetimes to temperature changes. In order to interpret such data, it has proved helpful to adopt an operationally useful formalism whereby the excited-state decay rate constant is separated into temperatureindependent and temperature-dependent components (Eq. (9)) $[72,73,76]$.

$\tau^{-1}=k_{d}=k(T)+k^{\circ}$

Here, $\tau$ is the observed lifetime, $k_{d}$ is the overall rate constant for deactivation, $k^{\circ}$ is the nearly temperature independent rate constant for excited state deactivation, and $k(T)$ represents the

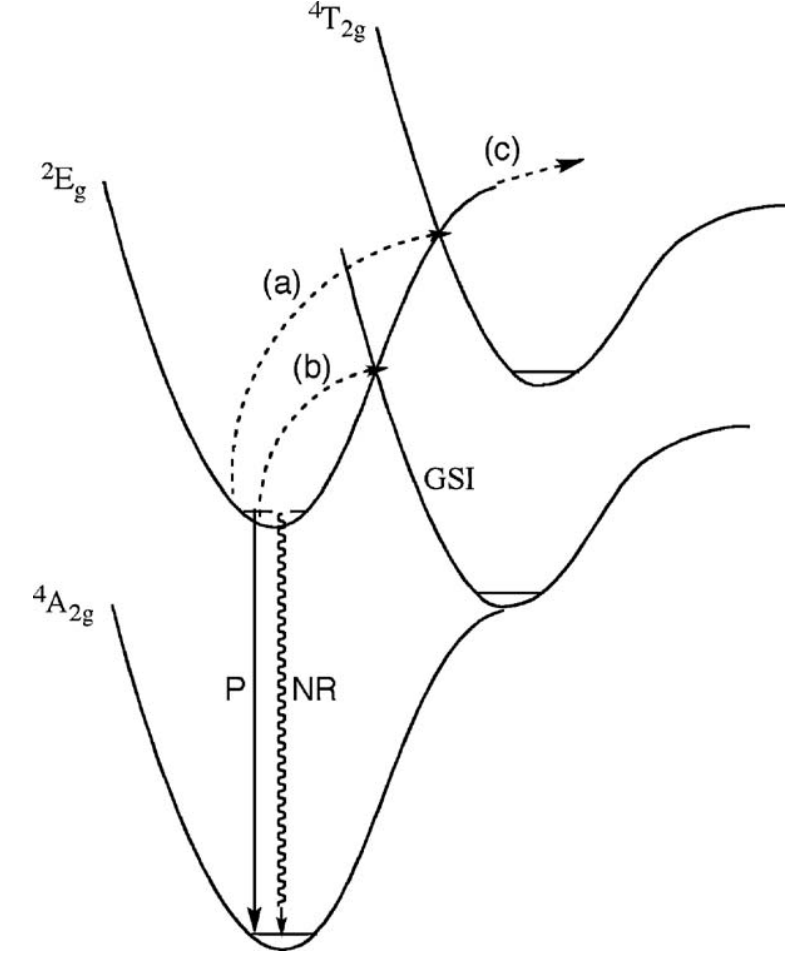

Fig. 11. Qualitative potential well diagram showing possible deactivation modes for the ${ }^{2} E_{g}$ excited state. These include phosphorescence $(P)$, nonradiative decay (NR), (a) back intersystem crossing, (b) crossing to a ground state intermediate (GSI), or (c) direct doublet reactivity.

temperature-dependent component. The term $k^{\circ}$ can be further separated into a radiative component due to phosphorescence, $k_{\mathrm{r}}$, and a nonradiative component due to ISC to the ground state, $k_{\mathrm{nr}}$. Likewise, the $k(T)$ term may be separated into several components owing to different thermally activated deactivation mechanisms (Fig. 11). At very low $T, k^{\circ}$ is the limiting value for $k_{d}$.

It is instructive to consider complexes in the low temperature limit, where $k(T)$ is negligible and the phosphorescence lifetime is effectively independent of T. For some complexes, e.g., trans$\mathrm{Cr}(\mathrm{cyclam})(\mathrm{CN})_{2}{ }^{+}$in fluid solution, this is the case nearly up to room temperature [77] (Fig. 12), whereas for others $\tau$ is dramatically shorter at room temperature than it is at $77 \mathrm{~K}[18,74]$.

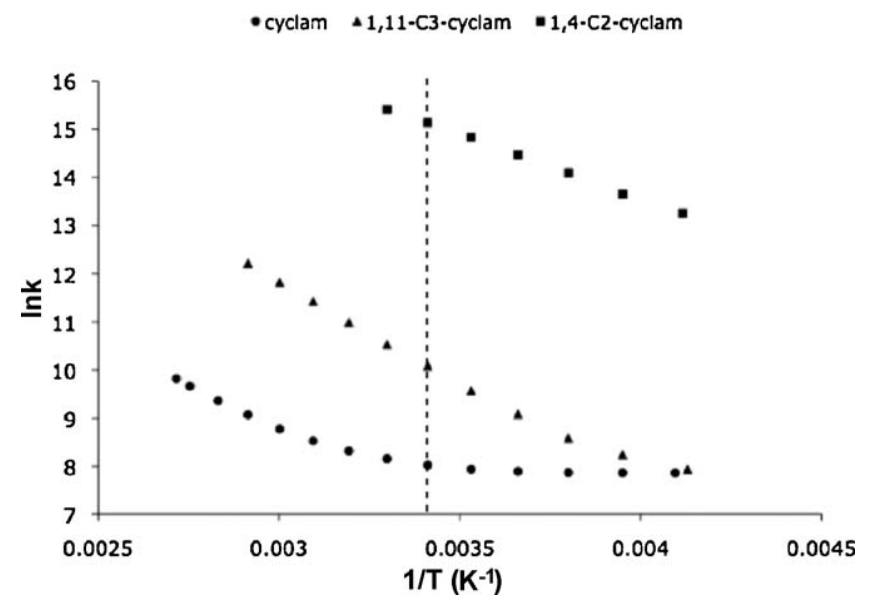

Fig. 12. Temperature dependence of the rate constant for ${ }^{2} \mathrm{E}_{\mathrm{g}}\left(\mathrm{O}_{\mathrm{h}}\right)$ excited state relaxation for trans-Cr(cyclam $)(\mathrm{CN})_{2}{ }^{+}$, trans- $\mathrm{Cr}\left(1,11-\mathrm{C}_{3}-\right.$ cyclam $)(\mathrm{CN})_{2}{ }^{+}$, and trans$\mathrm{Cr}\left(1,4-\mathrm{C}_{2}\right.$-cyclam $)(\mathrm{CN})_{2}{ }^{+}$in $1: 1 \mathrm{DMSO} / \mathrm{H}_{2} \mathrm{O}(0.01 \mathrm{M} \mathrm{HCl})$. Note that near $293 \mathrm{~K}$ (vertical dashed line), the rate constant for the cyclam complex is relatively temperature independent, whereas the decay rate constants for the other two complexes exhibit Arrhenius behavior [78]. 
At the low temperature limit, phosphorescence and nonradiative deactivation are responsible for excited state relaxation. Since phosphorescence quantum yields, $\phi_{\mathrm{P}}$, are small for most $\mathrm{Cr}$ (III) complexes [79], the ${ }^{2} \mathrm{E}_{\mathrm{g}}$ lifetime must be dominated by NR $\left(k_{\mathrm{nr}} \gg k_{\mathrm{r}}\right)$. Because the ${ }^{2} \mathrm{E}_{\mathrm{g}}$ and ${ }^{4} \mathrm{~A}_{2 \mathrm{~g}}$ electronic states are nested, i.e. weak-coupled, this nonradiative relaxation involves tunneling from the ES potential surface into the GS potential surface and should be facilitated by high frequency vibrations $[28,30]$. Typically, the more N-H oscillators directly bound to the metal, the shorter the phosphorescence lifetime [73,80]. For example, the $77 \mathrm{~K}$ lifetime of $\mathrm{Cr}\left(\mathrm{NH}_{3}\right)_{6}{ }^{3+}$ (with $18 \mathrm{~N}-\mathrm{H}$ oscillators on atoms directly coordinated to the $\mathrm{Cr}(\mathrm{III}))$ is $70 \mu \mathrm{s}$, whereas that for trans- $\mathrm{Cr}($ cyclam $)\left(\mathrm{NH}_{3}\right)_{2}{ }^{3+}$ (with only $10 \mathrm{~N}-\mathrm{H}$ oscillators) is $180 \mu \mathrm{s}$ [81]. These lifetimes also respond substantially to deuteration of the am(m)ines [18,82], e.g., $\mathrm{N}-\mathrm{H}$ deuteration of trans- $\mathrm{Cr}(\mathrm{cyclam})\left(\mathrm{NH}_{3}\right)_{2}{ }^{3+}$ increases its $77 \mathrm{~K}$ lifetime to $3720 \mu \mathrm{s}$ [81].

The thermally activated pathway for ${ }^{2} \mathrm{E}_{\mathrm{g}}$ excited state deactivation often exhibits an Arrhenius dependence (Fig. 12), though there are exceptions $[43,83]$. In accordance with expectations for a surface crossing pathway, there is typically little to no deuterium isotope effect on this component of the nonradiative deactivation. However, because the $\mathrm{Cr}$ (III) doublet states are largely nested with the ground state, it is unlikely that this crossing would involve a strong coupling mechanism directly between these two states. A more likely possibility would be back intersystem crossing to the lowest energy quartet ES. Because this state is strongly distorted from the GS geometry, a surface crossing with the GS would then provide the deactivation pathway. In this latter case, the activation barrier for this pathway would have two components: one corresponding to BISC, the other to the additional energy necessary to further promote the system to the surface crossing between the excited and ground quartet states.

In this context, it has been demonstrated for a series of aci$\operatorname{doam}(\mathrm{m})$ ine $\mathrm{Cr}(\mathrm{III})$ complexes (e.g. cis- and trans- $\mathrm{Cr}\left(\mathrm{N}_{2}\right)_{2} \mathrm{XY}^{n+}$, where $\mathrm{N}_{2}=1$,2-ethanediamine or 1,3-propanediamine, and $\mathrm{X}$ and $\mathrm{Y}$ are among $\mathrm{F}^{-}, \mathrm{Cl}^{-}, \mathrm{Br}^{-}, \mathrm{NCS}^{-}$, and $\mathrm{H}_{2} \mathrm{O}$ ) that the phosphorescence lifetime becomes considerably longer as the energy gap between the lowest energy quartet and doublet excited states increases. This would be consistent with a mechanism involving BISC followed by rapid ${ }^{4} \mathrm{~T}_{2 \mathrm{~g}} \rightarrow{ }^{4} \mathrm{~A}_{2 \mathrm{~g}}\left(\mathrm{O}_{\mathrm{h}}\right)$ relaxation [84]. A key question, however, is whether this latter relaxation demonstrated deuterium isotope effects, since both weak and strong coupling deactivation mechanisms of the quartet ES might be expected.

With stronger field ligands that give large ${ }^{2} \mathrm{E}_{\mathrm{g}} /{ }^{4} \mathrm{~T}_{2 \mathrm{~g}}\left(O_{\mathrm{h}}\right)$ energy gaps (e.g. trans- $\mathrm{Cr}\left(\mathrm{N}_{4}\right)(\mathrm{CN})_{2}{ }^{+}$, where $\mathrm{N}_{4}=$ a macrocyclic tetraamine ligand such as cyclam), the apparent activation energy for ${ }^{2} \mathrm{E}_{\mathrm{g}}$ phosphorescence decay is much smaller than the estimated ${ }^{2} \mathrm{E}_{\mathrm{g}} /{ }^{4} \mathrm{~T}_{2 \mathrm{~g}}$ energy gap. This observation led some authors to rule out BISC as a principal mechanism for ${ }^{2} \mathrm{E}_{\mathrm{g}}\left(O_{\mathrm{h}}\right)$ deactivation [18,25,72,85]. Instead another thermally activated process involving surface crossing from the doublet to a hypothetical intermediate, such as the GSI in Fig. 11, was proposed [72-75]. Once formed, the GSI could continue along a trajectory to products or along a separate trajectory to the original GS.

One suggested distortion coordinate for such a GSI is a molecular twisting motion toward a trigonal prismatic structure $\left(O_{\mathrm{h}} \rightarrow D_{3 \mathrm{~h}}\right)$. Such a distortion would relax the Laporte selection rule ${ }^{6}$ and allow $\mathrm{p} / \mathrm{d}$ orbital mixing. Furthermore, none of the ligand field excited states would be nested with the ground state, providing more opportunity for potential well surface crossing [73].

This proposal was tested by comparing several pairs of $\mathrm{Cr}\left(\mathrm{N}_{6}\right)^{3+}$ complexes having different thermodynamic barriers toward a trig-

\footnotetext{
${ }^{6}$ It should be noted that the Laporte selection rule applies only to radiative transitions.
}

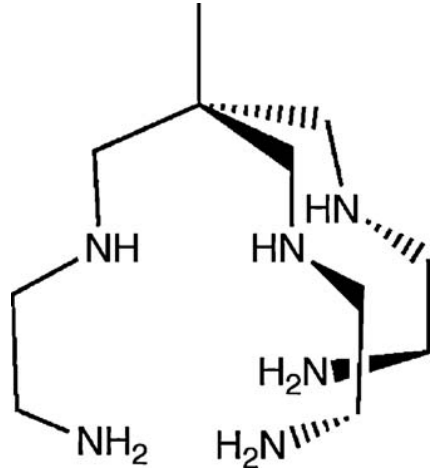

Fig. 13. The quasi-cage ligand, sen can be thought of as three ethylenediamine ligands joined by a neopentyl capping group.

onal twist. Species for which this twist was more facile had the shorter excited state lifetimes at room temperature, consistent with this mechanism [73]. For example, the complexes $\mathrm{Cr}(\mathrm{en})_{3}{ }^{3+}$ and $\mathrm{Cr}(\mathrm{sen})^{3+}$ (Fig. 13) have nearly identical the ground state coordination geometries. However, the crystal structure shows larger than normal bond angles in the neopentyl cap for the antiprismatic arrangement of the coordinated sen ligand, and molecular mechanics calculations suggest that a $14^{\circ}$ twist toward a prismatic geometry would reduce ligand strain by $18 \mathrm{~kJ} / \mathrm{mol}$. This should result in a lower barrier for a trigonal twist for $\mathrm{Cr}(\mathrm{sen})^{3+}$ than for $\mathrm{Cr}(\mathrm{en})_{3}{ }^{3+}$. Consistent with the relaxation mechanism discussed above, the excited state lifetime of $\mathrm{Cr}(\mathrm{sen})^{3+}$ in room temperature fluid solution is shorter than that of $\mathrm{Cr}(\mathrm{en}) 3^{3+}$ by more than a factor of $10^{4}$ [74]. This dependence of deactivation rates on steric constraint finds parallel in the recent ultrafast kinetic studies on $\mathrm{Cr}(\mathrm{acac})_{3}$ demonstrating that the rate of ISC decreases by an order of magnitude upon replacing the acac methyl groups with sterically bulky $t$-butyl groups [62].

Another study comparing the photophysical properties of a series of complexes $\operatorname{Cr}(\mathrm{mac}) \mathrm{X}_{2}{ }^{n+}$ (where $\mathrm{mac}=\mathrm{a}$ series of $\mathrm{N}_{4}$ and $\mathrm{N}_{3} \mathrm{~S}$ macrocyclic ligands) has suggested that crossing to a GSI and BISC are competitive [75]. Indeed, when $\mathrm{X}$ is a strong field ligand such as $\mathrm{NH}_{3}$ and $\mathrm{CN}^{-}$, giving a high barrier to BISC, GSI is the dominant channel; when $\mathrm{X}$ is a weak field ligand such as $\mathrm{Br}^{-}$or $\mathrm{Cl}^{-}, \mathrm{BISC}$ is the dominant channel. These results clearly demonstrate that tuning the relative excited state energies can define the trajectories of the nonradiative deactivation mechanism.

\subsection{Photosubstitution reactions}

Photoexcitaton of $\mathrm{Cr}$ (III) complexes in solution often leads to ligand substitution reactions, aquation (e.g. Eq. (10)) being the most commonly studied. Quantum yields of several representative complexes are listed in Table 1.

$\mathrm{Cr}\left(\mathrm{NH}_{3}\right)_{6}^{3+}+\mathrm{H}_{2} \mathrm{O} \stackrel{h v}{\longrightarrow} \mathrm{Cr}\left(\mathrm{NH}_{3}\right)_{5}\left(\mathrm{H}_{2} \mathrm{O}\right)^{3+}+\mathrm{NH}_{3}$

Table 1

Photoaquation quantum yields $\left(\Phi_{\mathrm{L}}\right)$ for a representative set of homoleptic and heteroleptic $\mathrm{Cr}(\mathrm{III})$ complexes.

\begin{tabular}{llll}
\hline Complex & $\lambda_{\text {ex }}$ & $\Phi_{\mathrm{L}}$ (main mode) & Ref. \\
\hline $\mathrm{Cr}\left(\mathrm{NH}_{3}\right)_{6}{ }^{3+}$ & 436 & 0.47 & {$[86]$} \\
$\mathrm{Cr}(\mathrm{en})_{3}{ }^{3+}$ & 514 & 0.42 & {$[87]$} \\
$\mathrm{Cr}(\mathrm{sen})^{3+}$ & 355 & 0.10 & {$[74]$} \\
$\mathrm{Cr}(\mathrm{NCS})_{6}{ }^{3-}$ & 546 & 0.26 & {$[88]$} \\
$\mathrm{Cr}(\mathrm{CN})_{6}{ }^{3-}$ & 365 & 0.11 & {$[88]$} \\
$\mathrm{Cr}\left(\mathrm{NH}_{3}\right)_{5}\left(\mathrm{H}_{2} \mathrm{O}\right)^{3+}$ & 546 & $0.20\left(\mathrm{NH}_{3}\right)$ & {$[89]$} \\
$\mathrm{Cr}\left(\mathrm{NH}_{3}\right)_{5}(\mathrm{CN})^{2+}$ & 495 & $0.33\left(\mathrm{NH}_{3}\right)$ & {$[90]$} \\
$\mathrm{Cr}(\mathrm{py})(\mathrm{CN})_{5}{ }^{2-}$ & 400 & $0.08(\mathrm{py}) ; 0.011\left(\mathrm{CN}^{-}\right)$ & {$[91]$} \\
\hline
\end{tabular}


Looking back at Fig. 11, several mechanistic possibilities (or channels) exist for photosubstitution [18,42], namely,

(1) "prompt" reactivity of the quartet ES,

(2) "delayed" reactivity of the quartet ES following BISC from the doublet ES,

(3) direct reactivity of the doublet ES following ISC from the quartet,

(4) reactivity originating in the doublet but occurring via surface crossing or tunneling to a GSI, and/or

(5) reaction of a vibrationally excited "hot" ground state following doublet or quartet NR deactivation.

How might these mechanisms differ experimentally? Channels 1 and 2 would be expected to yield similar product distributions, since in both cases the reaction is that of the quartet ES. However, reaction through channel 2 should be quenched by species that quench the doublet state phosphorescence. Likewise, channels 3 and 4 should be quenched under conditions of phosphorescence quenching. Product distributions from the hot ground state mechanism (channel 5) might be expected to mimic those of ground state thermal reactions. On the other hand, it is difficult to predict the products from channel 4 , as the GSI may well have different reactivity channels than either the GS or the quartet ES. Although some investigators have argued that there is little reason to expect that reactivity via channel 4 should differ from that via the "hot" ground state [42], the fact that the GSI may involve a twisting trajectory from the structure of the doublet ES suggests a that unique reaction pattern might be expected. Many of the experimental studies aimed at distinguishing among these mechanistic possibilities have been performed on heteroleptic complexes where the quartet and doublet states are split [42,43] (Fig. 7), yet the above mechanistic considerations still mostly apply. ${ }^{7}$

Before mining the extensive database on $\mathrm{Cr}$ (III) photosubstitution reactions to test some of the finer points, it might be noted that there are a number of examples where the photoproducts are "antithermal", i.e., do not duplicate ground state reactions [92]. For example, thermal ligand substitution on $\mathrm{Cr}\left(\mathrm{NH}_{3}\right)_{5} \mathrm{X}^{2+}$ complexes generally result in replacement of the acido ligand (Eq. (11)), whereas the corresponding photochemical reaction results in replacement of an ammine ligand (Eq. (12)) [92].

$$
\begin{aligned}
& \mathrm{Cr}\left(\mathrm{NH}_{3}\right)_{5} \mathrm{X}^{2+} \stackrel{k T}{\longrightarrow} \mathrm{Cr}\left(\mathrm{NH}_{3}\right)_{5} \mathrm{H}_{2} \mathrm{O}^{3+}+\mathrm{X}^{-} \\
& \left(\mathrm{X}^{-}=\mathrm{Cl}^{-}, \mathrm{Br}^{-}, \mathrm{NCS}^{-} \text {, etc } . .\right)
\end{aligned}
$$

$$
\mathrm{Cr}\left(\mathrm{NH}_{3}\right)_{5} \mathrm{X}^{2+} \underset{\mathrm{H}_{3} \mathrm{O}^{+}}{\stackrel{h v}{\longrightarrow}} \operatorname{cis}-\mathrm{Cr}\left(\mathrm{NH}_{3}\right)_{4}\left(\mathrm{H}_{2} \mathrm{O}\right) \mathrm{X}^{2+}+\mathrm{NH}_{4}{ }^{+}
$$

Furthermore, thermal aquation of trans- $\mathrm{Cr}\left(\mathrm{NH}_{3}\right)_{4} \mathrm{Cl}_{2}{ }^{+}$proceeds with retention of stereochemistry (Eq. (13)), whereas the corresponding photochemical reaction does not (Eq. (14)) [92].

$$
\begin{aligned}
& \text { trans- } \mathrm{Cr}\left(\mathrm{NH}_{3}\right)_{4} \mathrm{Cl}_{2}+\stackrel{k T}{\longrightarrow} \text { trans- } \mathrm{Cr}\left(\mathrm{NH}_{3}\right)_{4}\left(\mathrm{H}_{2} \mathrm{O}\right) \mathrm{Cl}^{2+}+\mathrm{Cl}^{-} \\
& \text {trans- } \mathrm{Cr}\left(\mathrm{NH}_{3}\right)_{4} \mathrm{Cl}_{2}+\stackrel{h v}{\longrightarrow} \text { cis- } \mathrm{Cr}\left(\mathrm{NH}_{3}\right)_{4}\left(\mathrm{H}_{2} \mathrm{O}\right) \mathrm{Cl}^{2+}+\mathrm{Cl}^{-}
\end{aligned}
$$

These results clearly indicate that the photoproducts are not simply the result of a hot ground state mechanism. Rather, both the quartet and doublet ES should be thought of as distinct chemical species with reaction channels not necessarily accessible by the ground

\footnotetext{
7 There is one important exception. In cases where the state of ${ }^{2} \mathrm{~T}_{1 \mathrm{~g}}\left(\mathrm{O}_{\mathrm{h}}\right)$ parentage is lowest in energy, this state no longer has the ground state geometry since its orbital occupation is different from the ground state. See Refs. $[46,93,94]$.
}

state. Debate over the mechanistic roles of the lowest energy doublet and quartet ES in photoreactivity has dominated this field and been exhaustively reviewed $[18,42]$. A few important experiments designed to illuminate some of the above considerations follow.

Product monitoring experiments following pulsed laser photolysis on certain systems have demonstrated ligand substitutions to occur on two different time-scales. The shorter is method limited (ns) and the longer occurs with the lifetime of the doublet excited state [95-97]. The former is suggestive of a "prompt" reaction from the quartet state; the slower one indicates a second pathway involving the doublet state.

Additional evidence for two channel reactivity comes from photoproduct monitoring in the presence of reagents, such as $\mathrm{OH}^{-}$. that effectively quench doublet phosphorescence. For example, $\mathrm{Cr}(\mathrm{tn})_{3}{ }^{3+}$ undergoes photoaquation in room temperature aqueous solution (Eq. (15)) with a quantum yield of 0.15 .

$\mathrm{Cr}(\operatorname{tn})_{3}{ }^{3+} \stackrel{h v}{\longrightarrow}$ cis/trans $-\mathrm{Cr}(\operatorname{tn})_{2}(\operatorname{tnH}) \mathrm{H}_{2} \mathrm{O}^{4+}$

When the phosphorescence and photoreaction yields were monitored upon adding increasing $\left[\mathrm{OH}^{-}\right]$, extrapolation to conditions of total phosphorescence quenching, revealed that $28 \%$ of the photoaquation remained unquenched [98]. Similarly, for many other $\mathrm{Cr}(\mathrm{III})$ systems, much, but not all, of the photoreaction was quenched under conditions where phosphorescence was quenched totally $[41,42]$. For such systems, it appears that there is prompt ES reactivity too fast to be quenched, and a second channel involving the doublet. Ligand labilization from the quartet ES might be expected inasmuch as population of the $\sigma$-antibonding $\mathrm{e}_{\mathrm{g}}{ }^{*}$ orbital would facilitate a dissociative mechanism, while the resulting vacancy in the $t_{2 g}$ orbitals would facilitate an associative process. The role of the doublet ES in photoreactivity is less clear, but, because of its relatively long lifetime in room temperature solution, has long been recognized as a likely candidate.

Earlier studies were aimed at explaining the antithermal nature of the photoreactivity, and more importantly, the patterns of photosubstitution, i.e., identifying which ligand will be substituted in heteroleptic complexes [99]. The photosubstitution patterns were described in a set of empirical guidelines typically referred to as "Adamson's rules" [99]. These rules have been rationalized both with ligand field theory [94] and with angular overlap models $[100,101] .{ }^{8}$ The reasonably good predictive powers of models assuming quartet state reactivity is often viewed as support for a pathway following BISC to the quartet (channel 2). Additional evidence for this mechanism is found in those cases where the substitution patterns for the quenchable (doublet channel) and unquenchable (prompt quartet channel) portions of the photochemistry are similar (e.g. $\mathrm{Cr}(\mathrm{en})_{3}{ }^{3+}$ and $\mathrm{Cr}\left(\mathrm{NH}_{3}\right)_{5} \mathrm{CN}^{2+}$ ) [42,103-105]. There are a few cases for which little to no reaction quenching is detected under conditions of total phosphorescence quenching, namely, for $\mathrm{Cr}(\mathrm{CN})_{5} \mathrm{X}^{n-}$ complexes [91,106-108]. Note that such complexes have very high ligand field strengths, prohibiting BISC and leaving prompt quartet reactivity as the only (quartet) reaction channel available. Overall, the quantum yields for the photoreactions are small, consistent with expectations that reactivity from such a short-lived intermediate should be less significant.

Certainly, whether or not channel 2 (BISC followed by quartet reactivity) is a viable mechanism depends on the relative energies of the lowest energy doublet and quartet excited states. The chief argument against the BISC mechanism (and therefore in favor of

\footnotetext{
8 Modern rigorous theoretical models based on DFT methods have emerged as far superior predictive tools, yet at the same time these methods support traditional ligand-field calculations [34,102]
} 


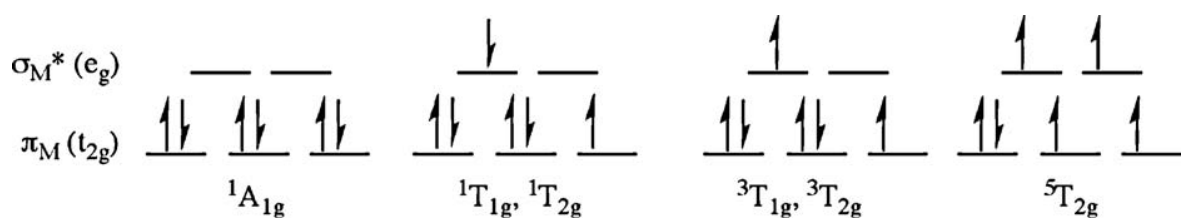

Fig. 14. The $d$ orbital diagram for the electronic ground and excited states for low-spin $d^{6}$ complexes assuming $O_{\mathrm{h}}$ symmetry.

the GSI mechanism) has been that the estimated quartet to doublet energy spacing does not correlate well with excited state behavior. This question cannot be resolved without a clearer picture of the relative excited state energies.

Finally, a discussion of the associative or dissociative nature of the photosubstitution mechanism is in order. The angular overlap model for explaining photosubstitution patterns $[100,101]$ is based on an assumption of quartet reactivity with dissociative ligand loss, resulting in a five-coordinate intermediate with trigonal bipyramidal geometry. This model has been useful in rationalizing the stereochemical change accompanying most photosubstitution reactions of $\mathrm{Cr}(\mathrm{III})$ complexes (see, for example, Eq. (14)), particularly those involving axial ligand loss in heteroleptic complexes of $D_{4 \mathrm{~h}}$ and $C_{4 \mathrm{v}}$ symmetry [42]..$^{9}$ However, the apparent volumes of activation measured for photosubstitution point to an associative pathway for $\mathrm{Cr}(\mathrm{III})$ photochemistry $[86,110]$. This has led to the suggestion of an asymmetric pentagonal bipyramidal intermediate formed from a Lewis base attack at the vacant $t_{2 g}$ orbital $[89,111,112]$, or alternatively, a face capped trigonal prismatic intermediate resulting from an attack at one of the octahedral faces $[112,113]$. The latter would likely involve a trigonal twist similar to that suggested for the GSI relaxation pathway (Section 3.2).

Although we have merely outlined the vast body of experimental studies on $\mathrm{Cr}(\mathrm{III})$ complexes, it should be clear that the relative energies of the doublet and quartet excited states are central to the photochemistry and photophysics of these systems. The energies of these states can be manipulated by varying the ligand field, by adjusting polydentate ligand geometrical constraints, or by applying pressure. Furthermore, the roles of ES deactivation mechanisms are a function of temperature. As a result, the excited state properties and dynamics can be tuned and these findings offer examples of how such systems might be manipulated in the development of photooptical devices.

\section{Photochemistry and photophysics of low-spin $d^{6}$ complexes}

Complexes with a low-spin $d^{6}$ configuration, including Pt(IV), $\operatorname{Ir}(\mathrm{III}), \mathrm{Rh}(\mathrm{III}), \mathrm{Os}(\mathrm{II}), \mathrm{Ru}(\mathrm{II})$ and $\operatorname{Re}(\mathrm{I})$, are significant players in the design of photooptical devices. Certain complexes of Fe(II) and many of $\mathrm{Co}(\mathrm{III})$ also fall into this category as do the organometallic and carbonyl compounds of $\mathrm{Mn}(\mathrm{I})$ and the zero-valent group 6 metals.

\subsection{Ligand field excited states}

In contrast to the $d^{3}$ ligand field states discussed above, all the ligand field transitions for low spin $d^{6}$ complexes of $O_{\mathrm{h}}$ symmetry necessarily involve promotion of an electron from a $t_{2 g}$ orbital to an $\mathrm{e}_{\mathrm{g}}$ orbital. Singlet and triplet ES both with the $\mathrm{t}_{2 \mathrm{~g}}{ }^{5} \mathrm{eg}^{1}$ configurations are predicted as well as a quintet ES with the $\mathrm{t}_{2 \mathrm{~g}}{ }^{4} \mathrm{eg}_{\mathrm{g}}{ }^{2}$ configuration (Fig. 14).

\footnotetext{
${ }^{9}$ The discovery that trans- $\left[\mathrm{Cr}(\text { cyclam }) \mathrm{Cl}_{2}\right]^{+}$is nearly photoinert [109] has been used to argue that stereochemical change might even be a requirement for the photosubstitution [42]
}

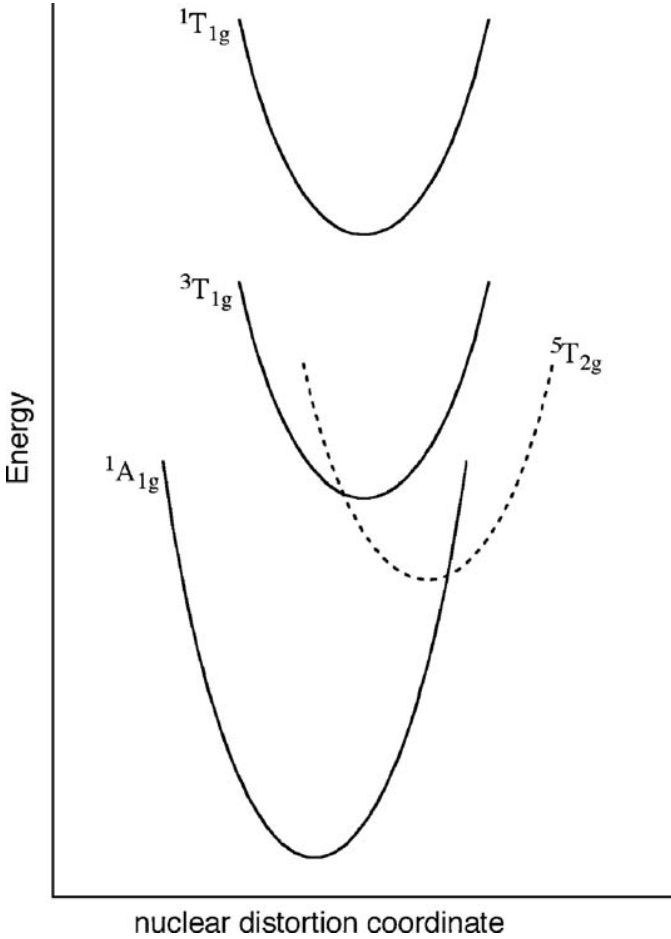

Fig. 15. Potential well diagram showing the lowest energy electronic states for $\mathrm{Co}\left(\mathrm{NH}_{3}\right)_{6}{ }^{3+}$ with respect to an $\mathrm{a}_{1 \mathrm{~g}}$ vibrational coordinate. Adapted from Ref. [114]. For complexes with higher ligand field splitting, the ${ }^{5} \mathrm{~T}_{2 g}$ will be at higher energy, leaving the ${ }^{3} \mathrm{~T}_{1 \mathrm{~g}}$ as the LEES.

All the ES involve population of the $\sigma^{*} e_{g}$ orbitals and thus are predicted to be distorted from the GS structure, regardless of multiplicity. This is evidenced by Franck-Condon analysis of high resolution absorption spectra of diluted single crystals. For example, both $\mathrm{Co}\left(\mathrm{NH}_{3}\right)_{6}{ }^{3+}[114]$ and $\mathrm{Rh}\left(\mathrm{NH}_{3}\right)_{6}{ }^{3+}$ [115], show $\mathrm{M}-\mathrm{N}$ bond elongations $\geq 10 \mathrm{pm}$ in their ${ }^{3} \mathrm{~T}_{1 \mathrm{~g}}$ excited states. The ES potential wells are all displaced along the nuclear coordinate with respect to the GS (Fig. 15) and any luminescence observed would be significantly Stokes shifted from the corresponding absorption band.

Once again, a question arises concerning the identity of the lowest energy excited state (LEES). Given the $\left(t_{2 g}\right)^{4}\left(e_{g}\right)^{2}$ electronic configuration of the quintet state relative to the $\left(t_{2 g}\right)^{6}$ ground state, the energy of the former is extremely dependent on ligand field strength (Fig. 16). Thus, the quintet state is expected to be the LEES for low-spin $d^{6}$ complexes with ground state orbital splittings fairly close to the low-spin/high-spin crossover, whereas higher field complexes will have a triplet LEES. For example, the quintet would be expected to be the LEES for most $\mathrm{Co}(\mathrm{III}) \mathrm{am}(\mathrm{m})$ ine complexes, ${ }^{10}$ whereas for complexes with larger LF splittings (e.g.

\footnotetext{
10 The role of the quintet states is especially apparent in the spin-crossover complexes [33] of $\mathrm{Fe}(\mathrm{II})$ where the singlet and quintet states are close enough in energy to be in thermal equilibrium. The large distortion of the quintet vs. the singlet is sufficient that applications of hydrostatic pressure markedly affect the equilibrium constants and rates of the spin-crossover process [116]
} 


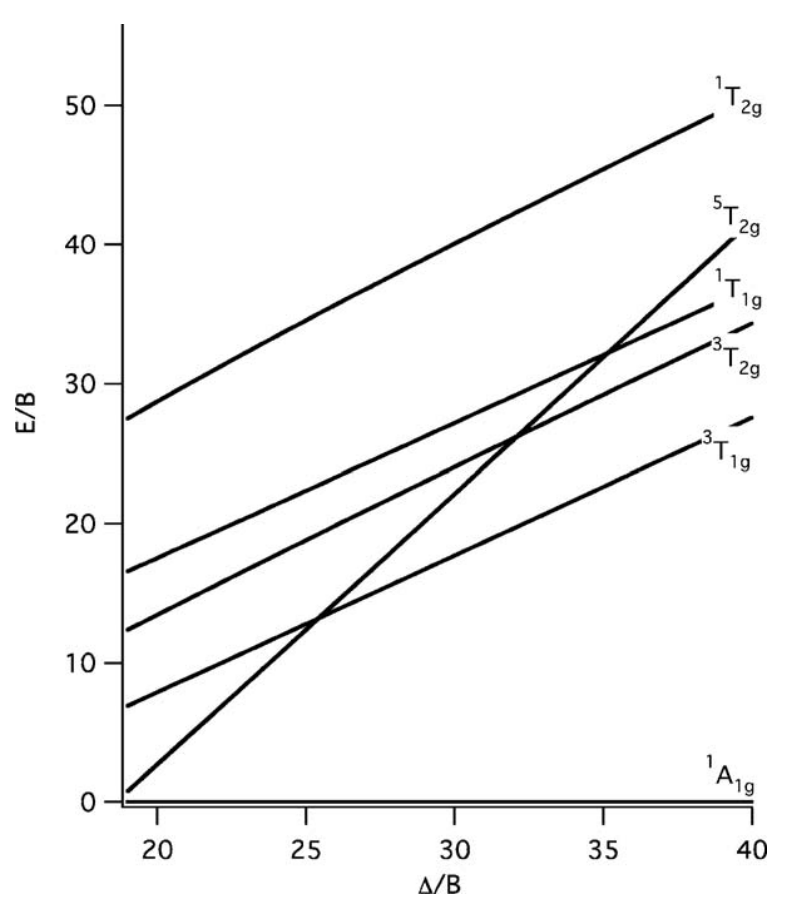

Fig. 16. Simplified Tanabe and Sugano type diagram for the $d^{6}$ electronic configuration in $\mathrm{O}_{\mathrm{h}}$ symmetry (low-spin region only).

$\mathrm{Co}(\mathrm{CN})_{6}{ }^{3-}$ and most $\mathrm{Rh}(\mathrm{III})$ and $\mathrm{Ir}(\mathrm{III})$ complexes), the triplet is the LEES [117]. Not surprisingly, the $\mathrm{Co}(\mathrm{III})$ am(m)ine complexes show notable differences in photochemical reaction patterns relative to their $\mathrm{Rh}(\mathrm{III})$ and $\mathrm{Ir}(\mathrm{III})$ analogues and to $\mathrm{Co}(\mathrm{CN})_{6}{ }^{3-}$ (Section 4.3).

Owing to these distortions, none of the ligand field ES of low spin $d^{6}$ complexes of $O_{\mathrm{h}}$ symmetry are nested with the GS, These distortions set up possible surface crossings with the GS. The singlet and triplet MC excited states, however, are similarly distorted and are much more likely to be nested (Fig. 15). The potential implications are discussed in Sections 4.2 and 4.3.

\subsection{Photophysics of Rh(III) complexes: a case study}

For complexes of $\mathrm{Rh}(\mathrm{III})$, initial excitation is followed by rapid internal conversion/intersystem crossing to the triplet LEES with near unitary efficiency $[19,118]$. ISC rate constants, $k_{\mathrm{ISC}}$, have been determined to be $>5 \times 10^{9} \mathrm{~s}^{-1}$ for a series of $\mathrm{Rh}\left(\mathrm{NH}_{3}\right)_{5} \mathrm{X}^{2+}$ and $\mathrm{Rh}\left(\mathrm{NH}_{3}\right)_{4} \mathrm{X}_{2}^{+}$complexes [119], and $\sim 5 \times 10^{11} \mathrm{~s}^{-1}$ for cis$\mathrm{RhX}_{2}$ (bpy) ${ }_{2}^{+}$complexes [120], (where $\mathrm{X}^{+} \mathrm{Br}^{-}$and $\mathrm{Cl}^{-}$for both studies). The nested nature of the LF ES singlet and triplet surfaces (with respect to each other) for $\mathrm{Rh}(\mathrm{III})$ complexes suggests that the internal conversion/intersystem crossing processes would be expected to occur through a weak-coupling mechanism. The somewhat faster intersystem crossing rate constant $\left(>1 \times 10^{13} \mathrm{~s}^{-1}\right)$ measured for $\mathrm{Cr}(\mathrm{acac}) 3^{3-}$ [54] may reflect strong coupling between the quartet and doublet surfaces for $\mathrm{Cr}$ (III) complexes due to the large displacements along the nuclear coordinate.

Even though the LEES for Rh(III) complexes are displaced relative to the ground state and are expected to show a strong-coupling mechanism for nonradiative deactivation (Fig. 15), a weak-coupling mechanism should also be evident when the thermal energy is insufficient to promote surface crossing to the singlet ground state. Direct nonradiative relaxation from the LEES to the GS should have two components, a thermally activated surface crossing and a relatively temperature independent tunneling pathway. Thus, the overall deactivation rate constant should show two terms, $k^{\circ}$ and $k(T)$, as described by Eq. (9). Moreover, $k^{\circ}$ should be sensitive to deuterium labeling of ligands such as am(m)ines [121]. In this context,
ES deactivation for several trans- $\mathrm{Rh}\left(\mathrm{N}_{4}\right)(\mathrm{CN})_{2}{ }^{+}$ions (where $\mathrm{N}_{4}=\mathrm{a}$ macrocyclic tetraamine ligand) has been shown to display two distinct temperature regimes [122]. Since these complexes display no unimolecular reactivity, the temperature effects on the lifetimes can be attributed to the competing weak and strong coupling mechanisms for nonradiative deactivation.

For $\mathrm{Rh}(\mathrm{III})$ acidoammine complexes, the $k(T)$ regime begins well below room temperature. Thus, phosphorescence lifetimes are typically three to four orders of magnitude longer in $77 \mathrm{~K}$ glasses $(1-20 \mu \mathrm{s})$ than in $298 \mathrm{~K}$ fluid solution (1-20 ns) [18]. Deuteration of the am(m)ine ligands typically increases $\tau$ for both sets of conditions. However, this effect is much larger at $77 \mathrm{~K}(10-50$-fold), where excited state lifetimes are nearly temperature independent [121], than at $298 \mathrm{~K}$ (two-fold) [123]. It is important to note that most of these $\mathrm{Rh}$ (III) acidoammine complexes are photoreactive in room temperature fluid solution (Section 4.3) so reactive deactivation is also a competitive pathway for excited state decay.

An interesting exception is trans- $\mathrm{Rh}(\mathrm{cyclam})(\mathrm{CN})_{2}{ }^{+}$, which is photoinert to ligand substitution $[122,124,125]$. Here the ${ }^{3} \mathrm{~T}_{1 \mathrm{~g}}\left(O_{\mathrm{h}}\right)$ splits into ${ }^{3} \mathrm{E}_{\mathrm{g}}$ and ${ }^{3} \mathrm{~A}_{2 \mathrm{~g}}\left(D_{4 \mathrm{~h}}\right)$ levels, with the ${ }^{3} \mathrm{~A}_{2 \mathrm{~g}}$ being the lower energy (see also Section 4.3). Although that state might be expected to be susceptible to ligand labilization in the equatorial plane, this pathway is effectively blocked by the macrocyclic constraint. The phosphorescence lifetime between $77 \mathrm{~K}$ and $300 \mathrm{~K}$ clearly shows both temperature independent behavior and a region $(>160 \mathrm{~K})$ that demonstrates an Arrhenius dependence with an $E_{a}$ of $6.4 \mathrm{kcal} \mathrm{mol}^{-1}$ (in $\mathrm{MeOH} / \mathrm{H}_{2} \mathrm{O}$ ) [122]. The phosphorescence lifetime in room temperature aqueous solution is $10 \mu \mathrm{s}$, three orders of magnitude longer than that observed for most other $\mathrm{Rh}(\mathrm{III})$ aci$\operatorname{doam}(\mathrm{m})$ ine complexes. While it might be tempting to ascribe this increase to the elimination of the reactive deactivation pathway, quantum yields for ligand substitution from complexes of the type $\mathrm{Rh}\left(\mathrm{NH}_{3}\right)_{5} \mathrm{X}^{2+}$ are typically less than 0.5 . For example, the photoreaction shown in Eq. (16) has a $\Phi_{\mathrm{NH}_{3}}$ of 0.09 in ambient temperature aqueous solution [126].

$\mathrm{Rh}\left(\mathrm{NH}_{3}\right)_{5} \mathrm{CN}^{2+}+\mathrm{H}_{2} \mathrm{O} \stackrel{h v}{\longrightarrow}$ cis- $\mathrm{Rh}\left(\mathrm{NH}_{3}\right)_{4}\left(\mathrm{H}_{2} \mathrm{O}\right) \mathrm{CN}^{2+}+\mathrm{NH}_{3}$

Thus, suppressing the reactive pathway only would not be expected to increase $\tau$ for the lowest energy ligand field excited state by more than a factor of two.

Molecular mechanics calculations for trans- $\mathrm{Rh}(\mathrm{cyclam})(\mathrm{CN})_{2}{ }^{+}$ suggest an alternative explanation, namely, that the macrocyclic cyclam restricts the equatorial $\mathrm{Rh}-\mathrm{N}$ expansion expected for the equilibrated triplet level [122]. For the lowest energy triplet excited state, this would result in a higher 0-0 energy, a steeper potential surface, and a relatively small nuclear displacement. These latter features would lead to a higher activation energy for surface crossing to the ground state, thus disfavoring the strong coupling mechanism for nonradiative decay $[18,122]$.

\subsection{Photosubstitution reactions of cobalt(III), rhodium(III), and iridium(III) complexes}

The photochemistry of $\mathrm{Co}(\mathrm{III}), \mathrm{Rh}(\mathrm{III})$, and $\mathrm{Ir}(\mathrm{III})$ complexes has been extensively reviewed $[18,19,127]$, so the examples chosen for discussion here will be limited. Table 2 lists quantum yields $\left(\Phi_{\mathrm{L}}\right)$ for the aquation of several $\mathrm{ML}_{6}$ complexes. For these data, it should be noted that the reaction quantum yields are all less than $50 \%$, and given that the photoemission under these conditions is exceptionally weak, the principal pathway(s) leading to ES deactivation in each case is nonradiative deactivation.

Given the $\lambda_{\text {ex }}$ independence observed for the photosubstitution quantum yields for $\mathrm{Rh}\left(\mathrm{NH}_{3}\right)_{6}{ }^{3+}$ and $\mathrm{Ir}\left(\mathrm{NH}_{3}\right)_{6}{ }^{3+}$, it was concluded that initial excitation is followed by rapid IC/ISC to a common excited state, the lowest energy triplet state, ${ }^{3} \mathrm{~T}_{1 \mathrm{~g}}$. This excited state, 
Table 2

Photoaquation quantum yields $\left(\Phi_{\mathrm{L}}\right.$ ) for $\mathrm{ML}_{6}$ complexes in $298 \mathrm{~K}$ aqueous solution. $\mathrm{ML}_{6}+\mathrm{H}_{2} \mathrm{O} \stackrel{h v}{\longrightarrow} \mathrm{ML}_{5}\left(\mathrm{H}_{2} \mathrm{O}\right)+\mathrm{L}$.

\begin{tabular}{lllll}
\hline Complex & $\lambda_{\text {ex }}$ & Assignment & $\Phi_{\mathrm{L}}$ & Ref. \\
\hline$\left[\mathrm{Co}\left(\mathrm{NH}_{3}\right)_{6}\right]^{3+}$ & 365 & ${ }^{1} T_{2 g} \leftarrow{ }^{1} A_{1 g}$ & 0.0054 & {$[128]$} \\
{$\left[\mathrm{Co}(\mathrm{CN})_{6}\right]^{3-}$} & 460 & ${ }^{1} T_{1 g} \leftarrow{ }^{1} A_{1 g}$ & 0.00052 & \\
& 254 & ${ }^{1} T_{2 g} \leftarrow{ }^{1} A_{1 g}$ & 0.31 & {$[129]$} \\
& 313 & ${ }^{1} T_{1 g} \leftarrow{ }^{1} A_{1 g}$ & 0.31 & \\
& 365 & ${ }^{1} T_{1 g} \leftarrow{ }^{1} A_{1 g}$ & 0.31 & \\
{$\left[\mathrm{Rh}\left(\mathrm{NH}_{3}\right)_{6}\right]^{3+}$} & 405 & ${ }^{3} T_{1 g} \leftarrow{ }^{1} A_{1 g}$ & 0.29 & \\
{$\left[\operatorname{Ir}\left(\mathrm{NH}_{3}\right)_{6}\right]^{3+}$} & 236 & ${ }^{3} T_{1 g} \leftarrow{ }^{1} A_{1 g}$ & 0.34 & {$[31]$} \\
& 313 & ${ }^{1} T_{2 g} \leftarrow{ }^{1} A_{1 g}$ & 0.07 & \\
& 254 & ${ }^{1} T_{1 g} \leftarrow{ }^{1} A_{1 g}$ & 0.075 & \\
\hline
\end{tabular}

and those in equilibrium with it, were viewed as being responsible for the bulk of the photochemistry [130]. By analogy, $\mathrm{Co}(\mathrm{CN})_{6}{ }^{3-}$ is included in this category owing to its ligand field strength being comparable to that of the Rh(III) amines $[19,129]$ and the $\lambda_{\text {ex }}$ independence of its photoaquation quantum yields.

The photoreaction behavior of $\mathrm{Co}\left(\mathrm{NH}_{3}\right)_{6}{ }^{3+}$ differs from the others in Table 2 in two notable aspects: the $\Phi_{\mathrm{L}}$ values are significantly smaller and they are markedly dependent on $\lambda_{\mathrm{ex}}$. The wavelength dependence of $\Phi_{\mathrm{L}}$ indicates that ligand substitution occurs from electronic states higher than the LEES and perhaps by processes competitive with vibrational relaxation of the initially formed excited state. The very low quantum yields suggest that IC/ISC to the LEES, in this case the quintet state, remains the major deactivation pathway for the higher energy excited states, and that the LEES, once formed, undergoes relaxation to the ground state much more rapidly than ligand substitution [19]. ${ }^{11}$ This is consistent with the fact that emission from MC states of the acidoam(m)ine $\mathrm{Co}(\mathrm{III})$ complexes has eluded detection, perhaps because the lifetimes are very short and emission quantum yields quite small. ${ }^{12}$ Transient absorbancies following excitation of trans-Co(en $)_{2}\left(\mathrm{NO}_{2}\right)_{2}{ }^{+}$ and cis- $\mathrm{Co}(\mathrm{en})_{2}(\mathrm{NCS}) \mathrm{Cl}^{+}$are suggestive of LEES with lifetimes of approximately 150 and $40 \mathrm{ps}$, respectively, nearly 100 times shorter than those observed for Rh(III) amine complexes [131].

There are several proposals to explain the apparent lack of reactivity from the LEES of $\mathrm{Co}\left(\mathrm{NH}_{3}\right)_{6}{ }^{3+}$. One is that the estimated energy of the ${ }^{5} \mathrm{~T}_{2 \mathrm{~g}}$ state of $\mathrm{Co}\left(\mathrm{NH}_{3}\right)_{6}{ }^{3+}$ is less than that of the transition state for thermal substitution [117], thus there is insufficient energy to break the metal-ligand bond. Another is that the ${ }^{5} \mathrm{~T}_{2 g}$ state for $\mathrm{Co}\left(\mathrm{NH}_{3}\right)_{6}{ }^{3+}$ is simply much shorter lived than the ${ }^{3} \mathrm{~T}_{1 \mathrm{~g}}$ states of the $\mathrm{Rh}(\mathrm{III})$ and $\mathrm{Ir}(\mathrm{III})$ complexes [127].

Photochemical investigations on $\mathrm{Rh}(\mathrm{III})$ acidoam(m)ine complexes have revealed significant mechanistic information regarding ligand field excited state reactivities. Since many of these studies have involved hexacoordinate complexes with non-octahedral ligand fields, it is worth noting the consequences of decreased symmetry to the lowest energy ligand field excited states for low spin $d^{6}$ complexes.

For an $O_{\mathrm{h}}$ complex such as for $\mathrm{Rh}\left(\mathrm{NH}_{3}\right)_{6}{ }^{3+}$, the ${ }^{3} \mathrm{~T}_{1 \mathrm{~g}}$ state with a $\left(t_{2 g}\right)^{5}\left(e_{g}\right)^{1}$ orbital population is the LEES. When the complex is modified by replacing one ammine to give $\mathrm{Rh}\left(\mathrm{NH}_{3}\right)_{5} \mathrm{X}^{2+}$ or $\mathrm{Rh}\left(\mathrm{NH}_{3}\right)_{5} \mathrm{Y}^{2+}$, there is a reduction in symmetry and the ${ }^{3} \mathrm{~T}_{1 \mathrm{~g}}$ state splits into ${ }^{3} \mathrm{E}$ and ${ }^{3} \mathrm{~A}_{2}$ states (Fig. 17).

When $\mathrm{X}$ is a weaker $\sigma$-donor, but stronger $\pi$-donor ligand such as a $\mathrm{Cl}^{-}$, the ${ }^{3} \mathrm{E}$ is lowest in energy; but when $\mathrm{Y}$ is a stronger $\sigma$ -

\footnotetext{
11 Aquation and redox decomposition from LMCT excited states of $\mathrm{Co}$ (III) complexes are efficient processes. The LMCT transitions often overlap with the LF transitions, complicating the determination of $\Phi_{\mathrm{L}}$ values related to LF excitation [22].

12 Additionally it is likely that such emission may be occurring in the NIR
}

a

\begin{tabular}{|c|c|c|}
\hline${ }^{3} \mathrm{E}$ & & \\
\hline \multirow[t]{2}{*}{${ }^{3} \mathrm{~A}_{2}$} & ${ }^{3} \mathrm{~T}_{1}$ & ${ }^{3} \mathrm{~A}_{2}$ \\
\hline & & ${ }^{3} \mathrm{E}$ \\
\hline${ }^{1} \mathrm{~A}_{1}$ & ${ }^{1} \mathrm{~A}_{1}$ & ${ }^{1} \mathrm{~A}_{1}$ \\
\hline $\mathrm{Rh}\left(\mathrm{NH}_{3}\right)_{5} \mathrm{Y}^{2+}$ & $\mathrm{Rh}\left(\mathrm{NH}_{3}\right)_{6}{ }^{3+}$ & $\mathrm{Rh}\left(\mathrm{NH}_{3}\right)_{5} \mathrm{X}^{2+}$ \\
\hline
\end{tabular}

b

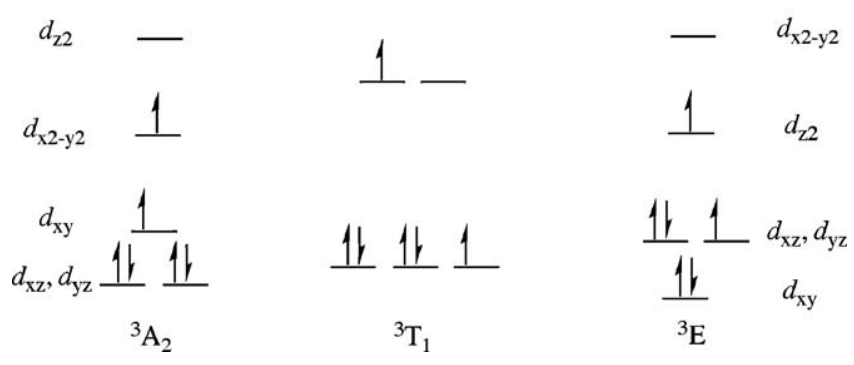

Fig. 17. (a) Splitting of the lowest energy MC ligand field excited state of a low-spin octahedral $d^{6}$ complex such as $\mathrm{Rh}\left(\mathrm{NH}_{3}\right)_{6}{ }^{3+}$ by replacing one ammine with an anion (see text) to give the $C_{4 v}$ complexes. (b) Molecular orbital diagrams for each state, labeled according to the metal orbital(s) which is/are the major component(s).

donor, $\pi$-acceptor ligand such as a $\mathrm{CN}^{-}$, the ${ }^{3} \mathrm{~A}_{2}$ is LEES. Since the MOs with significant $d_{\mathrm{z} 2}$ and $d_{\mathrm{x} 2-\mathrm{y} 2}$ contributions are $\sigma^{*}$, one can predict different ligand labilization trajectories for the ${ }^{3} \mathrm{E}$ and ${ }^{3} \mathrm{~A}_{2}$ states: axial labilization for the former; equatorial labilization for the latter. Indeed, the $\mathrm{NH}_{3}$ labilization observed for the photoaquation of $\mathrm{Rh}\left(\mathrm{NH}_{3}\right)_{5} \mathrm{CN}^{2+}$ (Eq. (16), above), for which the ${ }^{3} \mathrm{~A}_{2}$ is the LEES, agrees with this prediction. Similarly, $\mathrm{Rh}\left(\mathrm{NH}_{3}\right)_{5} \mathrm{Cl}^{2+}$ would be expected to display axial labilization and the products observed (Eq. (17), $\Phi_{\mathrm{Cl}}=0.18, \Phi_{\mathrm{NH}_{3}}=0.02$ in aqueous solution) [123] are consistent with this prediction as well.

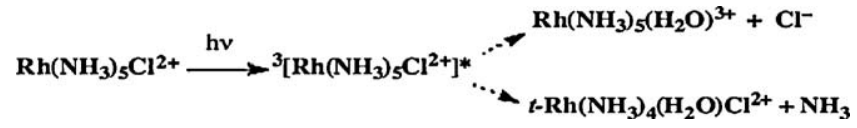

Regarding the mechanism for these photosubstitution reactions, a clear correlation between deuteration induced changes in phosphorescence lifetimes and the changes in $\Phi_{\mathrm{L}}$ values was observed for a series of $\mathrm{Rh}(\mathrm{NH})_{5} \mathrm{X}^{2+}$ and $\mathrm{Rh}\left(\mathrm{ND}_{3}\right)_{5} \mathrm{X}^{2+}$ complexes $\left(\mathrm{X}=\mathrm{Cl}^{-}\right.$ and $\mathrm{Br}^{-}$). These results suggest that ligand substitution is directly competitive with nonradiative decay of the LEES $[31,123,132]$. In a similar vein, the observation of different kinetic parameters for aquation and for nonradiative decay from the LF excited states of $\mathrm{Rh}(\mathrm{en})_{2} \mathrm{Br}_{2}{ }^{+}$and $\mathrm{Rh}\left(\mathrm{NH}_{3}\right)_{5} \mathrm{Br}^{2+}$ offers further evidence that reactive and nonradiative decay follow distinct pathways from the LEES [133]. Such experimental results rule out a mechanism where reactive and nonradiative decay both occur solely by rate determining ISC to a vibrationally hot ground state followed by branching to products and/or the original ground state. This conclusion is further confirmed by the demonstration that photoaquation of $\mathrm{Cl}^{-}$from cis- $\mathrm{Rh}\left(\mathrm{NH}_{3}\right)_{4} \mathrm{Cl}_{2}{ }^{+}$gives the anti-thermal product trans$\mathrm{Rh}\left(\mathrm{NH}_{3}\right)_{4}\left(\mathrm{H}_{2} \mathrm{O}\right) \mathrm{Cl}^{2+}$. In contrast, thermal labilization of $\mathrm{Cl}^{-}$from the cis complex occurs with retention of configuration [134].

The above observations clearly indicate ligand labilization occurring as a distinct pathway from the metal centered ligand field excited state. Further evidence supports a dissociative mechanism for these ES reactions. For instance, solvent effects on the rate constant for $\mathrm{Cl}^{-}$labilization from the LEES of $\mathrm{Rh}\left(\mathrm{NH}_{3}\right)_{5} \mathrm{Cl}^{2+}[135]$ have been rationalized in terms of significant charge separation along 
the $\mathrm{Rh}^{3+}-\mathrm{Cl}^{-}$bond at the transition state, the energy of which is influenced strongly by the ability of the solvent to stabilize the charge separation [127]. Consistently, the pattern shown by activation volumes for the ES substitution rate constants for the LF excited states support this interpretation [136-139]. Finally, theoretical models similar to those applied to predict substitution patterns for the quartet states of $d^{3}$ complexes via a dissociative mechanism are also successful in predicting photosubstitution patterns for $d^{6}$ complexes [100,101].

Experimental studies on $\mathrm{Rh}(\mathrm{III})$ acidoam( $\mathrm{m}$ )ine complexes have thus served as a model for understanding $d^{6}$ photochemistry. The key aspects can be summarized as follows: initial LF excitation is followed by rapid IC/ISC to a LF triplet state that is displaced along a nuclear coordinate relative to the ground state. The direction of this distortion is defined by the symmetry of the LEES (Fig. 17) and determines the trajectory of product formation. From this relatively short-lived LEES (1-20 ns in room temperature solution) there is competitive deactivation via ligand substitution and nonradiative decay. The nonradiative decay can occur through both strong-coupled (temperature dependent) and weak-coupled (temperature independent) mechanisms, the relative contributions depending on $T$. Ligand substitution from the LEES occurs through a dissociative pathway that is likely to be related to the strongcoupled mechanism for nonradiative deactivation, inasmuch as both involve movement away from the ES potential well minimum, along a Rh-L elongation coordinate (Fig. 15).

\subsection{Polypyridyl complexes of ruthenium(II)}

When the complex includes ligands that are good $\pi$-donors and/or $\pi$-acceptors, the CT and LC excited states must also be considered. The most investigated example is $\mathrm{Ru}(\mathrm{bpy})_{3}{ }^{2+}$ (bpy $=2,2^{\prime}$-bipyridine, Fig. 18) [140-142].

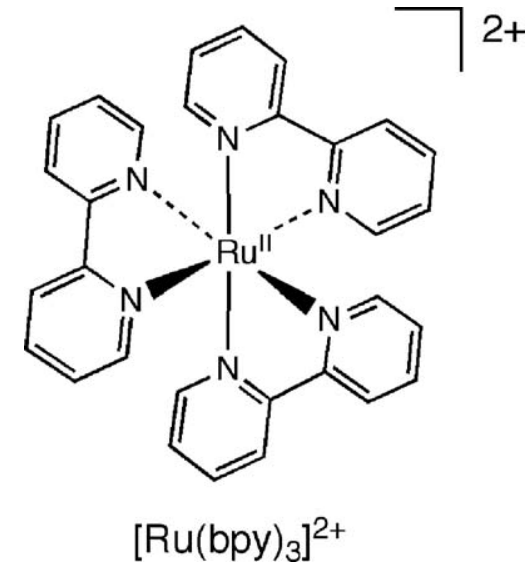

Fig. 18. $R u(b p y)_{3}{ }^{2+}$.

The visible range spectrum of $\mathrm{Ru}(\mathrm{bpy})_{3}{ }^{2+}$ is dominated by strong, symmetry allowed, metal to ligand charge transfer absorption bands. Furthermore, $\mathrm{Ru}(\mathrm{bpy})_{3}{ }^{2+}$ is strongly emissive in ambient temperature solutions $(\tau \sim 1 \mu \mathrm{s})$ [141], and this behavior is attributed to ISC from initially populated ${ }^{1}$ MLCT states to a manifold of three closely spaced lowest energy ${ }^{3}$ MLCT states with near unit efficiency [140] (Fig. 19).

This "averaged" triplet state can be formally characterized as ${ }^{*}\left[\mathrm{Ru}^{\mathrm{III}}(\mathrm{bpy})_{2}\left(\mathrm{bpy}^{-}\right)^{2+}\right]$. Because the GS and MLCT states do not involve a change in $e_{g}$ orbital occupation, the corresponding potential wells are relatively undisplaced along the $\mathrm{Ru}-\mathrm{N}$ coordinates.

Although not obvious in the absorption or emission spectra, metal centered excited states for these $\mathrm{Ru}(\mathrm{II})$ polypyridyl com-

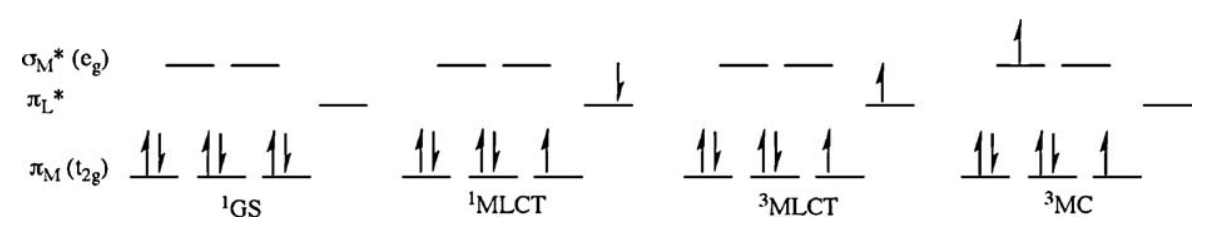

Fig. 19. Orbital diagram for the electronic ground (GS) and the most relevant excited states for Ru(bpy) ${ }_{3}^{2+}$.
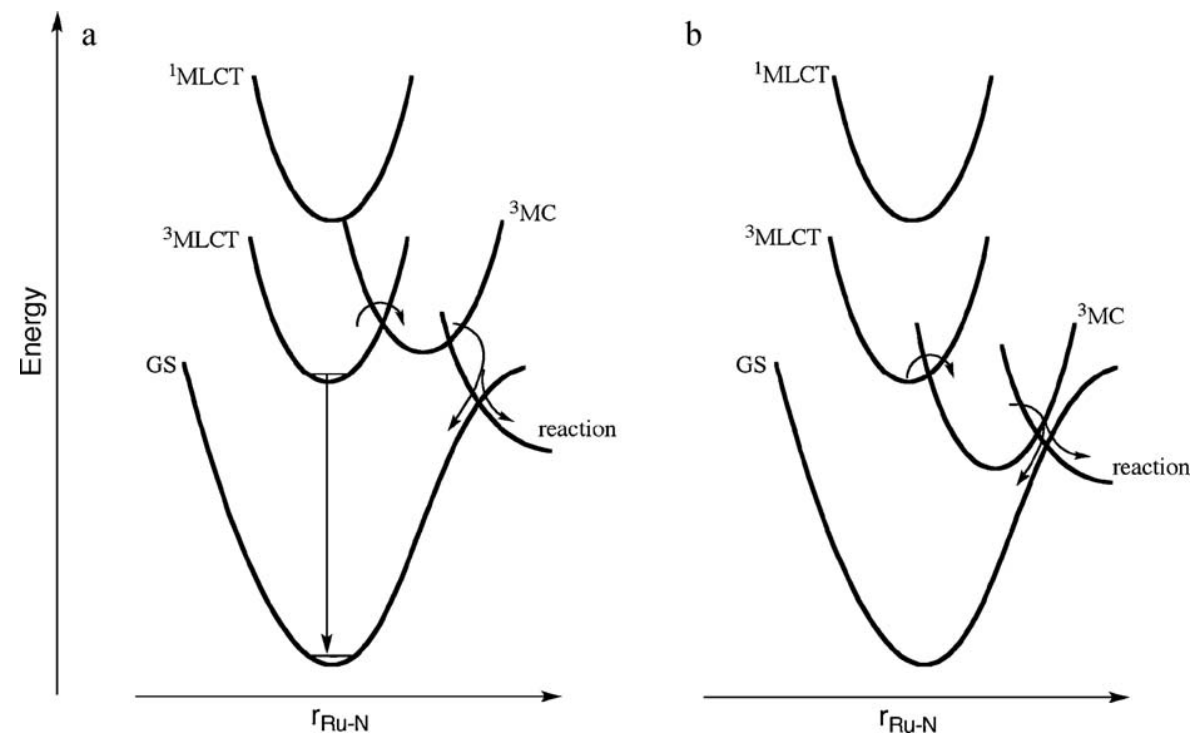

Fig. 20. Potential well diagrams for limiting cases involving relative energies of the ${ }^{3} \mathrm{MC}$ and ${ }^{3} \mathrm{MLCT}$ for Ru(II) polypyridyl complexes. (a) The ${ }^{3} \mathrm{MLCT}$ is the LEES and (b) the ${ }^{3} \mathrm{MC}$ is the LEES.

Adapted from Ref. [142]. 
plexes should be present at energies comparable to that of the MLCT state. In contrast to the ${ }^{3}$ MLCT state, the lowest energy ${ }^{3} \mathrm{MC}$ ligand field state is expected to be significantly distorted relative to the ground state (Fig. 20), relatively short-lived (1-20 ns or less), and potentially reactive toward ligand labilization (Sections 4.2 and 4.3). Thus, the accessibility of this ${ }^{3} \mathrm{MC}$ state can be expected to have profound effects on the photochemistry and photophysics of the $\mathrm{Ru}(\mathrm{bpy})_{3}{ }^{2+}$ cation.

Once again, the excited state decay (in this case from the ${ }^{3} \mathrm{MLCT}$ ) can be discussed in terms of temperature-independent and -dependent components (Eq. (9)). Deuterium labeling experiments demonstrating that $k^{\circ}$ nr is moderately sensitive to deuteration are consistent with a weak-coupled component to nonradiative deactivation of the ${ }^{3}$ MLCT [143]. The temperature dependent term can be modeled using three features, interpreted as: (1) a term involving the melting of the matrix (100-150 K); (2) an Arrhenius term thought to involve equilibration with a fourth MLCT state $\left(\Delta E=90 \mathrm{~cm}^{-1}\right)$ and (3) an Arrhenius term corresponding to surface crossing to a higher energy but very short-lived ES generally thought to be the lowest ${ }^{3} \mathrm{MC}$ state(s) [142]. Identification of this as the ${ }^{3} \mathrm{MC}$ state is based on experiments demonstrating that photolabilization occurs in aqueous solution at elevated temperatures $\left(95^{\circ} \mathrm{C}\right)^{13}$ and this photolabilization is accompanied by a reduction of the deuterium isotope effect on the lifetime [143].

Interpreting activation energies $\left(\Delta E_{a}\right)$ and Arrhenius preexponential factors $(A)$ obtained from the temperature dependence of activated crossing to the ${ }^{3} \mathrm{MC}$ state requires an understanding of the limiting kinetic regimes. The scheme proposed for $\mathrm{Ru}$ (diimine $)_{3}{ }^{2+}$ complexes [144,145] involves a pre-equilibrium between the ${ }^{3}$ MLCT and ${ }^{3} \mathrm{MC}$ states prior to irreversible decay to the GS or to photoproducts (Eq. (18)).

${ }^{3} \mathrm{MLCT} \underset{k_{\mathrm{r}}}{\stackrel{k_{\mathrm{f}}}{\rightleftharpoons}}{ }^{3} \mathrm{MC} \stackrel{k_{1}}{\longrightarrow}$ GS and/or photoproducts

Two limiting cases result. The first occurs when $k_{1} \gg k_{\mathrm{r}}$. Here, the ${ }^{3} \mathrm{MLCT}$ to ${ }^{3} \mathrm{MC}$ surface crossing is essentially irreversible and the experimental activation energy corresponds to the energy gap between the ${ }^{3} \mathrm{MLCT}$ potential minimum and the ${ }^{3} \mathrm{MLCT} /{ }^{3} \mathrm{MC}$ intersection. The second occurs when $k_{\mathrm{r}} \gg k_{1}$. In this case, the two triplet states are in equilibrium and the meaning of the activation energy is less clear, though its magnitude is often dominated by the energy gap between the ${ }^{3}$ MLCT and ${ }^{3}$ MC potential minima [144,145]. $\mathrm{Ru}$ (diimine $)_{3}{ }^{2+}$ complexes typically fall into the first case with values for $A$ and $\Delta E_{a}$ characteristically in the range $10^{12}$ to $10^{14} \mathrm{~s}^{-1}$ and $2500-4000 \mathrm{~cm}^{-1}$, respectively [140,145]. Notably, Arrhenius preexponential factors in the range $10^{12}$ to $10^{14} \mathrm{~s}^{-1}$ have been cited as evidence for vibrationally activated, rate-determining crossing to a ${ }^{3} \mathrm{MC}$ surface [145] (see also Sections 4.5 and 5.2).

It should also be noted that the emission lifetimes of Ru(bpy) $3_{3}{ }^{2+}$ in solution are also pressure dependent, growing longer as hydrostatic pressure is applied [146]. This observation was interpreted in terms of the ${ }^{3} \mathrm{MC}$ state distortions (lengthening of the Ru-N bonds) from the geometry of the ${ }^{3}$ MLCT state; i.e., applied hydrostatic pressure raises the relative energy of the former and slows nonradiative deactivation via this pathway.

The interplay between the ${ }^{3} \mathrm{MLCT}$ and ${ }^{3} \mathrm{MC}$ excited states suggests that it should be possible to exercise control over ES lifetimes and reactivity by manipulating the relative excited state energies. An early demonstration of such control involved a series of $\mathrm{Ru}\left(\mathrm{NH}_{3}\right)_{5} \mathrm{py}-\mathrm{X}^{2+}$ complexes (where py-X is a substituted pyridine

\footnotetext{
13 Although $\mathrm{Ru}(\mathrm{bpy})_{3}{ }^{2+}$ is generally considered inert to photosubstitution, presumably due in part to the chelate effect, this result indicates this is not strictly true. Additionally, photosubstitution with halide counterions occurs with $0.01<\Phi<0.1$ in room temperature methylene chloride [144].
}

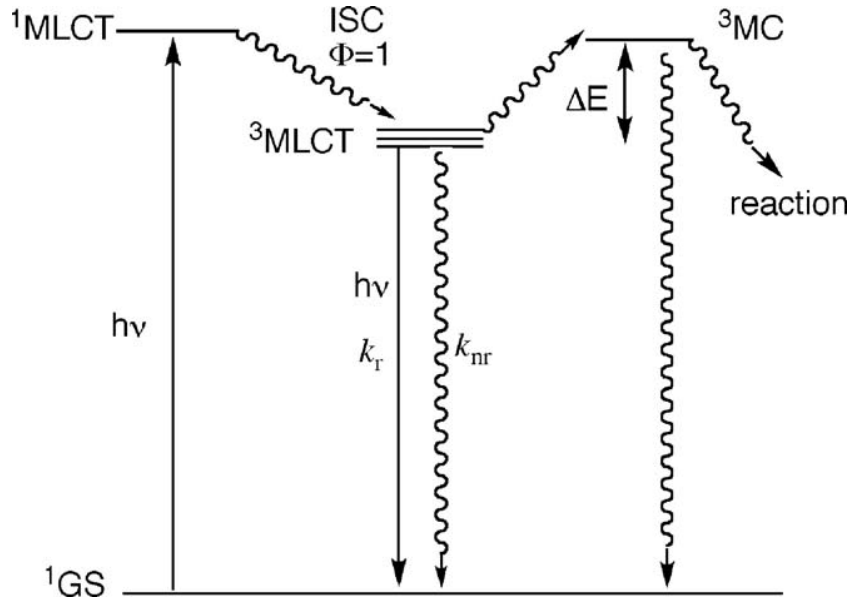

Fig. 21. Simplified Jablonski diagram for $\mathrm{Ru}(\mathrm{NN})_{3}{ }^{2+}$ complexes. The thermal accessibility of the ${ }^{3} \mathrm{MC}$ state is controlled by the energy spacing $(\Delta E)$ of the ${ }^{3} \mathrm{MLCT}$ and ${ }^{3} \mathrm{MC}$ states.

or related aromatic heterocycle) [147]. Ligand solvolysis following initial excitation into the ${ }^{3}$ MLCT was attributed to population of the ${ }^{3} \mathrm{MC}$ state(s). The relative energy ordering of the ${ }^{3} \mathrm{MC}$ state and ${ }^{3}$ MLCT states were altered by variation of the py-X ligand, electron withdrawing X-groups shifting the MLCT states to lower energy, electron donating groups having the opposite effect. Photosolvation quantum yields in aqueous solutions demonstrated that the complexes could be categorized as "reactive", those with a ${ }^{3} \mathrm{MC}$ state LEES (Fig. 20b), and "unreactive", those with the ${ }^{3}$ MLCT state being the LEES (Fig. 20a) [147]. These results clearly indicate that photoreactivity is a function of the thermal accessibility of the ${ }^{3} \mathrm{MC}$ state from the ${ }^{3}$ MLCT state.

The relative energies of the ${ }^{3} \mathrm{MC}$ and ${ }^{3} \mathrm{MLCT}$ states of $\mathrm{Ru}(\mathrm{NN})_{3}{ }^{2+}$ complexes ( $\mathrm{NN}=$ a substituted bipyridine), can also be altered by substituents on the bipyridine ligand. In one study [148], the ${ }^{3}$ MLCT emission was progressively red-shifted using substituted bipyridyl ligands. This increased $\Delta E$ in Fig. 21 since the ${ }^{3} \mathrm{MC}$ states are relatively independent of the bipy substituents. Thus, the temperature dependence of the ${ }^{3} \mathrm{MLCT}$ emission demonstrated an increased $E_{a}$ for populating the upper ${ }^{3} \mathrm{MC}$ state that correlated well with the ${ }^{3}$ MLCT energy differences [148]. However, this increased activation barrier did not lead to longer ${ }^{3}$ MLCT lifetimes in room temperature solution, the explanation being that there is a concomitant increase in $k_{\mathrm{nr}}$ from the ${ }^{3} \mathrm{MLCT}$ (Fig. 21) owing to the decreased energy gap between the ${ }^{3}$ MLCT and the GS. This result emphasizes the complicated interplay of the various relaxation mechanisms found in such systems and the need to address all of these in order to control the photophysical and photochemical properties of such materials.

In a similar study, the complexes $\mathrm{Ru}(\mathrm{bpy})_{2}(\mathrm{py})_{2}{ }^{2+}$ and $\mathrm{Ru}(\mathrm{bpy})_{2} \mathrm{diaz}^{2+}$ (diaz=4,5-diazafluorene) were investigated. Their ${ }^{3}$ MLCT state energies are about the same as for $\mathrm{Ru}(\mathrm{bpy})_{3}{ }^{2+}$, but their ${ }^{3} \mathrm{MC}$ states are lower in energy than to those of $\mathrm{Ru}(\mathrm{bpy})_{3}{ }^{2+}$ [149] owing to the lower ligand field strengths. As a consequence these derivatives were essentially non-emissive above $230 \mathrm{~K}$. The $E_{a}$ values determined for emission lifetimes of Ru(bpy $)_{2}(\mathrm{py})_{2}{ }^{2+}$ and $\mathrm{Ru}(\text { bpy })_{2} \mathrm{diaz}^{2+}$ at lower $T$ ( 2758 and $2271 \mathrm{~cm}^{-1}$, respectively) were used as estimates of the respective ${ }^{3} \mathrm{MLCT} /{ }^{3} \mathrm{MC}$ energy gaps. From such data were predicted room temperature $\tau$ s for $\mathrm{Ru}(\mathrm{bpy})_{2} \mathrm{diaz}^{2+}$ $(0.07 \mathrm{~ns})$ and for $\mathrm{Ru}(\mathrm{bpy})_{2}(\mathrm{py})_{2}{ }^{2+}(2.7 \mathrm{~ns})$, that are much shorter than the that for $\mathrm{Ru}(\mathrm{bpy}) 3_{3}{ }^{2+}(\sim 1 \mu \mathrm{s})$. In other studies, the ${ }^{3} \mathrm{MC}$ states were lowered by replacing one bpy ligand with a constrained bipyridyl ligand that modifies its bite angle, effectively lowering its ligand field strength due to poorer orbital overlap [150]. In such cases, there can be a drastic reduction in room temperature emission intensity, again ascribed to more efficient population of the 
short lived ${ }^{3} \mathrm{MC}$ state. Such studies help to define the role of the ${ }^{3} \mathrm{MC}$ states in the photochemistry/physics of this important class of compounds.

Another strategy for adjusting the relative energy levels of the ${ }^{3} \mathrm{MC}$ and ${ }^{3} \mathrm{MLCT}$ is suggested by experiments where $\mathrm{Ru}(\mathrm{bpy})_{3}{ }^{2+}$ is incorporated into a solid matrix of cellulose acetate [151] or entrapped in a zeolite [152]. Such immobilization has profound effects on the kinetic parameters for the thermally activated decay of the ${ }^{3} \mathrm{MLCT}$ emission. These effects have been attributed to the raising of the ${ }^{3} \mathrm{MC}$ state energy (increasing $\Delta E$ in Fig. 21) owing to a restriction toward $\mathrm{Ru}-\mathrm{N}$ bond elongation by the solid matrix as was described above for the pressure effects.

Another factor especially relevant to the relative energy levels of the ${ }^{3} \mathrm{MC}$ and ${ }^{3} \mathrm{MLCT}$ states is that for the same charge and ligand set, the ligand field splitting parameter increases $\sim 30 \%$ from the first to second transition series and by another $30 \%$ from the second to the third $[23,140]$. Thus, the ${ }^{3}$ MLCT excited states for Fe(II) polypyridyl complexes are essentially unexploitable due to the low energy ${ }^{3} \mathrm{MC}$ states, while the same states for corresponding Os(II) complexes are typically so high in energy that they play no significant role in the photobehavior [140]. The $\mathrm{Ru}(\mathrm{NN}) 3_{3}{ }^{2+}$ complexes represent an intermediate situation where the photobehavior is strongly influenced by the comparable energies of the ${ }^{3} \mathrm{MC}$ and ${ }^{3} \mathrm{MLCT}$ excited states.

Because of their short lifetimes and high reactivity, ${ }^{3} \mathrm{MC}$ states have been described as a "nuisance in the attempt to design new classes of photosensitizers" utilizing the ${ }^{3}$ MLCT states of $\mathrm{Ru}(\mathrm{II})$ polypyridyl complexes [140]. It is clear that several strategies are available for altering the relative energy levels. One is adjustment of the ligand electronic properties to affect the MLCT energies and/or the ligand field strength. A second is modification of the ligand steric properties to enhance or diminish orbital overlap. A third is introducing matrix effects or other constraints on excited state $\mathrm{M}$-L bond lengthening. Such strategies have been cleverly exploited by several groups, particularly in the area related to applications requiring photoinduced charge separation (Section 5).

\subsection{Polypyridyl complexes of rhodium(III) and iridium(III)}

The photophysical properties of $\mathrm{Rh}(\mathrm{III})$ [153] and $\operatorname{Ir}(\mathrm{III})$ [154] polypyridine complexes has been reviewed elsewhere but is briefly discussed here to highlight some differences and similarities with the $\mathrm{Fe}(\mathrm{II}), \mathrm{Ru}(\mathrm{II})$, and $\mathrm{Os}(\mathrm{II})$ systems. Representative of this class of complexes is $\mathrm{Rh}(\text { phen })_{3}{ }^{3+}$ which exhibits intense $(\Phi=1)$ longlived ( $\tau=48 \mathrm{~ms}$ ) structured emission in $77 \mathrm{~K}$ matrices. This has been assigned to phosphorescence from a ligand centered $\pi-\pi^{*}$ triplet state in contrast to the emission from the MLCT state observed in the analogous $\mathrm{Ru}(\mathrm{II})$ systems. The situation is different in room temperature aqueous solution where emission is extremely weak and has two components, one at $22,200 \mathrm{~cm}^{-1}$ assigned to LC emission and one at $17,300 \mathrm{~cm}^{-1}$ assigned to $\mathrm{MC}$ emission. That both components have a lifetime of $250 \mathrm{~ns}$ is interpreted as indicating rapid thermal equilibrium between the lowest energy ${ }^{3} \mathrm{LC}$ and ${ }^{3} \mathrm{MC}$ ligand-field states, with emission occurring from both [155].

The relative energy of these two states has been manipulated for a series of cis-Rh(phen) $)_{2} \mathrm{XY}^{n+}$ complexes. The identities of the $\mathrm{X}$ and $\mathrm{Y}$ ligands control the energies of the MC states, but have little effect on the energy of the LC state [156]. For example, emissions from $\mathrm{Rh}(\text { phen })_{2}\left(\mathrm{NH}_{3}\right)_{2}{ }^{3+}$ or $\mathrm{Rh}(\text { phen })_{2}(\mathrm{CN})_{2}{ }^{+}$at $77 \mathrm{~K}$ in water:ethylene glycol show the structure expected for phosphorescence from a ${ }^{3} \mathrm{LC}$ state. In contrast, $\mathrm{Rh}$ (phen) $)_{2}\left(\mathrm{NH}_{3}\right) \mathrm{Cl}^{2+}$ displays a lower energy, broad, structureless emission indicative of phosphorescence from $\mathrm{a}^{3} \mathrm{MC}$ state. This can be explained in terms of the potential surface diagram shown in Fig. 22, where the LEES for the chloro-ammine complex is the ${ }^{3} \mathrm{MC}$ state but for the dicyano and diammine complexes the LEES is the ${ }^{3} \mathrm{LC}$. When the temperature is raised from

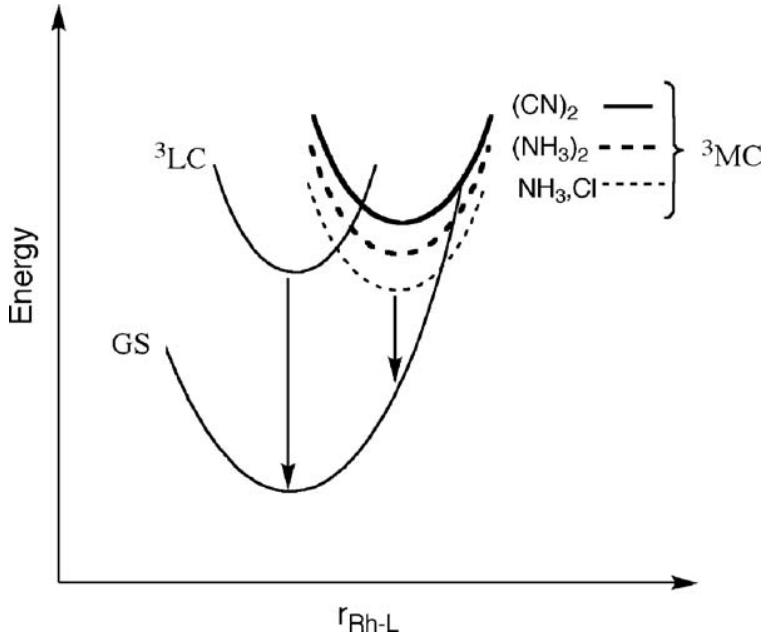

Fig. 22. Potential surface diagram for $\mathrm{Rh}(\mathrm{phen})_{2} \mathrm{XY}^{n+}$ complexes rationalizing the effect of $\mathrm{X}$ and $\mathrm{Y}$ on the emission properties. Adapted from Refs. [153,156].

$77 \mathrm{~K}$ to room temperature, the dicyano complex continues to show only ${ }^{3} \mathrm{LC}$ emission, indicating that the ${ }^{3} \mathrm{MC}$ state remains thermally inaccessible over this temperature range. The diammine complex, on the other hand, clearly shows emission from both the ${ }^{3} \mathrm{LC}$ and ${ }^{3} \mathrm{MC}$ states in the temperature range of $170-200 \mathrm{~K}$. The lifetimes of these two emissions are identical as would be expected if the two states are in thermal equilibrium [156].

For polypyridyl complexes of Ir(III), on the other hand, the ${ }^{3} \mathrm{MC}$ states arising from mixing the iridium $5 \mathrm{~d}$ and ligand orbitals are expected to be significantly higher in energy than for $\mathrm{Rh}(\mathrm{III}) .{ }^{14}$ Experimental evidence supports this. The ${ }^{3} \mathrm{LC}$ excited state lifetimes for $\operatorname{Ir}(\mathrm{bpy})_{3}{ }^{3+}$ and $\operatorname{Ir}(\mathrm{tpy})_{2}{ }^{3+}$ in room temperature fluid solution are relatively long (2.4 and $1.2 \mu \mathrm{s}$, respectively) [154]. Furthermore, the magnitude of the pre-exponential factor for deactivation of the emissive state of $\operatorname{Ir}(\text { tpy })_{2}{ }^{3+}\left(\ll 10^{12} \mathrm{~s}^{-1}\right)$ falls outside the range cited for thermally activated surface crossing to the ${ }^{3} \mathrm{MC}$ state [157].

The lowest energy ${ }^{3} \mathrm{MC}$ state for $\mathrm{Ir}(\mathrm{III})$ polypyridine complexes does become thermally accessible when weaker-field ligands such as chloride replace one of the polypyridines. For example, in room temperature DMF solution, dual emission is evident from $\operatorname{Ir}(\mathrm{NN})_{2} \mathrm{Cl}_{2}{ }^{+}(\mathrm{NN}=$ bpy or 5,6-dimethyl-1,10-phenanthroline, $\mathrm{Me}_{2}$ phen). The lower energy band originates from the ${ }^{3} \mathrm{MC}$ state and the higher energy band from either the MLCT state (for $\mathrm{NN}=$ bpy) or mixed MLCT/LC state (for $\mathrm{NN}=\mathrm{Me}_{2}$ phen). When this system was subjected to hydrostatic pressure $(0-300 \mathrm{MPa})$ the intensity of the emission from the ${ }^{3} \mathrm{MC}$ state of $\operatorname{Ir}\left(\mathrm{Me}_{2} \text { phen }\right)_{2} \mathrm{Cl}_{2}{ }^{+}$ decreased relative to that of the MLCT $/ \pi \pi^{*}$ emission. This decrease was attributed to a pressure-induced shift in the equilibrium populations of the two excited states resulting from the difference in their partial molar volumes, the ${ }^{3} \mathrm{MC}$ state being $\sim 4 \mathrm{~cm}^{3} / \mathrm{mol}$ larger than the ${ }^{3} \mathrm{MLCT} / \mathrm{LC}$ state, consistent with the populating the $\sigma_{\mathrm{M}-\mathrm{L}}{ }^{*}$ orbital in the former case [158].

\subsection{Cyclometallated complexes of rhodium(III) and iridium(III)}

Potential applications in OLED devices [4-6] have let to a significant interest in $\mathrm{Rh}$ (III) and Ir(III) complexes with cyclometallating ligands such as deprotonated 2-phenylpyridine and

\footnotetext{
14 For complexes with the same charge and ligand set, the ligand field splitting parameter increases $\sim 30 \%$ from the second to third transition series [23].
} 


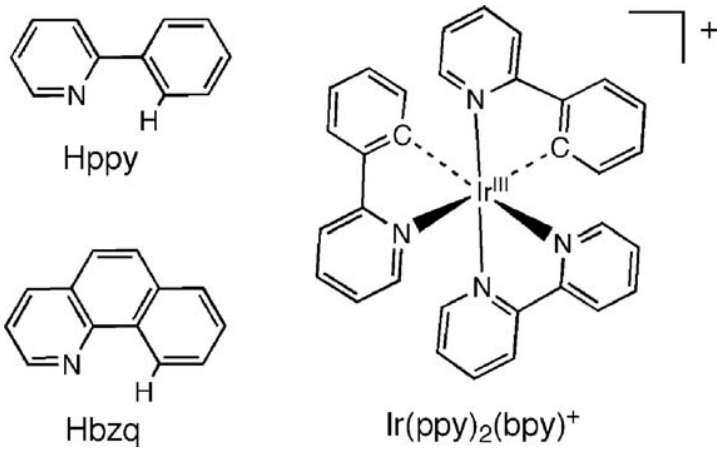

Fig. 23. Cyclometallating ligands and an example complex.

benzo[ $h]$ quinoline (ppy ${ }^{-}$and bzq ${ }^{-}$, respectively, Fig. 23) [153,154]. The stronger $\sigma$-donor character of $\mathrm{C}^{-}$relative to $\mathrm{N}$ results in several important differences between complexes with cyclometallating ligands and those of polypyridine ligands. One difference is the increased energy of the MC states owing to the greater ligand field strengths of the cyclometallating ligands [159]. Whereas the $\mathrm{Rh}$ (bpy) ${ }_{2} \mathrm{Cl}_{2}{ }^{+}$and $\mathrm{Rh}$ (phen) ${ }_{2} \mathrm{Cl}_{2}{ }^{+}$cations show broad emissions characteristic of phosphorescence from the ${ }^{3} \mathrm{MC}$ state [160], the related cyclometallated dimers $\left[\mathrm{Rh}(\mathrm{ppy})_{2} \mathrm{Cl}_{2}\right.$ and $\left[\mathrm{Rh}(\mathrm{bzq})_{2} \mathrm{Cl}\right]_{2}$ show structured LC emission only. This finding has been attributed entirely to the increased energy of the MC states [159].

A second difference between cyclometallated complexes and the corresponding polypyridine complexes is that the strong donor properties of the cyclometallating ligands increase electron density on the metal center, resulting in lower energy MLCT states $[159,161]$. Consequently, the emissive state of many $\operatorname{Ir}(\mathrm{III})$ complexes with cyclometallating ligands is of ${ }^{3} \mathrm{MLCT}$ or mixed ${ }^{3} \mathrm{LC} /{ }^{3} \mathrm{MLCT}$ character $[154,161,162]$. Typically, the ${ }^{3} \mathrm{MC}$ ligand field states for these complexes are too high in energy to serve as an effective pathway for excited state deactivation. However, excited state deactivation through the intermediacy of these states has been implicated in cases where the energy of the emissive state has been increased by ligand modification (Section 5.2 ).

\section{Applications involving low-spin $d^{6}$ complexes}

\subsection{The conversion of solar to stored chemical energy}

One potential application is the TM mediated conversion of solar energy to stored chemical energy. Taking center stage in early phases of these investigations was the $\mathrm{Ru}(\mathrm{bpy})_{3}{ }^{2+}$ ion $[140,142,163-165]$. As described in Section 4.4, "Rubipy" is strongly colored and its ${ }^{3}$ MLCT excited state is relatively long lived $(\sim 1 \mu \mathrm{s}$ in ambient fluid solution) making it a good candidate for bimolecular electron transfer reactions. Much of the work utilizing Rubipy and related derivatives involve electron transfer from the MLCT state, formally ${ }^{*}\left[\mathrm{Ru}^{\mathrm{III}}(\mathrm{bpy})_{2}\left(\mathrm{bpy}^{-}\right)^{2+}\right]$. For example, this excited state species reduces methylviologen $\left(\mathrm{MV}^{2+}\right)$, storing about $1.6 \mathrm{eV}$ of free energy as the charge separated state (Eq. (19)). However, this energy storage is short-lived owing to the very large second order rate constant for the back electron transfer (Eq. (20), $k=8 \times 10^{9} \mathrm{M}^{-1} \mathrm{~s}^{-1}$ ) [166].

$*\left[\mathrm{Ru}^{\mathrm{III}}(\mathrm{bpy})_{2}\left(\mathrm{bpy}^{-}\right)^{2+}\right]+\mathrm{MV}^{2+} \rightarrow \mathrm{Ru}^{\mathrm{III}}(\mathrm{bpy})_{3}{ }^{3+}+\mathrm{MV}^{+}$

$\mathrm{Ru}^{\mathrm{III}}(\mathrm{bpy})_{3}{ }^{3+}+\mathrm{MV}^{+} \rightarrow \mathrm{Ru}^{\mathrm{II}}(\mathrm{bpy})_{3}{ }^{2+}+\mathrm{MV}^{2+}$

More recently, this type of reactivity has been exploited by tethering Rubipy derivatives onto $\mathrm{TiO}_{2}$ surfaces to serve as light absorbing dyes for applications in dye sensitized solar cells [1-3]. In DSSC applications, the excited state of the $\mathrm{Ru}$ (II) complex serves to inject an $\mathrm{e}^{-}$into the conduction band of $\mathrm{TiO}_{2}$, initiating charge

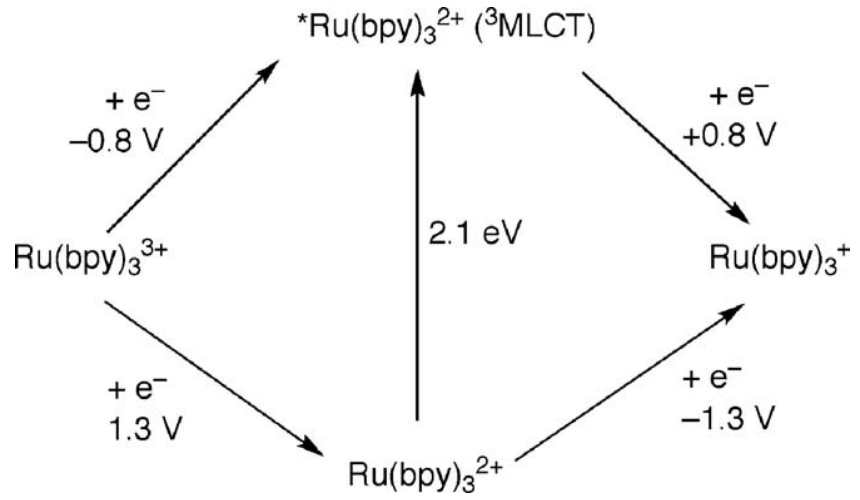

Fig. 24. Energies and potentials related to the excited and ground state redox properties of $\mathrm{Ru}(\mathrm{bpy})_{3}{ }^{2+}$. Reported potentials are in $\mathrm{CH}_{3} \mathrm{CN}$ vs. the saturated sodium chloride calomel reference electrode (SSCE) [168].

separation that results in electrical current across a voltage load, i.e., power. Efforts to optimize such devices have focused on structural modifications to the $\mathrm{Ru}(\mathrm{II})$ complex designed to tune the sensitizer- $\mathrm{TiO}_{2}$ interactions and/or increase the spectral window over which such devices function, thus capturing a larger fraction of the incident solar radiation [1-3]. Because of extremely fast $\mathrm{e}^{-}$injection rates (fs to ps timescale [3]), it is not imperative that the sensitizer excited states have remarkably long lifetimes. Indeed, much of the charge injection may be coming from the initially formed, but very short lived, singlet MLCT excited states, perhaps even those in vibrational excited states. Even so, competition between electron injection and deactivation through thermal population of ligand field states has been implicated in lowered efficiency for electron injection in some systems [167].

Although the ${ }^{3}$ MLCT excited state of Rubipy is a strong reducing agent, like all excited states it is both a better reductant and a better oxidant than the corresponding ground state. This is illustrated in Fig. 24. The ${ }^{3} \mathrm{MLCT}$ state has a reduction potential, $E^{0}\left({ }^{*} \mathrm{Ru}^{2+} / \mathrm{Ru}^{+}\right)$, of $+0.8 \mathrm{~V}$ vs. SSCE, demonstrating the good oxidizing capability of this excited state species.

Artificial photosynthesis is another research area where metal polypyridyl complexes are of interest [165,168-172]. Here it is envisioned that initial photoinduced charge separation followed by electron transfer to (and/or from) a redox catalyst would ultimately result in the production of useful chemical species (e.g. $\mathrm{H}_{2}$ and $\mathrm{O}_{2}$ from water, or $\mathrm{CH}_{3} \mathrm{OH}$ from $\mathrm{CO}_{2}$ ). Such a feat requires the preparation of supramolecular assemblies comprised of antenna molecules to collect light, molecular conduits for subsequent energy and electron transfer, and redox catalysts (Fig. 25).

The preparation of donor-antenna-acceptor triads based on $\mathrm{Ru}(\mathrm{II})$ complexes with substituted bipyridine ligands are hampered because of the mixture of geometric isomers that results from a typical synthesis [169]. This has directed researchers toward the construction of such assemblies using bis-tridentate complexes of ligands such as substituted $2,2^{\prime}: 6^{\prime}, 2^{\prime \prime}$-terpyridine (tpy) $[169,170,173]$. With these latter ligands, the preparation of rod-like assemblies that promote the vectorial transport of electrons is possible. However, whereas the excited state lifetimes for $\mathrm{Ru}(\mathrm{bpy})_{3}{ }^{2+}$ derivatives are often relatively long, the lifetime of $\mathrm{Ru}(\mathrm{tpy})_{2}{ }^{2+}$ is about three orders of magnitude smaller $(0.25 \mathrm{~ns})$ in room temperature fluid solution [174]. This short lifetime has been ascribed to efficient thermal population of the short-lived lowest energy ${ }^{3} \mathrm{MC}$ state, the energy of which has been lowered because of ligand imposed deviations from $O_{\mathrm{h}}$ symmetry [175].

Longer lifetimes are considered essential for long range electron transfer. Thus several strategies for increasing the energy of the ${ }^{3} \mathrm{MC}$ state relative to that of the ${ }^{3} \mathrm{MLCT}$ state have been developed [173]. One is derived from the understanding that unfavorable 

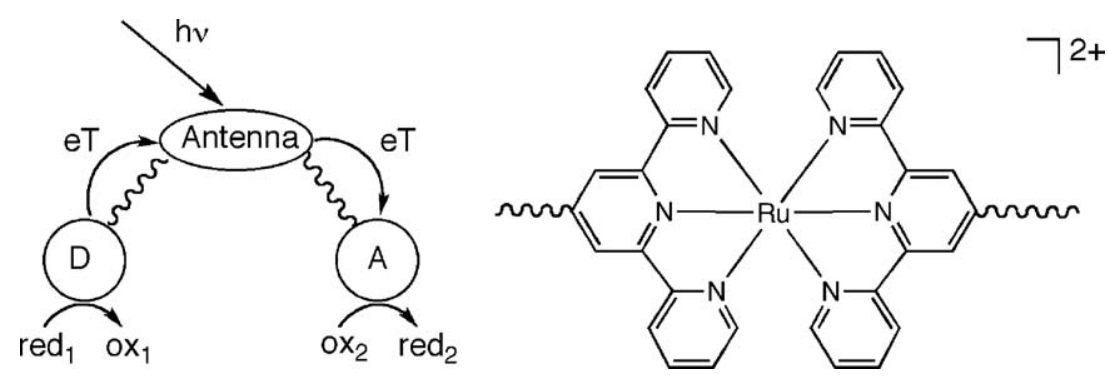

Fig. 25. Schematic diagram for a donor-antenna-acceptor triad (left), and the Ru(tpy) ${ }_{2}{ }^{2+}$ scaffold (right) for the synthesis of rod-like assemblies.<smiles>c1ccc(-c2cccc(-c3ccccn3)n2)nc1</smiles>

tpy<smiles>[R]C([R])(c1ccccn1)c1cccc(-c2ccccn2)n1</smiles>

1: $R=H \quad$ 2: $R=M e$<smiles>c1cnc2c(-c3ccc4ncccc4n3)cccc2c1</smiles>

bqp

Fig. 26. Tridentate polypyridyl ligands with varying bite angles.

Table 3

Photophysical data for $\mathrm{Ru}(\mathrm{II})$ polypyridyl complexes. ${ }^{\mathrm{a}}$

\begin{tabular}{|c|c|c|c|c|c|c|}
\hline \multirow[t]{2}{*}{ Complex } & \multicolumn{3}{|c|}{ Emission $(298 \mathrm{~K})^{\mathrm{b}}$} & \multicolumn{3}{|c|}{ Emission $(77 \mathrm{~K})^{\mathrm{b}}$} \\
\hline & $\lambda_{\max }$ & $\tau(\mathrm{ns})$ & $\Phi$ & $\lambda_{\max }$ & $\tau(\mathrm{ns})$ & $\Phi$ \\
\hline $\mathrm{Ru}(\mathrm{bpy})_{3}{ }^{2+c}$ & 630 & 1150 & 0.089 & 582 & 5100 & 0.52 \\
\hline $\mathrm{Ru}(\mathrm{tpy})_{2}{ }^{2+\mathrm{d}}$ & e & 0.25 & e & 598 & 11,000 & 0.48 \\
\hline $\operatorname{Ru}(\mathbf{2})_{2}{ }^{2+d}$ & 650 & 0.3 & $1 \times 10^{-4}$ & 603 & 3500 & 0.52 \\
\hline $\operatorname{Ru}(\mathbf{1})_{2}^{2+d}$ & 655 & 15.0 & $1 \times 10^{-3}$ & 609 & 3700 & 0.21 \\
\hline $\mathrm{Ru}(\mathrm{bqp}) 2^{2+\mathrm{f}}$ & 700 & 3000 & 0.02 & 673 & 8500 & 0.06 \\
\hline
\end{tabular}

a All complexes are $\mathrm{PF}_{6}{ }^{-}$salts.

b In MeOH:EtOH.

c From Ref. [141].

d From Ref. [179].

e Not given.

${ }^{f}$ From Ref. [178].

bite angles of tpy lower the energy of the ${ }^{3} \mathrm{MC}$ state (Section 4.4) and thus involves preparing new tridentate polypyridyl ligands that bind $\mathrm{Ru}(\mathrm{II})$ with geometries more closely approximating $\mathrm{O}_{\mathrm{h}}$ symmetry [172]. Examples are shown in Fig. 26 [176-179]. The photophysical properties of several homoleptic bis-tridentate $\mathrm{Ru}(\mathrm{II})$ complexes (along with those of $\mathrm{Ru}(\mathrm{bpy})_{3}{ }^{2+}$ for comparison) are summarized in Table 3.

The $\mathrm{N}(1)-\mathrm{Ru}-\mathrm{N}(2)$ (see Fig. 26 for numbering scheme) bite angles for these complexes are as follows: $\mathrm{Ru}(\mathrm{tpy})_{2}{ }^{2+}$ (158.4-159.1 ${ }^{\circ}$ [180]; $\operatorname{Ru}(2)_{2} 2^{2+}\left(165.16^{\circ}\right)$ [179]; $\operatorname{Ru}(\mathbf{1}) 2^{2+}\left(168.4^{\circ}\right)$ [179]; and $\mathrm{Ru}(\mathrm{bqp})_{2}{ }^{2+}\left(177.6^{\circ}\right)$ [178]. As the bite angles increase, the room-temperature lifetimes increase. Indeed, $\mathrm{Ru}(\mathrm{bqp})_{2}{ }^{2+}$ has a longer lifetime than even $\mathrm{Ru}(\mathrm{bpy})_{3}{ }^{2+}$ in fluid solution. These longer lifetimes can be ascribed to increasing the energy of the ${ }^{3} \mathrm{MC}$ state, thus raising the activation barrier for decay via population of this state [178,179] (see Fig. 21).

Another strategy involves manipulating the energies of the MLCT and MC states by varying the electronic nature of the tridentate ligands. This topic has recently been reviewed [173]. Replacing one of the pyridine rings of tpy with a phenyl ring results in a cyclometallated ligand, phbpy ${ }^{-}$, with an increased ligand field strength (Fig. 27). Coordination of $\mathrm{phbpy}^{-}$to $\mathrm{Ru}$ (II) also increases electron density on the metal center relative to tpy, thereby lowering the energy of the lowest lying ${ }^{3}$ MLCT state (which is centered on the ttpy ligand).

The result is a greater thermal barrier for accessing the ${ }^{3} \mathrm{MC}$ state from the ${ }^{3} \mathrm{MLCT}$. Consequently, Ru(phbpy)(ttpy) ${ }^{+}$is luminescent in room temperature fluid solution and displays a lifetime of $60 \mathrm{~ns}$ [181], despite the expectation that, according to the energy gap law, the lower ${ }^{3} \mathrm{MLCT}$ energy should have enhanced nonradiative relaxation. Since the ${ }^{3}$ MLCT state lifetimes of the $\mathrm{Ru}(\mathrm{NNN})(\mathrm{NNC})^{+}$ complexes are the result of competing processes (direct nonradiative relaxation and the activated decay through the ${ }^{3} \mathrm{MC}$ state), optimizing these lifetimes requires balancing the effects on both processes [181,182].

Another strategy involves appending substituents onto the tpy ligand that lower the energy of the $\pi^{*}$ orbitals (and consequently the ${ }^{3}$ MLCT state) through extended delocalization. Examples include aryl [183] and ethynyl substituents [184] and this approach again results in longer excited state lifetimes. Likewise, electrondeficient analogues of terpyridine involving pyrazine [185] and triazine [186] rings stabilize the ${ }^{3}$ MLCT state and have led to some<smiles>c1ccc(-c2cccc(-c3ccccn3)n2)cc1</smiles>

Hphbpy<smiles>Cc1ccc(-c2cc(-c3ccccn3)nc(-c3ccccn3)c2)cc1</smiles>

ttpy

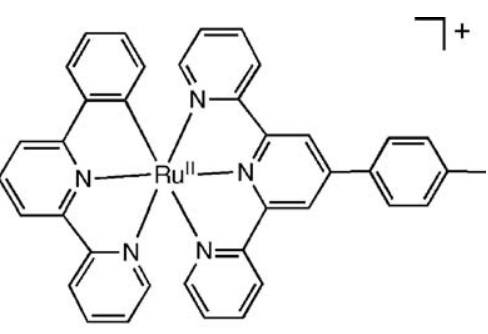

$\mathrm{Ru}\left(\right.$ phbpy)(ttpy) ${ }^{+}$

Fig. 27. 6-Phenyl-2,2'-bipyridine (Hphbpy); $4^{\prime}$-tolyl, 2,2': $6^{\prime}, 2^{\prime \prime}$-terpyridine (ttpy); and the heteroleptic Ru(II) complex of these ligands. 


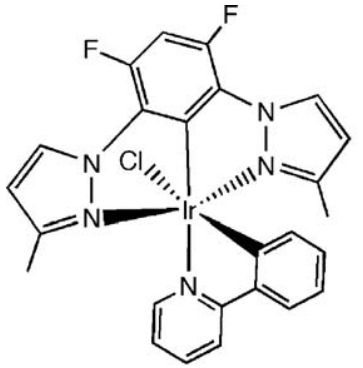

$\operatorname{Ir}(\mathrm{dfbpzb})(\mathrm{ppy}) \mathrm{Cl}$

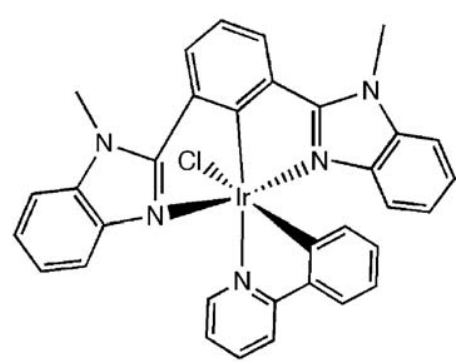

$\operatorname{Ir}($ Mebib)(ppy)Cl
Fig. 28. Structure of the blue/violet emissive $\operatorname{Ir}(\mathrm{dfbpzb})(\mathrm{ppy}) \mathrm{Cl}$ complex and its Mebib analogue.

excited state lifetime increases. Again, even though reducing the ${ }^{3}$ MLCT excited state energy does inhibit activated decay via the ${ }^{3} \mathrm{MC}$ states, the effect is offset by enhanced nonradiative relaxation directly from the ${ }^{3}$ MLCT state. Longer lifetimes may still result due to the relative balance between the two deactivation pathways. Notably, lowering the ${ }^{3}$ MLCT state energy also lowers the magnitude of the stored excited state energy.

\subsection{Organic light emitting diodes}

Another application for which the presence of MC states may negatively affect device performance involves organic light emitting diodes (OLEDs). Literature reports of new complexes for OLED applications have been dominated by $\operatorname{Ir}(\mathrm{III})$ complexes with cyclometallating ligands [4-6]. These emit from ${ }^{3} \mathrm{MLCT}$ and/or ${ }^{3} \mathrm{LC}$ $\pi \pi^{*}$ states. In the earlier applications the difference in energy between the luminactive states and the lowest energy ${ }^{3} \mathrm{MC}$ state(s) proved to be too large for the latter to have much impact on the emission efficiency. However, recent attention has focused on developing blue-to-violet phosphorescent Ir(III) complexes, requiring the preparation of complexes with higher energy emissive states. The result of pushing these mixed ${ }^{3} \mathrm{LC} /{ }^{3} \mathrm{MLCT}$ emissive states to higher energies may have the corresponding effect of making the ${ }^{3} \mathrm{MC}$ state thermally accessible from the emissive state(s).

One recent study involved comparing the photophysical behavior of $\operatorname{Ir}(\mathrm{dfbpzb})(\mathrm{ppy}) \mathrm{Cl}$ and $\operatorname{Ir}(\mathrm{Mebib})(\mathrm{ppy}) \mathrm{Cl}$ (Fig. 28) [187]. The emissive triplet states $\left(T_{1}\right)$ of these complexes are described as admixtures of states with MLCT ( $\mathrm{Ir} \rightarrow$ ppy) $\mathrm{XLCT}(\mathrm{Cl} \rightarrow \mathrm{ppy})$, and LC (ppy $\pi \rightarrow \pi^{*}$ ) character.

The $0-0$ band of the $T_{1} \rightarrow S_{0}$ phosphorescence was measured as $456 \mathrm{~nm}$ for $\operatorname{Ir}(\mathrm{dfbpzb})(\mathrm{ppy}) \mathrm{Cl}$ [187] and $535 \mathrm{~nm}$ for $\operatorname{Ir}($ Mebib)(ppy)Cl [188]. The $\operatorname{Ir}($ Mebib)(ppy)Cl complex is highly emissive with a room temperature quantum yield of 0.78 ( $\tau=1.78 \mathrm{~ms}$ ), whereas the more blue emitting $\operatorname{Ir}(\mathrm{dfbpzb})(\mathrm{ppy}) \mathrm{Cl}$ complex has an estimated quantum yield of $5 \times 10^{-3}(\tau=0.18 \mathrm{~ns})$. DFT calculations suggest that excited state deactivation involves the potential energy surfaces shown in Fig. 29, where the distortion coordinate involves bond elongation between Ir and both $\mathrm{N}$-atoms on the tridentate ligand.

According to the DFT calculations, the ${ }^{3} \mathrm{MC}$ state potential minimum for the highly emissive $\operatorname{Ir}($ Mebib)(ppy)Cl lies $0.7 \mathrm{eV}$ $\left(5600 \mathrm{~cm}^{-1}\right)$ above the $\mathrm{T}_{1}$ minimum, whereas for $\operatorname{Ir}(\mathrm{dfbpzb})(\mathrm{ppy}) \mathrm{Cl}$ the two minima are at nearly the same energy. This is ascribed to the weaker $\sigma$ - and $\pi$-donor character of the dfbpzb ligand relative to the analogous Mebib complex, leading to a higher energy MLCT state, as is consistent with the observed emission energies. At the same time, the weaker $\sigma$-donor character of the dfbpzb ligand also decreases the ligand field splitting, hence the energy of the ${ }^{3} \mathrm{MC}$ state [187]. Thus, the ${ }^{3} \mathrm{MC}$ state of $\operatorname{Ir}(\mathrm{Mebib})(\mathrm{ppy}) \mathrm{Cl}$ is thermally

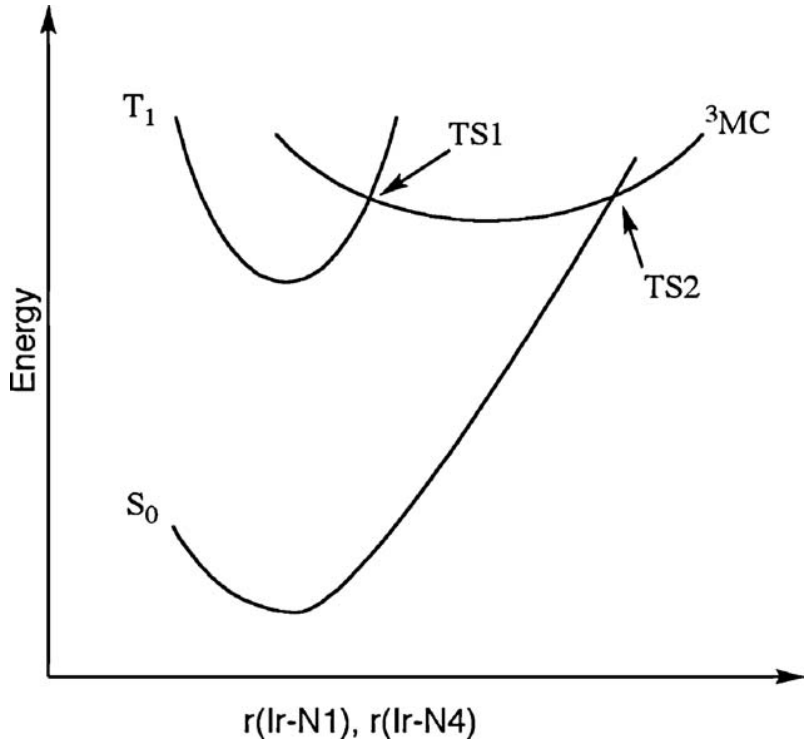

Fig. 29. Potential surface diagram for $\operatorname{Ir}(\mathrm{NCN})(\mathrm{ppy}) \mathrm{Cl}$ complexes. Nonradiative $\mathrm{T}_{1} \rightarrow \mathrm{S}_{0}$ relaxation can proceed along a trajectory involving transition states TS1 and TS2.

inaccessible under ambient conditions, and its excited state lifetime is essentially temperature independent between $77 \mathrm{~K}$ and $298 \mathrm{~K}$ $[187,188]$. In contrast, the excited state lifetime of $\operatorname{Ir}(\mathrm{dfbpzb})(\mathrm{ppy}) \mathrm{Cl}$ is highly temperature dependent above $120 \mathrm{~K}\left(A=2.3 \times 10^{13} \mathrm{~s}^{-1}\right.$ and $\left.E_{a}=1720 \mathrm{~cm}^{-1}\right)$. These activation parameters are consistent with surface crossing from the $\mathrm{T}_{1}$ potential surface to the ${ }^{3} \mathrm{MC}$ potential surface (through TS1) followed by surface crossing to $S_{0}$ (through TS2), with either crossing being rate determining.

In related investigations, excited state lifetimes for a series of homoleptic and heteroleptic facial (fac) cyclometallated $\operatorname{Ir}(\mathrm{III})$ complexes $f a c-\operatorname{Ir}(\mathrm{CN})_{3}$ were examined $[189,190]$. For these complexes, emission occurs from a triplet state of mixed LC/MLCT character $\left(\mathrm{T}_{1}\right.$ in Fig. 30) and the $0 \rightarrow 0$ band falls between 378 and $491 \mathrm{~nm}$. The temperature dependence of the excited state decay revealed two separate regimes, a lower temperature regime involving equilibration within the manifold of $T_{1}$ sublevels (dependent on zero-field splitting, see also [162,191]) and a higher temperature regime involving population of a nonradiative state with activation barriers, $E_{a}$, ranging from 1600 to $4800 \mathrm{~cm}^{-1}$. The experimentally determined activation barrier for population of the NR state appears to be the chief factor influencing the phosphorescence quantum yields. Complexes with the largest $E_{a}\left(>4000 \mathrm{~cm}^{-1}\right)$ display $\Phi_{\mathrm{P}}$ values $>0.93$, whereas several complexes with lowest $E_{a}\left(<2000 \mathrm{~cm}^{-1}\right)$ proved

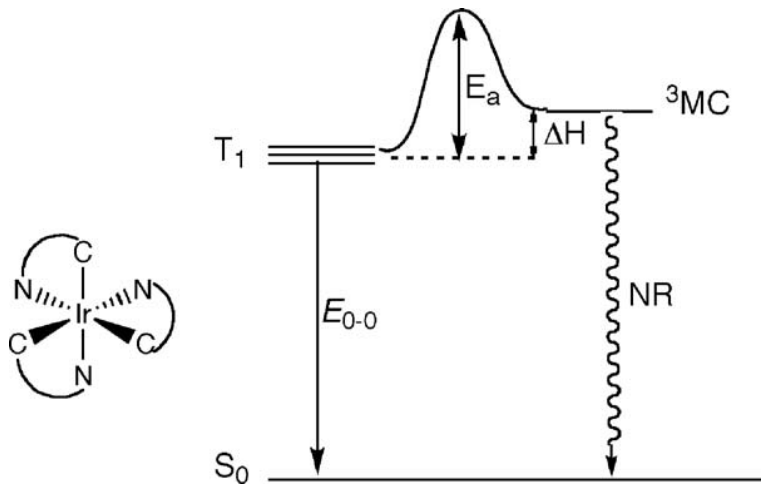

Fig. 30. $f a c-\operatorname{Ir}(\mathrm{CN})_{3}$ and an energy level diagram showing pathways for radiative and thermally activated nonradiative decay (through the ${ }^{3} \mathrm{MC}$ state) from $\mathrm{T}_{1}$. 


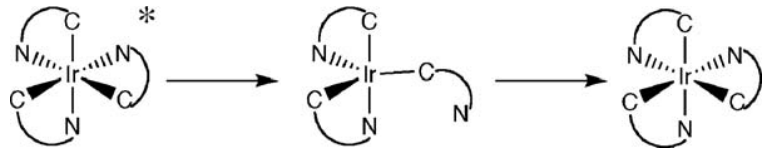

Fig. 31. Excited state Ir-N bond dissociation leading to the TBP NR species, followed by rearrangement back to the starting material.

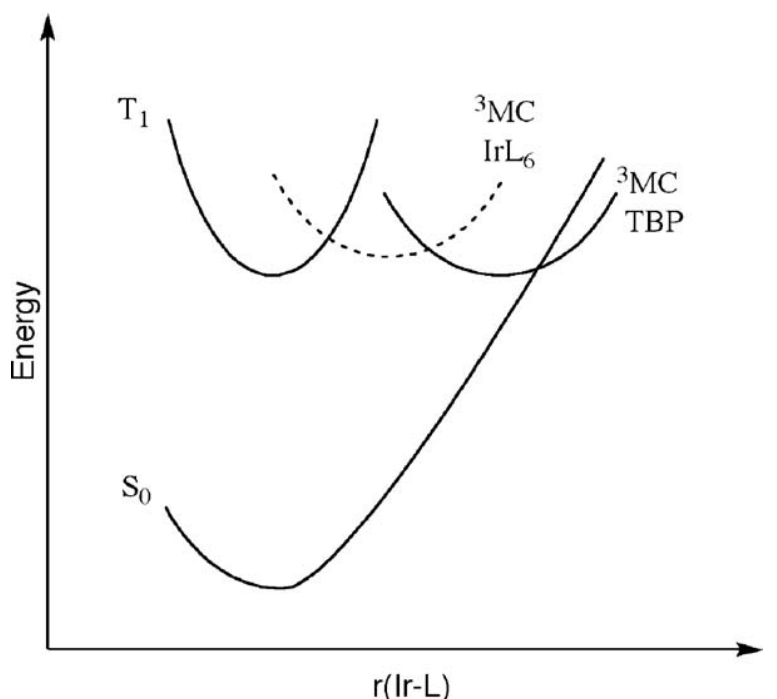

Fig. 32. Possible potential surface diagram for $f a c-\operatorname{Ir}(\mathrm{CN})_{3}$ showing surface crossings that may lead to nonradiative $\mathrm{T}_{1} \rightarrow \mathrm{S}_{0}$ deactivation.

to be non-emissive at room temperature. Complexes with intermediate activation barriers have quantum efficiencies near 0.6 [190].

The non-radiative state was proposed [190] to be a fivecoordinate complex resulting from Ir-ligand bond dissociation (Fig. 31). Initial evidence cited for this conclusion is two-fold. First, the barrier for population of the NR state for several of the complexes studied is $75-80 \mathrm{kcal} / \mathrm{mol}$ above the ground state (as determined from $E_{0-0}+E_{a}$ ) and this energy is comparable to Ir-L bond-strengths. ${ }^{15}$ Second, the values of the experimental Arrhenius pre-exponential terms for population of this state $\left(10^{11}\right.$ to $10^{14} \mathrm{~s}^{-1}$ ) are in the range associated with surface crossing to the ${ }^{3} \mathrm{MC}$ state for $\mathrm{Ru}(\mathrm{II})$ polypyridine complexes [145] (Section 4.4). Furthermore, DFT calculations suggest that the lowest energy triplet state is a five-coordinate distorted trigonal bipyramidal ${ }^{3} \mathrm{MC}$ state $[189,190]$. On the other hand, there is no direct evidence for this species given that deactivation regenerated the original GS.

DFT calculations were also used to calculate the relative thermodynamic stabilities of $\mathrm{T}_{1}$ and the TBP ${ }^{3} \mathrm{MC}$ state ( $\Delta H$ in Fig. 30 ). Accordingly, ligands that destabilize the $\mathrm{T}_{1}$ state (leading to higher energy emission) tend to destabilize the ${ }^{3} \mathrm{MC}$ state to a lesser extent, thus decreasing the energy gap for complexes with the highest energy emissions. In addition, there is a good correlation between the calculated $\Delta H$ and the experimental value for $E_{a}$. The authors do not speculate regarding possible potential surface diagrams for these systems but we shall consider them here.

One possibility is the potential surface diagram suggested for the relaxation of $\operatorname{Ir}(\mathrm{dfbpzb})(\mathrm{ppy}) \mathrm{Cl}$ (Fig. 29), but adding to this scheme the five coordinate intermediate proposed for the $f a c-\operatorname{Ir}(\mathrm{CN})_{3} \mathrm{com}-$ plexes as shown in Fig. 32.

Here the possibility for direct $\mathrm{T}_{1} \rightarrow \mathrm{TBP}^{3} \mathrm{MC}$ exists, but it is also likely that such a state would be accessed via initial crossing to a

15 Note that this line of reasoning implies a "hot ground state" mechanism. six-coordinate ${ }^{3} \mathrm{MC}$ surface (as in the case for $\operatorname{Ir}(\mathrm{dfbpzb})(\mathrm{ppy}) \mathrm{Cl}$ ). Precedence for this latter trajectory is found in the photochemistry of $\mathrm{Rh}(\mathrm{III})$ acidoam $(\mathrm{m})$ ine complexes. Time resolved emission and temperature dependence studies suggest that the six coordinate ${ }^{3} \mathrm{MC}$ state, from which both phosphorescence and photochemistry occurs, is a bound state with a measurable lifetime [133]. Various lines of mechanistic evidence point to photosubstitution occurring via a dissociative pathway to give a pentacoordinate intermediate. Furthermore, isomerization of the coordination sphere often occurs concomitantly with ligand labilization, and the isomeric products are best explained in terms of the pentacoordinate intermediate that is a ${ }^{3} \mathrm{MC}$ excited state [127]. A similar pathway can be invoked for $\mathrm{fac}-\operatorname{Ir}(\mathrm{CN})_{3}$ complexes.

The proposed excited state decay through a TBP intermediate for $f a c-\operatorname{Ir}(\mathrm{CN})_{3}$ complexes suggests that it might be possible to observe isomerization concomitant with excited state relaxation. Presumably, such isomerization would not be observed for $f a c-\operatorname{Ir}(\mathrm{CN})_{3}$ complexes because of the strong thermodynamic preference for the fac-isomer. However, it may be possible to design related complexes without such a preference, thereby allowing this observation.

\subsection{Applications requiring ligand labilization}

Although one can document numerous cases where the MC states have a negative impact on the performance of a specific device, there are other applications where photoreactivity specific to MC states is desirable. For example, as is clear from the discussion in Section 4.5, the ${ }^{3} \mathrm{MC}$ states of $c i s-\mathrm{Rh}(\mathrm{phen})_{2} \mathrm{Cl}_{2}{ }^{+}$and related complexes are readily accessible. Not surprisingly, this complex undergoes photoaquation [192]. This property has been exploited in studies showing that photolysis in the presence of calf thymus DNA results in the formation of covalent adducts involving $\mathrm{Rh}$ (phen) $)_{2}{ }^{3+}$ and one or more nucleoside nitrogen atoms [193]. The related $\mathrm{Rh}(\mathrm{dppz})($ phen $) \mathrm{Cl}_{2}{ }^{+}$complex $(\mathrm{dppz}=$ dipyridophenazine $)$ has demonstrated phototoxicity toward a variety of pathogens [194].

The targeted, light-activated release of small molecule bioregulators (see also, Section 6.3) is of particular importance in the treatment of several disease states [7-10]. In this context, the water soluble complex $\left[\mathrm{Ru}(\mathrm{bpy})_{2}(4 \mathrm{AP})_{2}\right] \mathrm{Cl}_{2}$, where $4 \mathrm{AP}=4-$ aminopyridine has been shown to release the neurotransmitter $4 \mathrm{AP}(\Phi=0.02$ at $473 \mathrm{~nm})$ at $\mathrm{pH} 7$ [195]. This release of 4AP was explained in terms of a pathway involving population of a labile LF state following primary excitation into the MLCT state. Notably, such photorelease was shown to activate medicinal leech neurons. Subsequent studies demonstrated that $4 \mathrm{AP}$ could also be released using two-photon excitation with $720 \mathrm{~nm}$ light, which excites the $360 \mathrm{~nm}$ band of $\left[\mathrm{Ru}(\mathrm{bpy})_{2}(4 \mathrm{AP})_{2}\right] \mathrm{Cl}_{2}$ [196]. One advantage of using two-photon excitation is that activated release can occur at wavelengths where tissue transmission is optimal $(\sim 700-1100 \mathrm{~nm})$.

Similar strategies have been used for release of the neurotransmitter glutamate (Glu). However, quantum yields for glutamate release from $\mathrm{Ru}(\mathrm{bpy})_{2}(\mathrm{Glu})^{+}$, where Glu is bound in a bidentate fashion, were extremely low. Replacement of one bpy ligand with a tridentate ligand such as tris(pyrazolylmethane) (tpm) resulted in a complex where glutamate binds in a monodentate fashion through the amino group, increasing the glutamate photolability $(\Phi=0.035)$ upon $450 \mathrm{~nm}$ irradiation at $\mathrm{pH} 7$ [197]. Likewise, $\mathrm{Ru}(\mathrm{bpy})_{2}\left(\mathrm{PMe}_{3}\right)(\mathrm{Glu})$, where $\mathrm{PMe}_{3}=$ trimethylphosphine, has been shown to release glutamate $(\Phi=0.13)$ upon $450 \mathrm{~nm}$ irradiation at $\mathrm{pH} 7$ [9].

Recently, much attention has been devoted to the design of molecular machines, that is, molecular architectures capable of performing directed nuclear motion following an external stimulus 


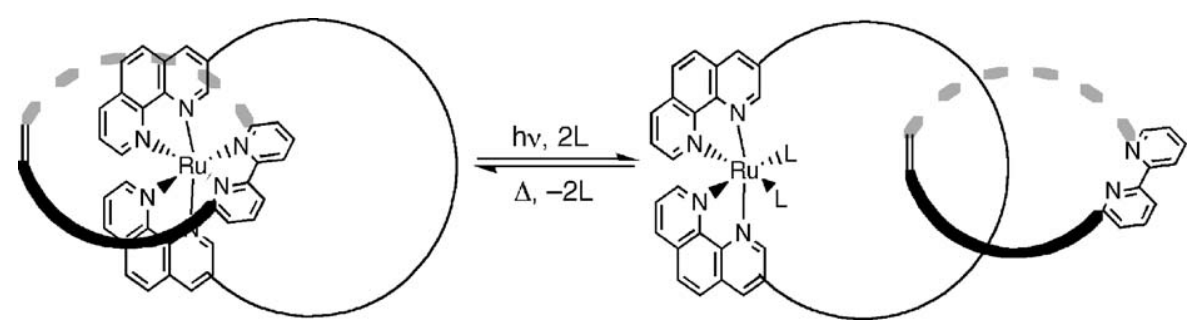

Fig. 33. Schematic representation of light and heat induced molecular motion for a Ru(II) catenane.

[11]. One particularly interesting example of this involves catenanes of the type shown in Fig. 33 [198].

Photolysis in $\mathrm{CH}_{3} \mathrm{CN}$ generates the ${ }^{3} \mathrm{MLCT}$ state, followed by thermal population of the ${ }^{3} \mathrm{MC}$ state, from which dissociation of the sterically hindered bpy ligand occurs. This sets the ring containing bpy in motion. Heating regenerates the starting complex, with both the forward and reverse processes being quantitative. In another case, ligands linking bpy and phen derivatives with long aliphatic linkers (phen...tpy) were prepared. Photolysis of the $\mathrm{Ru}^{\mathrm{II}}$ (phen $\ldots$ tpy) $\mathrm{L}^{n+}\left(\mathrm{L}=\mathrm{CH}_{3} \mathrm{CN}, \mathrm{Cl}^{-}\right.$, or py) cations resulted in coordination sphere isomerizations that resulted in dramatic conformational changes in the aliphatic linker. Again, this conformational shift can be reversed thermally [199].

\section{Applications involving complexes of $\mathrm{Cr}(\mathrm{III})$}

\subsection{The conversion of solar to stored chemical energy}

Several features suggest that $\mathrm{Cr}$ (diimine) $3_{3}{ }^{3+}$ complexes might be useful in solar energy conversion schemes [200-202]. Among these are their excited state oxidizing power, their thermal and photochemical stability, and their long ES lifetimes that allow for bimolecular redox reactions before relaxation. Less attractive features are the relatively small overlap between their absorption spectra and the solar emission spectrum, as well as the thermal lability of the $\mathrm{Cr}(\mathrm{II})$ products.

Unlike the widely investigated $\mathrm{Ru}$ (diimine) $3^{2+}$ complexes, charge transfer states do not dominate the photophysics/chemistry of the $\mathrm{Cr}(\mathrm{III})$ analogs; instead, the LEES are the MC ligand field doublet states. Thus, $\mathrm{Cr}$ (diimine $)_{3}{ }^{3+}$ ions generally show long-lived ${ }^{2} \mathrm{MC}$ phosphorescence at about $730 \mathrm{~nm}$ with lifetimes of $70-600 \mu \mathrm{s}$ in deaerated room temperature fluid solution. ${ }^{16}$ Interest in these species was prompted by the report that the ${ }^{2} \mathrm{E}$ excited state of $\mathrm{Cr}(\mathrm{bpy}) 3_{3}{ }^{3+}$ could be involved in bimolecular redox processes (Eq. (21)), demonstrating that such reactivity is not limited to charge transfer excited states [204].

${ }^{*} \mathrm{Cr}(\mathrm{bpy})_{3}{ }^{3+}+\mathrm{Ru}(\mathrm{bpy})_{3}{ }^{2+} \rightarrow \mathrm{Cr}(\mathrm{bpy})_{3}{ }^{2+}+\mathrm{Ru}(\mathrm{bpy})_{3}{ }^{3+}$

The excited state redox reactivity of the $\mathrm{Cr}$ (diimine) $3^{3+}$ complexes has since been demonstrated for numerous substrates [200,205-208]. The ES reduction potential, $E^{0}\left({ }^{*} \mathrm{Cr}^{3+} / \mathrm{Cr}^{2+}\right)$ can be estimated from the ${ }^{2} \mathrm{E} \rightarrow{ }^{4} \mathrm{~A}_{2}$ emission energy $\left(E_{0-0}\right)$ and the ground state reduction potential $E^{0}\left(\mathrm{Cr}^{3+} / \mathrm{Cr}^{2+}\right)$ (Fig. 34) [206-207]. Notably, the MC ligand field excited state, ${ }^{*} \mathrm{Cr}(\mathrm{bpy})_{3}{ }^{3+}$ is a significantly stronger oxidant than the MLCT excited state ${ }^{*} \mathrm{Ru}(\mathrm{bpy})_{3}{ }^{2+}$ (c.f. Fig. 24).

Hydrogen production from aqueous solutions using $\mathrm{Cr}(\mathrm{NN}) 3^{3+}$ complexes as the photosensitizer and EDTA as

\footnotetext{
16 A typical feature of the phosphorescence spectra is the presence of a band on the high-energy side of the principal emission band. Both features have the same lifetime and there is evidence to suggest that the high energy band represents emission from the ${ }^{2} \mathrm{~T}_{1 \mathrm{~g}}$ state in thermal equilibrium with the ${ }^{2} \mathrm{E}_{\mathrm{g}}$ state [203].
}

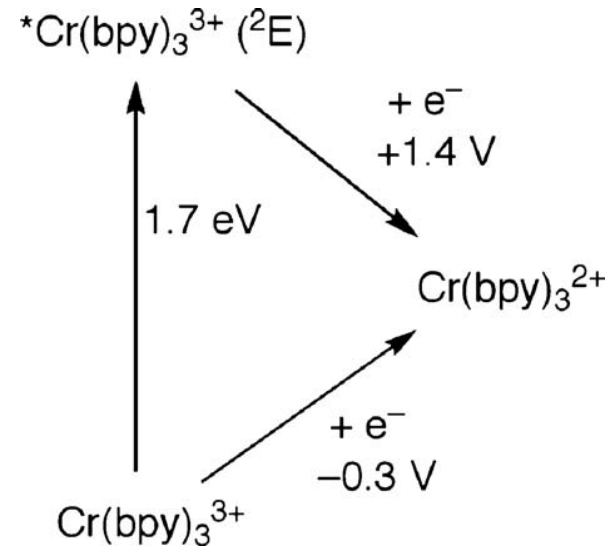

Fig. 34. Relevant energies and potentials related to the excited and ground state redox properties of $\mathrm{Cr}(\mathrm{bpy})_{3}{ }^{3+}$. Reported potentials are in $\mathrm{CH}_{3} \mathrm{CN}$ vs. SCE [206].

the sacrificial reducing agent has been reported (Fig. 35) [209].

It was demonstrated that only those $\mathrm{Cr}(\mathrm{NN}) 3^{3+}$ complexes with a reduction potential sufficiently negative to reduce protons at $\mathrm{pH} 4.8$ were good photosensitizers. Low turnover numbers were ascribed to the formation of small amounts of the ligand labilized product, $\mathrm{Cr}(\mathrm{NN})_{2}\left(\mathrm{H}_{2} \mathrm{O}\right)_{2}{ }^{2+}$, which can subsequently catalyze further thermal aquation of $\mathrm{Cr}(\mathrm{NN})_{3}{ }^{3+}$.

The introduction of carboxylate groups onto the diimine ligands has been shown to significantly increase the photooxidizing power of this class of complexes. For example, $\left[\mathrm{Cr}(4-\mathrm{dmcbpy})_{3}\right]\left(\mathrm{BF}_{4}\right)_{3}$, where 4-dmcbpy = dimethyl 2,2'-bipyridine-4,4'dicarboxylate, has an excited state reduction potential, $E^{0}\left({ }^{*} \mathrm{Cr}^{3+} / \mathrm{Cr}^{2+}\right)$, of $2.08 \mathrm{~V}$ vs. $\mathrm{NHE}$ [210]. The carboxylate groups are also intended for attachment to semiconductor surfaces in the construction of photocathodic solar cells.

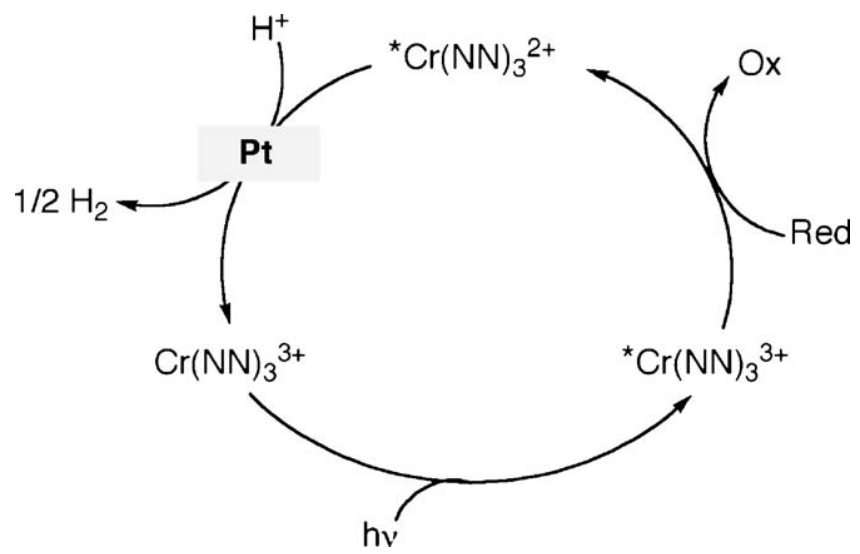

Fig. 35. Cycle for the photogeneration of hydrogen using $\mathrm{Cr}(\mathrm{NN})_{3}{ }^{3+}$ as the photosensitizer. Red = EDTA; Ox undergoes irreversible decomposition; $\mathbf{P t}=$ platinum catalyst stabilized with polyvinylalcohol.

Adapted from Ref. [209]. 


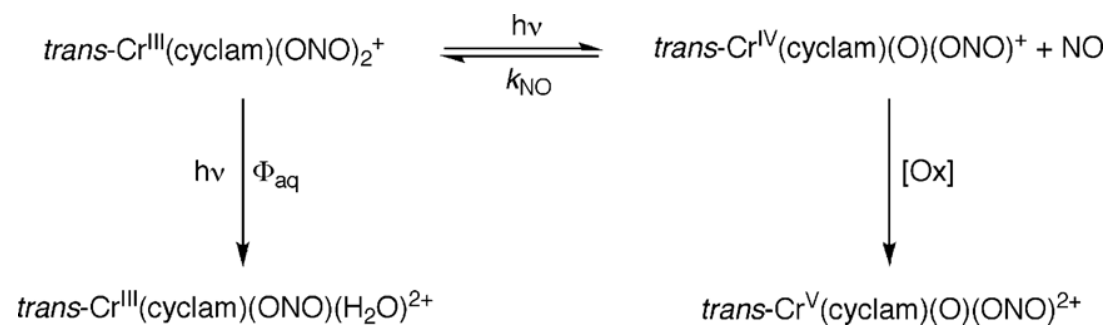

Fig. 36. Proposed mechanism for the photochemical reaction of trans- $\left[\mathrm{Cr}(\operatorname{cyclam})(\mathrm{ONO})_{2}\right]^{+}$.

\subsection{DNA photocleavage agents}

Another application involving $\mathrm{Cr}(\mathrm{NN})_{3}{ }^{3+}$ complexes centers around their possible utility as DNA photocleavage agents. For some time, there has been interest in the interaction of chiral $\mathrm{M}$ (diimine) $3^{n+}$ complexes with DNA for both diagnostic and phototherapeutic applications [211-213]. Once again, the $\mathrm{Ru}$ (diimine) ${ }_{3}{ }^{2+}$ complexes have dominated these investigations, partly due their ability to initiate oxidative photocleavage of DNA, as well as their readily observable MLCT emissions. However, apart from a few notable exceptions [214-217] it has been demonstrated that this damage involves singlet oxygen [218], not direct oneelectron oxidation by the ${ }^{3} \mathrm{MLCT}$ excited state of $\mathrm{Ru}(\mathrm{NN}) 3_{3}{ }^{2+}$. This is not surprising inasmuch as the reduction potentials of the ${ }^{3}$ MLCT states of the $\mathrm{Ru}(\mathrm{NN})_{3}{ }^{2+}$ complexes are typically too small for the direct one-electron oxidation of guanine, the most easily oxidized nucleobase $[41,216]$. For a cancer photochemotherapy approach, the requirement of dioxygen in order to facilitate oxidative cleavage might hinder the efficiency of such systems in the hypoxic environment of a tumor. The larger reduction potential of the $\operatorname{Cr}(\mathrm{NN})_{3}{ }^{3+}$ complexes in their ${ }^{2} \mathrm{E}_{\mathrm{g}}$ excited states, on the other hand, suggests that the $\mathrm{Cr}(\mathrm{III})$ complexes are capable of initiating DNA photocleavage through direct one-electron oxidation of guanine.

Initial confirmation of this proposal resulted from experiments involving the interaction of $\mathrm{Cr}(\mathrm{bpy})_{3}{ }^{3+}$ and $\mathrm{Cr}(\text { phen })_{3}{ }^{3+}$ with various mononucleotides and duplex DNA. The observation that the ${ }^{2} \mathrm{E}_{\mathrm{g}} \rightarrow{ }^{4} \mathrm{~A}_{2 \mathrm{~g}}$ emission is quenched by guanine containing nucleotides, (but not the more difficult to oxidize adenine, cytosine or thymidine containing nucleotides) and that oxygen plays no key role in this process, is consistent with a DNA quenching mechanism involving direct guanine base oxidation [219]. Subsequent studies involving $\mathrm{Cr}(\mathrm{phen})_{2}(\mathrm{dppz})^{3+}[220,221]$ demonstrate enhanced DNA binding, consistent with the known ability of the dppz ligand to intercalate into DNA base stacks. Furthermore, $\mathrm{Cr}(\text { phen })_{2}(\mathrm{dppz})^{3+}$ is a stronger oxidant (by $80 \mathrm{mV}$ ) in its ${ }^{2} \mathrm{E}_{\mathrm{g}}$ excited state than $\mathrm{Cr}$ (phen) $3_{3}{ }^{3+}$, thus is capable of both guanine and adenine nucleobase oxidation [220] This work has also been extended to $\mathrm{Cr}(\mathrm{III})$ complexes with substituted terpyridine ligands [222].

\subsection{Photochemical nitric oxide precursors}

Nitric oxide (NO) is an important bioregulatory agent that controls a range of processes including angiogenesis (the growth of new blood vessels from existing ones), apoptosis (programmed cell death) vasodilation, and neurotransmission [223]. Thus, there is much interest in delivering this important agent for medical applications, including the treatment of ischemia (restriction in blood supply) and/or cancer. Such treatments would require that the dosage and location of NO delivery be carefully controlled. In instances where NO is acting in concert with other agents (such as in radiation sensitization for cancer treatment), the timing of the dosage is important as well. Thus, the use of photochemical NO precursors allow one to control the timing, dosage, and location of NO release by the timing, intensity, and position of the incident radiation [7,224]. The same considerations can be directed toward the targeted release of other small molecule bioregulators, such as carbon monoxide [8] and glutamate [9]. A different, but related application of light for the treatment of disease states is called "photodynamic therapy" and is generally concerned with molecules that can act as photosensitizers for the generation of singlet dioxygen, ${ }^{1} \Delta \mathrm{O}_{2}$, which is toxic to cells [10].

Over the past decade numerous metal complexes have been investigated as photochemical NO precursors [7,224,225]. These have included complexes of $\mathrm{Fe}, \mathrm{Mn}, \mathrm{Ru}$, and $\mathrm{Cr}$, among others, with a diverse number of different ligands. Various types of excited states are involved in such applications including metal centered ligand field states and both single and two photon excitation has been used in such studies. The topic has been reviewed recently [7], so we will focus on the photochemistry of one such system based on $\mathrm{Cr}$ (III) nitrito complexes in order to illustrate the role for the MC states in that case.

A report [226] demonstrating that irradiation of $\mathrm{Cr}^{\mathrm{III}}(\mathrm{TPP})(\mathrm{ONO})$ (TPP = tetraphenylporphyrin) in benzene yielded NO and $\mathrm{Cr}^{\mathrm{IV}}(\mathrm{TPP})(\mathrm{O})$ suggested that such reactivity might be general to nitrito complexes of $\mathrm{Cr}(\mathrm{III})$. Indeed, upon ligand field excitation of $\mathrm{Cr}\left(\mathrm{NH}_{3}\right)_{5}(\mathrm{ONO})^{2+}$ and cis- $\mathrm{Cr}($ cyclam $)(\mathrm{ONO})_{2}{ }^{+}$, NO release was detected, but quantitative measurements were hampered by excited state ligand substitution chemistry [227]. Based on the knowledge that trans- $\mathrm{Cr}(\mathrm{cyclam}) \mathrm{Cl}_{2}{ }^{+}$is nearly inert to ES ligand substitution [109], the complex trans-Cr(cyclam $)(\mathrm{ONO})_{2}{ }^{+}$ was prepared in anticipation that $\mathrm{N}-\mathrm{O}$ bond cleavage would be favored over ligand substitution [228]. Photolysis of trans$\mathrm{Cr}(\mathrm{cyclam})(\mathrm{ONO})_{2}{ }^{+}$at $436 \mathrm{~nm}$ (corresponding to excitation into the lowest energy $\mathrm{MC}$ quartet state) in deaerated aqueous solution at $\mathrm{pH} 7$ led to the formation of the photoaquation product, trans- $\mathrm{Cr} \mathrm{rlI}^{\mathrm{III}}(\mathrm{cyclam})(\mathrm{ONO})\left(\mathrm{H}_{2} \mathrm{O}\right)^{2+}$, but with a very small quantum yield $(\Phi=0.009)$. In contrast, photolysis in aerated solution yielded an entirely different result, namely, the formation of trans $-\mathrm{Cr}^{\mathrm{V}}($ cyclam $)(\mathrm{O})(\mathrm{ONO})^{2+}(\Phi=0.27)$ and NO. The primary photoproduct was identified provisionally as trans$\mathrm{Cr}^{\mathrm{IV}}($ cyclam $)(\mathrm{O})(\mathrm{ONO})^{+}$, which is trapped by $\mathrm{O}_{2}$ to give a $\mathrm{Cr}(\mathrm{V})$ complex (Fig. 36). Flash photolysis demonstrated that NO photodissociation is reversible with a moderately fast back reaction $\left(k_{\mathrm{NO}}=3 \times 10^{6} \mathrm{M}^{-1} \mathrm{~s}^{-1}\right)$ [228]. Notably, more recent studies [229] have shown that the $\mathrm{Cr}$ (IV) oxo intermediate can also be trapped by reducing agents such as glutathione to give comparable quantum yields of net photochemical NO release.

Fig. 37 depicts a potential surface diagram for the proposed excited-state reaction mechanism for trans-Cr(cyclam $)(\mathrm{ONO})_{2}{ }^{+}$. Inasmuch as $\Phi_{\mathrm{NO}}$ is insensitive to $\lambda_{\mathrm{ex}}$, the reactive state is likely the lowest (thermalized) quartet or doublet ligand field excited state. Furthermore, photosensitization experiments indicate that the excited state responsible for NO release is the spin forbidden doublet state $[7,224,230]$. From this state, there would be no spin restriction in dissociating to the primary photoproducts, singlet $\mathrm{Cr}^{\mathrm{IV}}=\mathrm{O}$ plus doublet $\mathrm{NO}$.

One significant drawback of these systems is the relatively low absorption cross-sections of these complexes in the visible, 


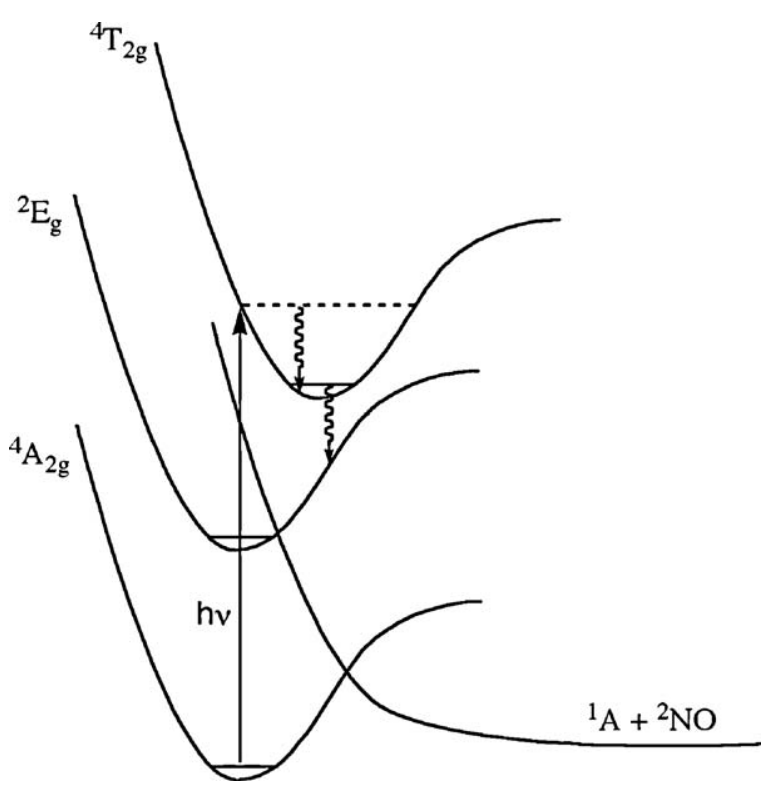

Fig. 37. Potential surface diagram for NO release from trans-Cr(cyclam $)(\mathrm{ONO})_{2}{ }^{+}$.

owing to the fact that these transitions are Laporte forbidden ligand field bands. This has been addressed by constructing molecules with an appropriate antenna, wherein energy transfer from the antenna to the nitrito complex would activate the latter to NO release [231] (Fig. 38). Upon excitation at 360-440 nm, the complexes with anthracene and pyrene pendants produced $\sim 8$ and 12 times as much NO, respectively, as the phenyl analogue, trans- $\mathrm{Cr}(\mathrm{mbc})(\mathrm{ONO})_{2}{ }^{+}$, under identical conditions. The difference is attributed to the much larger absorption cross-section for the anthracene and pyrene pendant complexes. Further studies in this area have been directed toward using sensitizers with large two-photon cross-sections, such that NO release can be activated at wavelengths where tissue transmission is optimal $(\sim 700-1100 \mathrm{~nm})[7,224,232]$.

\section{Summary and outlook}

The field of transition metal photochemistry, as its own discipline, is about 50 years old with the first authoritative monographs appearing in the early 1970s. [21,22]. Since then, there has been significant escalation of research directed both toward the detailed mechanistic understanding of photochemical and photophysical processes, and to applications involving the unique chemistry associated with the excited states. The rapid growth and specialization in this field may have rendered it difficult to see the connections between past and present, one electronic configuration and another, or one application and another. However, as demonstrated in this review, these connections do indeed exist, and understanding these relationships can only serve to enhance one's ability to solve mechanistic problems and develop new TM based photooptical devices.

Herein, we have limited our scope to those systems in which the metal centered states are known to play an important role. Indeed, MC ligand field states do play a major role in the development of transition metal based applications ranging from drug delivery to the conversion of solar energy to electrical and/or stored chemical energy. In cases involving $\mathrm{Cr}$ (III) complexes, the MC states play the leading role. In this context, formulating systems with appropriate absorption properties, excited state redox potentials, photoreactivity, and capacity for sensitization requires a thorough knowledge of the relevant quartet and doublet states. In many applications involving low-spin $d^{6}$ complexes, research has been aimed at limiting the deleterious role that the MC states play in device performance. This has been accomplished using a range of techniques aimed at increasing the energy gap between the MC states and the CT (and/or LC) states. As such, researchers today have greatly profited from early research demonstrating that the relative excited state energy levels could be controlled by taking advantage of their sensitivity to the identity of the metal, ligand, and environment.

The ability to exploit the unique chemistry associated with molecules in their excited states has long captured the interest of chemists. In a general lecture entitled "The Photochemistry of the Future" [233], given before the International Congress of Applied Chemistry in New York on September 11, 1912, Giacomo Ciamician of the University of Bologna envisions a society whose industry is based on photochemical molecular devices. He suggests, "On the arid lands there will spring up industrial colonies without smoke and without smokestacks; forests of glass tubes will extend over the plains and glass buildings will rise everywhere; inside of these will take place the photochemical processes that hitherto have been the guarded secret of the plants, but that will have been mas-

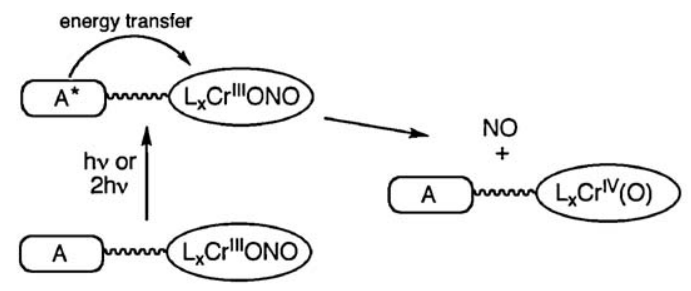

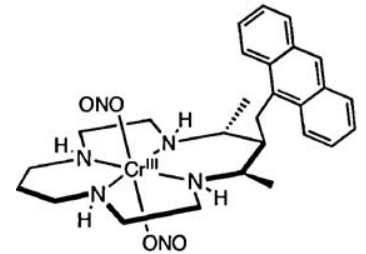

trans-Cr(mac)(ONO) ${ }_{2}^{+}$

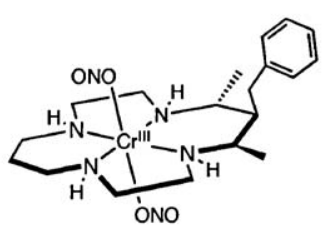

$\mathrm{R}=\mathrm{H} ;$ trans $-\mathrm{Cr}(\mathrm{mbc})(\mathrm{ONO})_{2}{ }^{+}$

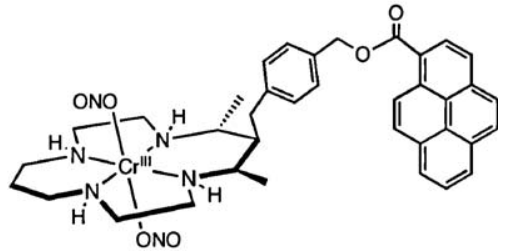

trans- $\mathrm{Cr}(\mathrm{pbc})(\mathrm{ONO})_{2}^{+}$

Fig. 38. General scheme for sensitized NO release (top). Macrocyclic $\mathrm{Cr}$ (III) complexes with appended chromophores (bottom). 
tered by human industry..." Now, nearly 100 years later, we can see glimpses of this future reality. The recent discoveries highlighted in this review suggest that full-scale realization will likely involve assemblies containing transition metal complexes, but will certainly require a steadfast dedication to this goal as well as a thorough understanding of the roles played by the various excited states involved.

\section{Acknowledgements}

Research at UCSB into the photoreactions of transition metal complexes has long been supported by the Chemistry Division of the US National Science Foundation, currently CHE-0749524. Research at Furman University into the photophysics of $\mathrm{Cr}(\mathrm{III})$ complexes is supported by the US National Science Foundation under Grant CHE-0709562. PSW received partial sabbatical support through matching commitments to an NSF RII Cooperative Agreement, EPS-0903795.

\section{References}

[1] M. Gratzel, Inorg. Chem. 44 (2005) 6841.

[2] G.J. Meyer, Inorg. Chem. 44 (2005) 6852.

[3] S. Ardo, G.J. Meyer, Chem. Soc. Rev. 38 (2009) 115.

[4] M.E. Thompson, P.E. Djurovich, S. Barlow, S. Marder, Comp. Organomet. Chem. III 12 (2007) 101.

[5] Y. Chi, P.-T. Chou, Chem. Soc. Rev. 39 (2010) 638

[6] H. Yersin (Ed.), Highly Efficient OLEDs with Phosphorescent Materials, Wiley, Weinheim, 2008

[7] A.D. Ostrowski, P.C. Ford, Dalton Trans. (2009) 10660.

[8] R.D. Rimmer, H. Richter, P.C. Ford, Inorg. Chem. 49 (2010) 1180.

[9] M. Salierno, E. Marceca, D.S. Peterka, R. Yuste, R.J. Etchenique, J. Inorg. Biochem. 104 (2010) 418.

[10] T.J. Dougherty, C.J. Gomer, B.W. Henderson, G. Jori, D. Kessel, M. Korbelik, J. Moan, Q. Peng, J. Natl. Cancer Inst. 90 (1998) 889.

[11] V. Balzani, A. Credi, M. Venturi, Chem. Soc. Rev. 38 (2009) 1542.

[12] V. Balzani, Photochem. Photobiol. Sci. 2 (2003) 459.

[13] A. Maldotti, Photochemistry 37 (2009) 240.

[14] V. Balzani, S. Campagna (Eds.), Photochemistry and Photophysics of Coordination Compounds, I, Springer, Berlin, 2007.

[15] V. Balzani, S. Campagna (Eds.), Photochemistry and Photophysics of Coordination Compounds, II, Springer, Berlin, 2007.

[16] C.G. Garcia, J.F. DeLima, N.Y.M. Iha, Coord. Chem. Rev. 196 (2000) 219.

[17] J.F. Endicott, in: E.I. Solomon, A.B.P. Lever(Eds.), Inorganic Electronic Structure and Spectroscopy, 2, Wiley, New York, 1999, p. 291.

[18] J.F. Endicott, T. Ramasami, R. Tamilarasan, R.B. Lessard, C.K. Ryu, G.R. Brubaker, Coord. Chem. Rev. 77 (1987) 1.

[19] P.C. Ford, Coord. Chem. Rev. 44 (1982) 61.

[20] P.D. Fleischauer, A.W. Adamson, G. Sartori, Prog. Inorg. Chem. 17 (1972) 1.

[21] V. Balzani, V. Carassiti, Photochemistry of Coordination Compounds, Academic Press, New York, 1970.

[22] A.W. Adamson, P.D. Fleischauer, Concepts of Inorganic Photochemistry, Wiley-Interscience, New York, 1975.

[23] A.B.P. Lever, Inorganic Electronic Spectroscopy, Elsevier, New York, 1968.

[24] R.G. McDonald, M.J. Riley, M.A. Hitchman, Inorg. Chem. 27 (1988) 894.

[25] P.S. Wagenknecht, C. Hu, D. Ferguson, L.C. Nathan, R.D. Hancock, J.R. Whitehead, K. Wright-Garcia, M.T. Vagnini, Inorg. Chem. 44 (2005) 9518.

[26] M. Kasha, Discuss. Faraday Soc. 9 (1950) 14.

[27] J.N. Demas, G.A. Crosby, J. Am. Chem. Soc. 92 (1970) 7262.

[28] R. Englman, J. Jortner, Mol. Phys. 18 (1970) 145.

[29] (a) N.J. Turro, Modern Molecular Photochemistry, University Science Books, Mill Valley, CA, 1991;

(b) N.J. Turro, V. Ramamurthy, J.C. Scaiano, Modern Molecular Photochemistry of Organic Molecules, University Science Books, Sausalito, CA, 2010.

[30] W.R. Browne, J.G. Vos, Coord. Chem. Rev. 219-221 (2001) 761.

[31] J.D. Peterson, P.C. Ford, J. Phys. Chem. 78 (1974) 1144.

[32] J.I. Zink, Coord. Chem. Rev. 211 (2001) 69.

[33] A. Hauser, Top. Curr. Chem. 233 (2004) 49.

[34] C. Anthon, J. Bendix, C.E. Schaffer, Struct. Bond. 107 (2004) 207.

[35] C. Daniel, Top. Curr. Chem. 241 (2004) 119.

[36] H. Riesen, Coord. Chem. Rev. 250 (2006) 1737.

[37] M.-C. Nolet, R. Beaulac, A.-M. Boulanger, C. Reber, Struct. Bond. 107 (2004) 145.

[38] K.L. Bray, Top. Curr. Chem. 213 (2001) 1.

[39] C. Reber, J.K. Grey, E. Lanthier, K.A. Frantzen, Comm. Inorg. Chem. 26 (2005) 233.

[40] C. Reber, Can. J. Anal. Sci. Spectrosc. 53 (2008) 91

[41] N.A.P. Kane-Maguire, Top. Curr. Chem. 280 (2007) 37.

[42] A.D. Kirk, Chem. Rev. 99 (1999) 1607.

[43] L.S. Forster, Chem. Rev. 90 (1990) 331.
[44] R.B. Wilson, E.I. Solomon, Inorg. Chem. 17 (1978) 1729

[45] A.F. Fucaloro, L.S. Forster, S.G. Glover, A.D. Kirk, Inorg. Chem. 24 (1985) 4242

[46] L.S. Forster, J.V. Rund, A.F. Fucaloro, J. Phys. Chem. 88 (1984) 5012.

[47] H.L. Schlafer, H. Gausman, H. Witzke, J. Chem. Phys. 46 (1967) 1423.

[48] G.B. Porter, H.L. Schlafer, hem, Z. Phys. C 37 (1963) 109.

[49] D.F. Nelson, M.D. Sturge, Phys. Rev. A 137 (1965) 1117

[50] A.D. Kirk, H.U. Gudel, Inorg. Chem. 31 (1992) 4564.

[51] C.D. Flint, P. Greenhough, J. Chem. Soc., Faraday Trans. 268 (1972) 897.

[52] C.D. Flint, P. Greenhough, J. Chem. Soc., Faraday Trans. 271 (1975) 579.

[53] K. Wright-Garcia, J. Basinger, S. Williams, C. Hu, P.S. Wagenknecht, Inorg. Chem. 42 (2003) 4885

[54] E.A. Juban, J.K. McCusker, J. Am. Chem. Soc. 127 (2005) 6857.

[55] N.A.P. Kane-Maguire, J.E. Phifer, C.G. Toney, Inorg. Chem. 15 (1976) 593.

[56] N.A.P. Kane-Maguire, D.E. Richardson, C.G. Toney, J. Am. Chem. Soc. 98 (1976) 3996.

[57] T. Sandrini, M.T. Gandolfi, L. Moggi, V. Balzani, J. Am. Chem. Soc. 100 (1978) 1463.

[58] R.L.P. Sasseville, C.H. Langford, Inorg. Chem. 19 (1980) 2850.

[59] G.E. Rojas, C. Dupuy, D.A. Sexton, D. Magde, J. Phys. Chem. 90 (1986) 87.

[60] A.D. Kirk, P.E. Hoggard, G.B. Porter, M.G. Rockley, M.W. Windsor, Chem. Phys. Lett. 37 (1976) 199.

[61] J.K. McCusker, Acc. Chem. Res. 36 (2003) 876.

[62] J.N. Schrauben, K.L. Dillman, W.F. Beck, J.K. McCusker, Chem. Sci. 1 (2010) 405

[63] C.E. Schäffer, C.K. Jørgensen, J. Inorg. Nucl. Chem. 8 (1958) 143.

[64] H. Witzke, Theor. Chim. Acta 20 (1971) 171.

[65] J.W. Kenney, J.W. Clymire, S.F. Agnew, J. Am. Chem. Soc. 117 (1995) 1645.

[66] J.W. Kenney, in: M. Roundhill, J. Fackler (Eds.), Optoelectronic Properties of Inorganic Compounds, Plenum Press, New York, 1999, p. 231.

[67] H. Yersin, P. Huber, G. Gietl, D. Trümbach, Chem. Phys. Lett. 199 (1992) 1.

[68] H.U. Gudel, T.R. Snellgrove, Inorg. Chem. 17 (1978) 1617.

[69] O.S. Wenger, R. Valiente, H.U. Gudel, J. Chem. Phys. 114 (2001) 5832.

[70] R. Beaulac, C. Reber, Inorg. Chem. 47 (2008) 5048.

[71] G. Rojas, D. Magde, Chem. Phys. Lett. 102 (1983) 399.

[72] R.B. Lessard, M.J. Heeg, T. Buranda, M.W. Perkovic, C.L. Schwarz, Y. Rudong, J.F. Endicott, Inorg. Chem. 31 (1992) 3091.

[73] J.F. Endicott, M.W. Perkovic, M.J. Heeg, C.K. Ryu, D. Thompson, in: S.S. Isied (Ed.), Electron Transfer Reactions, Advances in Chemistry Series 253, American Chemical Society, Washington, DC, 1997, p. 199.

[74] M.W. Perkovic, M.J. Heeg, J.F. Endicott, Inorg. Chem. 30 (1991) 3140

[75] R.B. Lessard, J.F. Endicott, M.W. Perkovic, L.A. Ochrymowycz, Inorg. Chem. 28 (1989) 2574.

[76] L.S. Forster, Coord. Chem. Rev. 227 (2002) 59.

[77] N.A.P. Kane-Maguire, W.S. Crippen, P.K. Miller, Inorg. Chem. 22 (1983) 696.

[78] M.T. Vagnini, N.A.P. Kane-Maguire, P.S. Wagenknecht, Inorg. Chem. 45 (2006) 3789.

[79] R.T. Walters, A.W. Adamson, Acta Chem. Scand. A33 (1979) 53.

[80] K. Kühn, F. Wasgestian, H. Kupka, J. Phys. Chem. 85 (1981) 665

[81] N.A.P. Kane-Maguire, K.C. Wallace, D.B. Miller, Inorg. Chem. 24 (1985) 597.

[82] C.D. Flint, A.P. Matthews, Chem. Commun. (1971) 954.

[83] J.F. Endicott, R. Tamilarasan, R.B. Lessard, Chem. Phys. Lett. 112 (1984) 381.

[84] N.J. Linck, S.J. Berens, D. Magde, R.G. Linck, J. Phys. Chem. 87 (1983) 1733.

[85] F. Bolletta, M. Maestri, L. Moggi, M.A. Jamieson, N. Serpone, M.S. Henry, M.Z Hoffmann, Inorg. Chem. 22 (1983) 2502.

[86] K. Angermann, R. van Eldik, H. Kelm, F. Wasgestian, Inorg. Chem. 20 (1981) 955.

[87] A.D. Kirk, M.A.R. Scandola, J. Phys. Chem. 86 (1982) 4141.

[88] K. Angermann, R. Schmidt, R. Van Eldik, H. Kelm, F. Wasgestian, Inorg. Chem. 21 (1982) 1175

[89] L. Moensted, O. Moensted, Coord. Chem. Rev. 94 (1989) 109.

[90] P. Riccieri, E. Zinato, Inorg. Chem. 19 (1980) 3279.

[91] P. Riccieri, E. Zinato, A. Aliboni, Inorg. Chem. 36 (1997) 2279.

[92] A.D. Kirk, J. Chem. Ed. 60 (1983) 843.

[93] C.D. Flint, A.P. Matthews, J. Chem. Soc., Faraday Trans. II 70 (1974) 1307.

[94] J.I. Zink, J. Am. Chem. Soc. 94 (1972) 8039.

[95] R. Fukuda, R.T. Walters, H. Macke, A.W. Adamson, J. Phys. Chem. 83 (1979) 2097.

[96] W.L. Waltz, R.T. Walters, R.J. Woods, Inorg. Chim. Acta 46 (1980) L153-L155

[97] W.L. Waltz, J. Lilie, S.H. Lee, Inorg. Chem. 23 (1984) 1768.

[98] A.D. Kirk, A.M. Ibrahim, Inorg. Chem. 29 (1990) 4848.

[99] A.W. Adamson, Coord. Chem. Rev. 3 (1968) 169

[100] L.G. Vanquickenborne, A. Ceulemans, J. Am. Chem. Soc. 99 (1977) 2208

[101] L.G. Vanquickenborne, A. Ceulemans, Coord. Chem. Rev. 48 (1983) 157.

[102] C. Anthon, J. Bendix, C.E. Schaffer, Inorg. Chem. 42 (2003) 4088.

[103] M.C. Cimolino, R.G. Linck, Inorg. Chem. 20 (1981) 3499.

[104] E. Zinato, A.W. Adamson, J.L. Reed, J.P. Paux, P. Riccieri, Inorg. Chem. 23 (1984) 1138.

[105] A.D. Kirk, Coord. Chem. Rev. 39 (1981) 225.

[106] E. Zinato, P. Riccieri, Coord. Chem. Rev. 211 (2001) 5.

[107] F. Wasgestian, J. Phys. Chem. 76 (1972) 1947.

[108] P. Riccieri, E. Zinato, Inorg. Chem. 29 (1990) 5035.

[109] C. Kutal, A.W. Adamson, Inorg. Chem. 12 (1973) 1990.

[110] D.A. Friesen, S.H. Lee, R.E. Nashiem, S.P. Mezyk, W.L. Waltz, Inorg. Chem. 34 (1995) 4026.

[111] A.D. Kirk, Comm. Inorg. Chem. 14 (1993) 89

[112] G. Irwin, A.D. Kirk, Coord. Chem. Rev. 211 (2001) 25

[113] J.F. Endicott, Comm. Inorg. Chem. 3 (1985) 349. 
[114] R. B. Wilson, E.I Solomon, J. Am. Chem. Soc. 102 (1980) 4085

[115] K. Hakamata, A. Urushiyama, H. Kupka, J. Phys. Chem. 85 (1981) 1983.

[116] J. DiBenedetto, V. Arkle, H. Goodwin, P.C. Ford, Inorg. Chem. 24 (1985) 455

[117] J.F. Endicott, G.J. Ferraudi, J. Phys. Chem. 80 (1976) 949

[118] T.L. Kelly, J.F. Endicott, J. Phys. Chem. 76 (1972) 1937.

[119] D.A. Sexton, P.C. Ford, D. Magde, J. Phys. Chem. 87 (1983) 197

[120] T. Kobayashi, Y. Ohashi, Chem. Phys. Lett. 86 (1982) 289.

[121] T.R. Thomas, R.J. Watts, G.A. Crosby, J. Chem. Phys. 59 (1973) 2123

[122] L.J. McClure, P.C. Ford, J. Phys. Chem. 96 (1992) 6640

[123] M.A. Bergkamp, J. Brannon, D. Magde, R.J. Watts, P.C. Ford, J. Am. Chem. Soc. 101 (1979) 4549.

[124] D.B. Miller, P.K. Miller, N.A.P. Kane-Maguire, Inorg. Chem. 22 (1983) 3831.

[125] N.A.P. Kane-Maguire, K.C. Wallace, D.P. Cobranchi, J.M. Derrick, D.G. Speece, Inorg. Chem. 25 (1986) 2101.

[126] L.H. Skibsted, P.C. Ford, Inorg. Chem. 22 (1983) 2749

[127] P.C. Ford, D.W. Wink, J. DiBenedeto, Prog. Inorg. Chem. 30 (1983) 213.

[128] V.F. Manfrin, G. Varani, L. Moggi, V. Balzani, Mol. Photochem. 1 (1969) 387.

[129] M. Nishizawa, P.C. Ford, Inorg. Chem. 20 (1981) 294.

[130] M. Talebinasab-Sarvari, A. Zanella, P.C. Ford, Inorg. Chem. 19 (1980) 1835.

[131] C.H. Langford, A.Y.S. Malkhasian, D.K. Sharma, J. Am. Chem. Soc. 106 (1984) 2727.

[132] M.E. Frink, P.C. Ford, Inorg. Chem. 24 (1985) 1033.

[133] D. Magde, G.E. Rojas, L.H. Skibsted, Inorg. Chem. 27 (1988) 2900.

[134] L.H. Skibsted, D. Strauss, P.C. Ford, Inorg. Chem. 18 (1979) 3171.

[135] M.A. Bergkamp, R.J. Watts, P.C. Ford, J. Am. Chem. Soc. 102 (1980) 2627.

[136] W. Weber, R. van Eldik, H. Kelm, J. DiBenedetto, Y. Ducommun, H. Offen, P.C. Ford, Inorg. Chem. 22 (1983) 623

[137] W. Weber, J. DiBenedetto, H. Offen, R. van Eldik, P.C. Ford, Inorg. Chem. 23 (1984) 2033.

[138] L.H. Skibsted, W. Weber, R. van Eldik, H. Kelm, P.C. Ford, Inorg. Chem. 22 (1983) 541.

[139] J. DiBenedetto, P.C. Ford, Coord. Chem. Rev. 64 (1985) 361.

[140] T.J. Meyer, Pure Appl. Chem. 58 (1986) 1193.

[141] A. Juris, V. Balzani, F. Barigelletti, S. Campagna, P. Belser, A. vonZelewsky, Coord. Chem. Rev. 84 (1988) 85

[142] S. Campagna, F. Puntoriero, F. Nastasi, G. Bergamini, V. Balzani, Top. Curr. Chem. 280 (2007) 117

[143] J. Van Houten, R.J. Watts, J. Am. Chem. Soc. 98 (1976) 4853.

[144] B. Durham, J.V. Caspar, J.K. Nagle, T.J. Meyer, J. Am. Chem. Soc. 104 (1982) 4803.

[145] F. Barigelletti, A. Juris, V. Balzani, P. Belser, A. von Zelewsky, J. Phys. Chem. 91 (1987) 1095

[146] M.L. Fetterolf, H.W. Offen, J. Phys. Chem. 90 (1986) 1828.

[147] G. Malouf, P.C. Ford, J. Am. Chem. Soc. 99 (1977) 7213

[148] W.R. Cherry, L.J. Henderson, Inorg. Chem. 23 (1984) 983.

[149] W.M. Wacholtz, R.A. Auerbach, R.H. Schmell, M. Ollino, W.R. Cherry, Inorg. Chem. 24 (1985) 1758.

[150] T.C. Strekas, H.D. Gafney, S.A. Tysoe, R.P. Thummel, F. Lefoulon, Inorg. Chem. 28 (1989) 2964.

[151] R.S. Lumpkin, E.M. Kober, L.A. Worl, Z. Murtaza, T.J. Meyer, J. Phys. Chem. 94 (1990) 239.

[152] K. Maruszewski, D.P. Strommen, J.R. Kincaid, J. Am. Chem. Soc. 115 (1993) 8345.

[153] M.T. Indelli, C. Chiorboli, F. Scandola, Top. Curr. Chem. 280 (2007) 215

[154] L. Flamigni, A. Barbieri, C. Sabatini, B. Ventura, F. Barigelletti, Top. Curr. Chem. $281(2007) 143$

[155] M.T. Indelli, A. Carioli, F. Scandola, J. Phys. Chem. 88 (1984) 2685

[156] M.T. Indelli, F. Scandola, Inorg. Chem. 29 (1990) 3056.

[157] J.-P. Collin, I.M. Dixon, J.-P. Sauvage, J.A. Gareth Williams, F. Barigelletti, L. Flamigni, J. Am. Chem. Soc. 121 (1999) 5009.

[158] J. DiBenedetto, R.J. Watts, P.C. Ford, Inorg. Chem. 23 (1984) 3039.

[159] S. Sprouse, K.A. King, P.J. Spellane, R.J. Watts, J. Am. Chem. Soc. 106 (1984) 6647.

[160] D.H.W. Carstens, G.A. Crosby, J. Mol. Spectrosc. 34 (1970) 113

[161] Y. Ohsawa, S. Sprouse, K.A. King, M.K. DeArmond, K.W. Hanck, R.J. Watts, J. Phys. Chem. 91 (1987) 1047.

[162] T. Hofbeck, H. Yersin, Inorg. Chem. 49 (2010) 9290

[163] H.D. Gafney, A.W. Adamson, J. Am. Chem. Soc. 94 (1972) 8238

[164] J.N. Demas, A.W. Adamson, J. Am. Chem. Soc. 95 (1973) 5159.

[165] T.J. Meyer, Acc. Chem. Res. 22 (1989) 163.

[166] R.C. Young, T.J. Meyer, D.G. Whitten, J. Am. Chem. Soc. 97 (1975) 4781

[167] F. Liu, G.J. Meyer, Inorg. Chem. 44 (2005) 9305

[168] M.H. Huynh, D.M. Dattlebaum, T.J. Meyer, Coord. Chem. Rev. 249 (2005) 457.

[169] J.-P. Sauvage, J.-P. Collin, J.-C. Chambron, S. Guillerez, C. Coudret, Chem. Rev. 94 (1994) 993.

[170] E. Baranoff, J.-P. Collin, L. Flamigni, J.-P. Sauvage, Chem. Soc. Rev. 33 (2004) 147.

[171] K. Kalyanasundaram, Photochemistry and Photophysics of Polypyridine and Porphyrin Complexes, 1st ed., Academic Press Limited, San Diego, 1992.

[172] L. Hammarstrom, O. Johansson, Coord. Chem. Rev. 254 (2010) 2546.

[173] E.A. Medlycott, G.S. Hanan, Coord. Chem. Rev. 250 (2006) 1763.

[174] J.R. Winkler, T.L. Netzel, C. Creutz, N. Sutin, J. Am. Chem. Soc. 109(1987) 2381

[175] J.M. Calvert, J.V. Caspar, R.A. Binstead, T.D. Westmoreland, T.J. Meyer, J. Am. Chem. Soc. 104 (1982) 6620.
[176] H. Wolpher, O. Johansson, M. Abrahamson, M. Kritikos, L. Sun, B. Åkermark, Inorg. Chem. Commun. 7 (2004) 337.

[177] M. Abrahamsson, H. Wolpher, O. Johansson, J. Larsson, M. Kritikos, L. Eriksson, P.-O. Norrby, J. Bergquist, L. Sun, B. Åkermark, L. Hammarström, Inorg. Chem. 44 (2005) 3215

[178] M. Abrahamsson, M. Jäger, T. Österman, L. Eriksson, P. Persson, H.-C. Becker, O. Johansson, L. Hammarström, J. Am. Chem. Soc. 128 (2006) 12616.

[179] M. Abrahamsson, M.J. Lundqvist, H. Wolpher, O. Johansson, L. Eriksson, J. Bergquist, T. Rasmussen, H.-C. Becker, L. Hammarström, P.-O. Norrby, B. Åkermark, P. Persson, Inorg. Chem. 47 (2008) 3540.

[180] K. Lashgari, M. Kritikos, R. Norrestam, T. Norrby, Acta Crystallogr. C55 (1999) 64.

[181] J.-P. Collin, M. Beley, J.-P. Sauvage, F. Barigelletti, Inorg. Chim. Acta 186 (1991)

[182] F. Barigelletti, B. Ventura, J.-P. Collin, R. Kayhanian, P. Gaviña, J.-P. Sauvage, Eur. J. Inorg. Chem. (2000) 113.

[183] C.R. Hecker, A.K.I. Gushurst, D.R. McMillin, Inorg. Chem. 30 (1991) 538.

[184] A.C. Benniston, V. Grosshenny, A. Harriman, R. Ziessel, Angew. Chem. Int. Ed. Engl. 33 (1994) 1884

[185] R. Liegghio, P.G. Potvin, A.B.P. Lever, Inorg. Chem. 40 (2001) 5485

[186] M.I.J. Polson, E.A. Medlycott, G.S. Hanan, L. Mikelsons, N.J. Taylor, M. Watanabe, Y. Tanaka, F. Loiseau, R. Passalacqua, S. Campagna, Chem. Eur.J. 10 (2004) 3640.

[187] L. Yang, F. Okuda, K. Kobayashi, K. Nozaki, Y. Tanabe, Y. Ishii, M. Haga, Inorg. Chem. 47 (2008) 7154.

[188] S. Obara, M. Itabashi, F. Okuda, S. Tamaki, Y. Tanabe, Y. Ishii, K. Nozaki, M. Haga, Inorg. Chem. 45 (2006) 8907.

[189] G. Treboux, J. Mizukami, M. Yabe, S. Nakamura, Chem. Lett. 36 (2007) 1344

[190] T. Sajoto, P.I. Djurovich, A.B. Tamayo, J. Oxgaard, W.A. Goddard, M.E. Thompson, J. Am. Chem. Soc. 131 (2009) 9813.

[191] A.F. Rausch, M.E. Thompson, H. Yersin, J. Phys. Chem. A 113 (2009) 5927.

[192] J.A. Broomhead, W. Grumley, Chem. Commun. (1968) 1211a.

[193] R.E. Mahnken, M.A. Billadeau, E.P. Nikonowicz, H. Morrison, J. Am. Chem. Soc. 114 (1992) 9253

[194] E.L. Menon, R. Perera, M. Navarro, R.J. Kuhn, H. Morrison, Inorg. Chem. 43 (2004) 5373.

[195] L. Zayat, C. Calero, P. Albores, L. Baraldo, R. Etchenique, J. Am. Chem. Soc. 125 (2003) 882.

[196] V. Nikolenko, R. Yuste, L. Zayat, L.M. Baraldo, R. Etchenique, Chem. Commun. (2005) 1752

[197] M. Salierno, C. Farneli, R. Etchenique, Eur. J. Inorg. Chem. (2008) 1125.

[198] P. Mobian, J.-M. Kern, J.-P. Sauvage, Angew. Chem. Int. Ed. 43 (2004) 2392.

[199] S. Bonnet, J.-P. Collin, J.-P. Sauvage, Inorg. Chem. 46 (2007) 10520

[200] M.A. Jamieson, N. Serpone, M.Z. Hoffman, Coord. Chem. Rev. 39 (1981) 121

[201] N. Serpone, M.Z. Hoffman, J. Chem. Ed. 60 (1983) 853.

[202] M.Z. Hoffman, N. Serpone, Israel J. Chem. 22 (1982) 91.

[203] N.A.P. Kane-Maguire, J. Conway, C.H. Langford, J. Chem. Soc., Chem. Commun. (1974) 801.

[204] F. Bolletta, M. Maestri, L. Moggi, V. Balzani, J. Chem. Soc., Chem. Commun. (1975) 901.

[205] R. Ballardini, G. Varani, F. Scandola, J. Am. Chem. Soc. 98 (1976) 7432

[206] R. Ballardini, G. Varani, M.T. Indelli, F. Scandola, V. Balzani, J. Am. Chem. Soc. 100 (1978) 7219

[207] B. Brunschwig, N. Sutin, J. Am. Chem. Soc. 100 (1978) 7568.

[208] N. Serpone, M.A. Jamieson, M.S. Henry, M.Z. Hoffman, F. Bolletta, M. Maestri, J. Am. Chem. Soc. 101 (1979) 2907.

[209] R. Ballardini, A. Juris, G. Varani, V. Balzani, Nouv. J. Chim. 4 (1980) 563.

[210] A.M. McDaniel, H.-W. Tseng, N.H. Damrauer, M.P. Shores, Inorg. Chem. 49 (2010) 7981

[211] A. Kirsch-De Mesmaeker, J.-P. Lecomte, J.M. Kelly, Top. Curr. Chem. 177 (1996) 25.

[212] K.E. Errkila, D.T. Odom, J.K. Barton, Chem. Rev. 99 (1999) 2777.

[213] N.A.P. Kane-Maguire, J.F. Wheeler, Coord. Chem. Rev. 211 (2001) 145.

[214] J.-P. Lecomte, A. Kirsch-De Mesmaeker, M.M. Feeney, J.M. Kelly, Inorg. Chem. 34 (1995) 6481

[215] I. Ortmans, C. Moucheron, A. Kirsch-De Mesmaeker, Coord. Chem. Rev. 168 (1998) 233

[216] B. Elias, A. Kirsch-De Mesmaeker, Coord. Chem. Rev. 250 (2006) 1627.

[217] Y. Sun, L.E. Joyce, N.M. Dickson, C. Turro, Chem. Commun. 46 (2010) 2426.

[218] M.B. Fleisher, K.C. Waterman, N.J. Turro, J.K. Barton, Inorg. Chem. 25 (1986) 3549.

[219] R.T. Watson, N. Desai, J. Wildsmith, J.F. Wheeler, N.A.P. Kane-Maguire, Inorg. Chem. 38 (1999) 2683

[220] K.D. Barker, B.R. Benoit, J.A. Bordelon, R.J. Davis, A.S. Delmas, O.V. Mytykh, J.T Petty, J.F. Wheeler, N.A.P. Kane-Maguire, Inorg. Chim. Acta 322 (2001) 74.

[221] M.S. Vandiver, E.P. Bridges, R.L. Koon, A.N. Kinnaird, J.W. Glaeser, J.F. Campbell, C.J. Priedemann, W.T. Rosenblatt, B.J. Herbert, S.K. Wheeler, J.F. Wheeler, N.A.P. Kane-Maguire, Inorg. Chem. 49 (2010) 839.

[222] V.G. Vaidyanathan, B.U. Nair, Eur. J. Inorg. Chem. (2004) 1840.

[223] L.J. Ignarro (Ed.), Nitric Oxide: Biology and Pathobiology, Academic Press, San Diego, CA, 2000 (and references therein)

[224] P.C. Ford, Acc. Chem. Res. 41 (2008) 190 (and references therein).

[225] M.J. Rose, P.K. Mascharak, Coord. Chem. Rev. 252 (2008) 2093.

[226] M. Yamaji, Y. Hama, M. Miyazake, M. Hoshino, Inorg. Chem. 31 (1992) 932.

[227] M. De Leo, P.C. Ford, Coord. Chem. Rev. 208 (2000) 47.

[228] M. De Leo, P.C. Ford, J. Am. Chem. Soc. 121 (1999) 1980 
[229] A.D. Ostrowski, S.J. Deakin, B. Azhar, T.W. Miller, N. Franco, M.M. Cherney, A.J Lee, J.N. Burstyn, J.M. Fukuto, I.L. Megson, P.C. Ford, J. Med. Chem. 53 (2010) 715

[230] R.O. Absalonson, Ph.D. dissertation, University of California, Santa Barbara, 2010.
[231] F. DeRosa, X. Bu, P.C. Ford, Inorg. Chem. 44 (2005) 4157.

[232] D. Neuman, A.D. Ostrowski, A.A. Mikhailovsky, R.O. Absalonson, G.F. Strouse P.C. Ford, J. Am. Chem. Soc. 130 (2008) 168

[233] G. Ciamician, Science 36 (1912) 385. 